\title{
Thermodynamic Modeling of High-grade Metabasites: A Case Study Using the Tso Morari
}

\section{UHP Eclogite}

Ruiguang Pan $^{1}$; Catherine A. Macris ${ }^{1, *}$; Carrie A. Menold ${ }^{2}$

${ }^{1}$ Department of Earth Sciences, Indiana University - Purdue University Indianapolis, Indianapolis, IN 46202, United States

${ }^{2}$ Department of Geology, Albion College, Albion, MI 49224, United States

*Corresponding author: Catherine A. Macris

Department of Earth Sciences, Indiana University - Purdue University Indianapolis,

E-mail: camacris@iupui.edu

\section{Highlights}

1. Eclogite from the Tso Morari UHP terrane is used as a representative metabasite to test the efficacy of various thermodynamic modeling protocols.

2. User's choice of modeling program, version, and thermodynamic database, have little effect on the model's outcome in terms of predicted stable mineral assemblage and $P-T$ path. However, the choice of garnet solution model can have a significant effect on pressure predictions.

3. Bulk compositions measured by XRF do not represent the reactant or effective bulk composition at the time of garnet nucleation and throughout garnet prograde growth. Taking into account calculations of the effective bulk composition of the system

This is the author's manuscript of the article published in final edited form as:

Pan, R., Macris, C. A., \& Menold, C. A. (2020). Thermodynamic modeling of high-grade metabasites: A case study using the Tso Morari UHP eclogite. Contributions to Mineralogy and Petrology, 175(8), 78. https://doi.org/10.1007/s00410-020-01717-w 
throughout prograde metamorphism leads to more realistic $P-T$ path predictions than modeling using only an initial bulk composition.

4. More careful consideration of the key mineral solid solution models in calculations, comparing results of calculations to petrological observations, and consideration of uncertainties are key to interpreting geological processes. 


\section{ABSTRACT}

Thermodynamic modeling is an important technique to simulate the evolution of metamorphic rocks, particularly the poorly preserved prograde metamorphic reactions. The development of new thermodynamic modeling techniques and availability of updated thermodynamic databases and activity-composition $(a-X)$ relations, call for an evaluation of best practices for modeling pressuretemperature $(P-T)$ paths of metabasites. In this paper, eclogite from the Tso Morari UHP terrane, NW India, is used as a representative metabasite to directly compare the outputs (pseudosections and $P$-T paths) generated from recent versions of the widely used THERMOCALC and TheriakDomino programs. We also evaluate the impact of using the most updated thermodynamic database (ds 62, Holland and Powell 2011) relative to an older version (ds 55, Holland and Powell 1998), and the effect of the user's choice of mineral $a-X$ relations while considering the effect garnet fractionation on the rock's effective bulk composition. The following modeling protocols were assessed: (1) TC33; THERMOCALC version 3.33 with database ds 55 and garnet $a-X$ relations of White et al. (2007); (2) TC47; THERMOCALC version 3.47 with database ds 62 and garnet $a-X$ relations of White et al. (2014a); (3) TDG; Theriak-Domino with database ds 62 and garnet $a$ - $X$ relations of White et al. (2014a), and (4) TDW; Theriak-Domino with database ds 62 and garnet $a-X$ relations of White et al. (2007).

TC47 and TDG modeling yield a similar peak metamorphic $P-T$ of $34 \pm 1.5 \mathrm{kbar}$ at $544 \pm$ $15{ }^{\circ} \mathrm{C}$ and $551 \pm 12{ }^{\circ} \mathrm{C}$, respectively. The results are 5-8 kbar higher in pressure than that determined from TC33 modeling $\left(26 \pm 1 \mathrm{kbar}\right.$ at $\left.565 \pm 8^{\circ} \mathrm{C}\right)$, and TDW modeling $(28.5 \pm 1.5 \mathrm{kbar}$ at $563 \pm 13{ }^{\circ} \mathrm{C}$ ). Results indicate that all four modeling protocols generally provide consistent metamorphic phase relations and thermodynamic simulations regarding fractionation of the bulk composition and prograde metamorphism within uncertainty. In all model calculations, the initial 
bulk composition measured by XRF does not represent the effective bulk composition at the time of garnet nucleation. The choice of garnet $a-X$ relations can affect predictions of peak pressure, regardless of program choice. This study illustrates the importance of careful consideration of which $a-X$ relations one chooses, as well as the need for comparison between modeling predictions and evidence from the geochemistry and petrography of the rock(s) themselves.

Key words: Metabasites, Thermodynamic modeling, Tso Morari, UHP eclogite, $P$ - $T$ paths, Garnet fractionation 


\section{Introduction}

Recent developments in high pressure-temperature $(P-T)$ experiments, theoretical petrochemistry, high-precision geochemical analysis, and computational science have led to improved models of the formation and evolution of metamorphic rocks. Thermodynamic modeling programs (e.g., THERMOCALC, Theriak-Domino) can calculate rock and mineral properties for a specific set of conditions (e.g., pressure, temperature, and composition) and predict equilibrium mineral assemblages (de Capitani 1994; Powell et al. 1998). These programs utilize internally consistent thermodynamic databases and activity-composition $(a-X)$ relations to calculate mineral stabilities and phase relations at different $P-T$ conditions. The user must carefully choose which program (and program version), database, and set of $a-X$ relations when executing a modeling protocol. These choices are nontrivial and can affect the outcome of the calculations in various ways - sometimes leading to significantly different predictions for the stability of phase assemblages, thus having important implications in the calculated $P-T$ path. The effects of user's choices for metabasic compositions have not yet been formally evaluated.

Many previous studies have applied thermodynamic modeling programs to metabasites using the internally consistent thermodynamic database (e.g., Helgeson et al. 1978; Berman 1988; Holland and Powell 1998) and various $a$-X relations (e.g., Berman 1990; Holland and Powell 1996; Meyre et al. 1997; Dale et al. 2000, 2005; Diener et al. 2007; Green et al. 2007; White et al. 2007) to model phase equilibrium and estimate $P$ - $T$ conditions during prograde metamorphism (KonradSchmolke et al. 2008; St-Onge et al. 2013; Hernández-Uribe et al. 2018, 2019). In some cases, studies modeling metabasites (Konrad-Schmolke et al. 2008; St-Onge et al. 2013; Imayama 2014; Hernández-Uribe et al. 2019) used $a$ - $X$ relations that were developed originally for modeling felsic rocks (White et al. 2007), omitted minor components (e.g., Mn, and Ti), or were not calibrated for 
ultra-high pressure (UHP) conditions. Updated versions of these modeling programs, internally consistent thermodynamic databases (e.g., ds 62; Holland and Powell 2011), and $a-X$ relations (Diener and Powell 2012; White et al. 2014a, 2014b; Green et al. 2016), offer improvements that may yield better results in terms of interpreting phase relations for minerals with a large group of endmembers (e.g., amphibole and clinopyroxene) and calculating phase stabilities using an expanded library of bulk components (e.g., $\mathrm{Mn}, \mathrm{Ti}$, and $\mathrm{Fe}^{3+}$ ).

New $a-X$ relations for metabasic rocks have resolved the stability fields of coexisting sodiccalcic pyroxenes, and clinoamphiboles (Green et al. 2007; Green et al. 2016). Also, improved $a-X$ relations for clino- and orthoamphiboles (Diener et al. 2007) and revised $a$ - $X$ relations for clinopyroxene and amphibole (Diener and Powell 2012) allow the prediction of mineral assemblages in ferric-bearing systems (NCFMASHO) and are more consistent with observed phase relations in natural rocks. In addition, the model formulation of $a-X$ relations for mafic melts in the $\mathrm{CaO}-\mathrm{MgO}-\mathrm{Al}_{2} \mathrm{O}_{3}-\mathrm{SiO}_{2}(\mathrm{CMAS})$ system, representing the core components for modeling metabasites, was recalibrated (Green et al. 2012, 2016) to calculate melting equilibria for a high pressure range (up to $50 \mathrm{kbar}$ at $1800^{\circ} \mathrm{C}$ ).

The ability to include minor components (e.g., $\mathrm{MnO}_{2}, \mathrm{Fe}_{2} \mathrm{O}_{3}$ ) in thermodynamic modeling (Diener et al. 2007; Diener and Powell 2012; White et al. 2014a, 2014b; Green et al. 2016) makes it possible to evaluate their effect on phase stabilities and phase reactions for key metamorphic minerals (e.g., spessartine garnet at low $P$ - $T$ conditions). Care must be taken when using the bulk rock composition to model metamorphic histories as it may lead to unrealistic results without consideration of chemical heterogeneity (e.g., outcrop scale, mineral zoning, and relics) and definition of reactive equilibrium volume (e.g., Warren and Waters 2006; Lanari and Engi 2017). 
Effective bulk composition (EBC, also called reactive bulk-rock composition) is the composition of the equilibration volume at a specific stage of metamorphism. A rock's EBC evolves along a $P-T$ trajectory because of compositional fractionation commonly due to porphyroblastic growth of minerals like garnet (Tracy 1982; Spear 1988; Spear et al. 1990; Lanari and Engi 2017), which will continuously consume constituents from the bulk rock composition, and may trap other minerals as inclusions inside. Components and inclusions locked in the garnet core are then excluded from participating in any subsequent chemical reactions in the matrix and hence should not be included when modeling later stages of the metamorphic history (Spear et al. 1990; Lanari and Engi 2017). For this reason, the EBC can differ from the bulk or whole-rock composition commonly measured by X-ray fluorescence spectrometry (XRF) (Evans 2004; Gaidies et al. 2008a; Moynihan and Pattison 2013; Lanari and Engi 2017; Spear and Wolfe 2018). Including EBC calculations in thermodynamic modeling makes it possible to more accurately model the $P$ - $T$ conditions and phase relations in metamorphic terranes with mafic rocks, and more effectively compare the results with previous studies and conventional thermobarometers (Palin et al. 2016; Hernández-Uribe et al. 2018; Yu et al. 2019).

This study evaluates the effects of the user's choice of modeling program, Theriak-Domino (TD; de Capitani 1994) and THERMOCALC (TC; Powell et al. 1998), database (ds 55 vs. ds 62), and garnet $a-X$ relations (White et al. 2007 vs. White et al. 2014a) on predictions of stable mineral assemblages and $P-T$ path estimates for metabasites, by providing direct comparisons and evaluation of the results achieved from various combinations of these choices, focusing on pitfalls, strengths, and limitations of the modeling protocols when applied to high pressure-ultra high pressure (HP-UHP) mafic rocks. We make recommendations for best practices in modeling metabasites and compare our results with those from previous studies. 
In all calculations, we use data collected from the well-characterized coesite-bearing eclogite of the Tso Morari UHP terrane, in NW Himalaya, as input for our models (Steck et al. 1998; de Sigoyer et al. 2000; Konrad-Schmolke et al. 2008; Mukherjee and Sachan 2009; Singh et al. 2013a, 2013b; Donaldson et al. 2013; St-Onge et al. 2013; Chatterjee and Jagoutz 2015; Palin et al. 2014, 2017; Jonnalagadda et al. 2017a, 2017b). The Tso Morari UHP eclogites were formed as a result of the continental collision and continuous subduction of the Indian subcontinent beneath the Eurasian continent (Pognante et al. 1990; Guillot et al. 1997; de Sigoyer et al. 2000; Lombardo and Rolfo 2000; Kohn and Parkinson 2002; O’Brien 2018, 2019). Previous studies have estimated the $P-T$ conditions and predicted metamorphic phase assemblages of Tso Morari UHP eclogites through thermodynamic modeling (Konrad-Schmolke et al. 2008; St-Onge et al. 2013), stable mineral assemblages and conventional thermobarometry (Guillot et al. 1997; de Sigoyer et al. 1997; Lombardo et al. 2000; Mukherjee et al. 2003; Lanari et al. 2013; Singh et al. 2013a, 2013b; Chatterjee and Jagoutz 2015; Wilke et al. 2015), thermomechanical modeling (Palin et al. 2017), and by the presence of coesite, suggesting peak conditions at UHP conditions were reached in the terrane (Mukherjee and Sachan 2001; Sachan et al. 2004). Multiple approaches have been applied to calculate prograde and peak $P-T$ conditions in the Tso Morari eclogite (e.g., pseudosection construction, stable mineral assemblages, and conventional thermobarometry) making it an ideal UHP metabasite case study for evaluating the performance of different modeling programs, thermodynamic databases, and $a-X$ relations.

Thermodynamic modeling studies on HP-UHP metabasites (e.g., eclogite facies) are not as well represented in the literature as those on metapelites and metagranites. Modeling HP-UHP metabasites can be difficult because they have a lower degree of variability in mineral phases or their endmembers (lower variance in thermodynamic modeling) making it harder to track changes 
in $P$-T-t space. The problem is exacerbated at eclogite-facies conditions, because the mineral compositions and proportions do not change significantly with changing $P$ and $T$. Additionally, the effects of dehydration during prograde metamorphism and compositional fractionation due to garnet growth make modeling metabasites even more challenging.

This study examines the effects of user choices in thermodynamic modeling protocols used with metabasites and uses information from the rocks themselves (mineral assemblages, compositions, and textures) as ground truth by which to evaluate the efficacy of the various protocols tested. Specifically, we use bulk compositions, in situ mineral compositions, and mineral modal proportions and textures from a Tso Morari eclogite block to test four different modeling protocols. The protocols were designed to evaluate the effect of choice of database (ds 55 vs. ds 62), program (TC vs. TD) and garnet solution model (White et al. 2007 vs. White et al. 2014a). The four protocols are as follows: (1) TC33 - THERMOCALC version 3.33 with database ds 55 and $a-X$ relations of White et al. (2007) for garnet; (2) TC47 - THERMOCALC version 3.47 with database ds 62 and $a-X$ relations of White et al. (2014a) for garnet; (3) TDG - Theriak-Domino with database ds 62 and $a-X$ relations of White et al. (2014a) for garnet; and (4) TDW - TheriakDomino with database ds 62 and modified $a-X$ relations using White et al. (2007) for garnet. Table 1 presents this information, as well as other details (e.g., $a-X$ relations of non-garnet minerals) of the different protocols. For each protocol, mineral phase diagrams (pseudosections) were constructed and $\mathrm{EBC}$ calculations were done to address element fractionation during prograde garnet growth. The ultimate goals of this study are to evaluate $P-T$ conditions during burial and exhumation of the Tso Morari UHP eclogite by thoroughly and thoughtfully comparing results of commonly used thermodynamic modeling software and databases, to determine which give the best results, and to make recommendations for best practices in modeling HP-UHP metabasites. 


\section{Geologic Setting: Tso Morari UHP Terrane}

UHP rocks occur in the Himalaya in two locations south of the Indus-Yarlung-Tsangpo (IYT) suture zone, which separates Indian and Asian rocks: (1) in the Kaghan Valley of northern Pakistan (Pognante and Spencer 1991; Spencer 1993; Spencer et al 1995; O’Brien et al. 1999, 2001, 2018 ; Lombardo et al. 2000; Lombardo and Rolfo 2000; Rehman et al. 2007, 2008; Wilke et al. 2010a, 2010b; Donaldson et al. 2013), and (2) north of Tso (Lake) Morari in northwestern India (Guillot et al. 1997, 2000; de Sigoyer et al. 1997, 1999, 2004; Sachan et al. 1999; Mukherjee and Sachan 2001, 2004; Mukherjee et al. 2003; Konrad-Schmolke et al. 2005, 2008; Leech et al. 2005, 2007; O’Brien 2019) (Fig. 1 inset). UHP metamorphism in Tso Morari rocks is confirmed by preserved coesite in eclogite blocks (Mukherjee and Sachan 2001; Sachan et al. 2004). UHP rocks crop out within dominantly felsic Indian supracrustal rocks (e.g., de Sigoyer et al. 2004), as seen in Figs. 1 and 2a. Table 2 presents mineral abbreviation used throughout this paper.

The Tso Morari is considered a relatively small UHP terrane (Kylander-Clark et al. 2012), primarily composed of the quartzo-feldspathic Puga Gneiss with rare, small eclogite blocks (Fig. 2a). Since the discovery of eclogite in the Tso Morari UHP terrane by Berthelsen (1953), it has been extensively studied. The terrane is chemically linked to subducted Tethyan Himalayan crust (Steck et al. 1998). The eclogite-facies boudins only occur within the Tso Morari nappe.

Some of the larger eclogite blocks in the UHP Tso Morari terrane preserve eclogite facies mineral assemblages with some amphibolite retrograde overprint especially near the block edges. The peak eclogite facies assemblage is garnet + omphacite \pm phengite + rutile + quartz/coesite (see O'Brien, 2019 for review). This study uses samples from the most extensively studied eclogite outcrop (e.g., Sachan et al. 1999; O'Brien and Sachan 2000; Mukherjee and Sachan 2001; 
Mukherjee et al. 2003; Sachan et al. 2004; Konrad-Schmolke et al. 2008; Donaldson et al. 2013; Singh et al. 2013a, 2013b; St. Onge et al. 2013; Palin et al. 2014; Chatterjee and Jagoutz 2015; Wilke et al. 2015; Jonnalagadda et al. 2017a, 2017b); the samples were also used in the Donaldson et al. (2013) geochronologic study. The eclogite has abundant garnet (1-1.5 mm in diameter), often found in clusters in a matrix of finer-grained omphacite (Fig. 2a \& b). The two iconic eclogite minerals occur with large porphyoblasts of carbonate and phengite and smaller crystals of rutile and quartz (Fig. 2a, b \& c). The high-pressure phases are partially overgrown with amphibole (barroisite-winchite), clinozoisite, and paragonite (Fig. 2c \& d). Garnets have significant zoning contain abundant inclusions (Fig. 3).

Previous $P-T$ studies have proposed that the Tso Morari UHP terrane either experienced a relatively cool, concave prograde $P-T$ path (St-Onge et al. 2013; Chatterjee and Jagoutz 2015; Palin et al. 2017) or a hotter, convex prograde path (Konrad-Schmolke et al. 2008; Warren et al. 2008; Beaumont et al. 2009). Hotter prograde $P$ - $T$ paths are predicted by thermal-mechanically modeling the subduction-collision dynamics of the continental Tso Morari UHP rocks (Warren et al. 2008; Beaumont et al. 2009) as opposed to the cold slab path by Syracuse et al. (2010). The position of the prograde path has implications for the prograde assemblage with the cooler path predicting significant lawsonite and hotter amphibole (see O'Brien et al. 2019 for review). The proposed peak pressure varies significantly from $\sim 28$ to $\sim 48$ kbar with the higher estimates (33-48 kbar) based on carbonate assemblages (Mukherjee et al. 2003; Wilke et al. 2015). Peak pressure calculations using the non-carbonate assemblage range from 22-28 kbar (Konrad-Schmolke et al. 2008; Lanari et al. 2013; St-Onge et al. 2013; Chatterjee and Jagoutz 2015; Palin et al. 2017). The duration of exhumation of the Tso Morari UHP terrane is proposed by multiple studies to be $\sim 6$ 
My (Leech et al. 2007; Guillot et al. 2008; St-Onge et al. 2013), putting it into the fast exhumation category of Kylander-Clark et al. (2012).

\section{Samples and Analytical Methods}

\subsection{Sample Description}

At Tso Morari, eclogite lenses are hosted as small boudins $(<20 \mathrm{~m})$ within the gneiss body (Fig. 2a). The eclogite boudins show strong ductile deformation and have lensoid shapes parallel to strongly developed shear fabric in the gneiss. Data from one sample was used in this study, TM15 (Fig. 2a). It was collected from the center of a single, well-studied eclogite boudin (see references above), where the largest proportion of eclogite-facies phases are preserved. The modal abundance of amphibolite facies minerals increases from core to rim of the block.

Sample TM-15 is medium-grained with granoblastic texture. Modal mineralogy was determined by using ImageJ (Schneider et al. 2012) to calculate percent area of different minerals based on grayscale levels in a backscattered electron image mosaic $(17 \times 40 \mathrm{~mm})$ of a thin section of TM-15 (part of which is shown in Fig. 2c). TM-15 is $28.6 \%$ garnet, $20.2 \%$ omphacite, $18.8 \%$ amphibole, $12.7 \%$ quartz, $9.3 \%$ epidote, and $9.2 \%$ phengite. The remaining $1.2 \%$ includes the minor minerals rutile, ilmenite, magnetite, dolomite, paragonite and zircon (Fig. 2b \& c). The abundance of high-pressure minerals (high-Mg garnet rims, omphacite, and high-Si phengite), and the discovery of coesite in this eclogite block (Mukherjee and Sachan 2001; Sachan et al. 2004) confirm that this sample experienced UHP conditions. TM-15 has a weak foliation defined by matric omphacite and phengite (Fig. 2b), fabric development is variable within the block and host gneiss (Fig. 2a). 
Garnet has abundant inclusions in darker red cores while the lighter rims have significantly less to no inclusions (Figs. $2 \mathrm{~b} \& \mathrm{c}, 3$ ). There is a change in the inclusion population from core to rim domain. The inclusion phases in garnet cores include aegirine-rich omphacite, sodic-calcic amphibole (winchite), epidote, muscovite, jadeite, chlorite, quartz, magnetite, and rutile (Fig. 3). The garnet rim has fewer mineral inclusions, including jadeite-rich omphacite, clinoamphibole, phengite, quartz and carbonates. We did not observe any lawsonite or its pseudomorph (as epidote or paragonite) or any glaucophane in this study.

The UHP phases are overgrown by sodic-calcic amphibole, clinozoisite, and paragonite (Fig. $2 c \& d)$. Matrix omphacite is partially replaced by symplectites of sodium-rich plagioclase and jadeite-poor clinopyroxene (Fig. 2d). Rutile grains are rimmed by titanite and magnesite is locally present with dolomite grains.

\subsection{Analytical Methods}

Bulk rock composition of TM-15 was measured by XRF (Thermo ARL-ARL Advant XP and $\mathrm{XP}+\mathrm{X}$-Ray Fluorescence Spectrometer) (Table 3). Part of the sample was crushed using a mortar and pestle to $<1 \mathrm{~mm}$, then powdered in a tungsten-carbide shatter box. Scanning electron microscope (SEM) and energy dispersive x-ray spectroscopy (EDS) analyses were performed using the Zeiss EVO-10 SEM with Bruker XFlash6, $60 \mathrm{~mm}^{2}$ EDS detector at Indiana UniversityPurdue University Indianapolis. Backscattered electron (BSE) images were obtained at $15 \mathrm{kV}$ with an analytical Resolution $3.0 \mathrm{~nm}$, and qualitative compositional data (EDS analyses) were also collected at these conditions. XMapTools (De Andrade et al. 2006; Lanari et al. 2019) was used on SEM/EDS X-ray maps to identify mineral phases and quantify mineral proportions for small areas. 
Electron probe micro-analyzer (EPMA) measurements were performed using the CAMECA SX-50 Electron Microprobe in EM laboratory at Indiana University, Bloomington to obtain quantitative compositional data from minerals. Analytical conditions were $15 \mathrm{keV}$ accelerating voltage, $20 \mathrm{nA}$ beam current, $1 \mu \mathrm{m}$ beam size and peak counting time of $20 \mathrm{~s}$ for major element analysis of all minerals. Analytical uncertainty for major elements is less than 2 wt. \%. Elements were calibrated by the following standards: Si (clinopyroxene), Al (anorthite), Mg (San Carlos olivine), Fe (fayalite), Mn (grueninite), $\mathrm{Na}$ (albite), K (orthoclase), Ca (clinopyroxene), Ti (ilmenite). The measured mineral phases include pyroxene (mainly omphacite), garnet, amphibole, micas (muscovite, biotite, paragonite), K-feldspar, albite, epidote, titanite, dolomite, calcite. Point analyses (EPMA) were also conducted on mineral inclusions trapped in garnet to evaluate its equilibrium status at the early stages of metamorphism.

\section{Mineral Chemistry and Petrography}

\section{Garnet}

In sample TM-15, garnet occurs as individual euhedral crystals with sizes ranging from 500 to $2000 \mu \mathrm{m}$, or as coalesced clumps of several grains (Fig. 2b-c). An EPMA traverse across TM15G\#3 (rim-core-rim) was collected to investigate compositional variation (Figs. 3b \& c, 4a \& b, 5; Table 4) in the garnet. A large $(\sim 1200 \times 800 \mu \mathrm{m})$, single garnet crystal with well-preserved zoning, referred to hereafter as TM-15G\#3, was chosen for detailed analysis (Fig. 3a-c). TM$15 \mathrm{G} \# 3$ preserves sharp growth zones, recognized in thin section and BSE images, and the commonly observed change in inclusion population from core to rim (Fig. 3a-c).

The garnet TM-15G\#3 has three zones from core to rim labeled on Fig. 5 as Core, Rim 1, and Rim 2. The large core domain displays variability with each element $\left(\mathrm{Alm}_{54-65} \mathrm{Grs}_{24-34} \mathrm{Sps}_{1.0-}\right.$ 
2.3Prp $1.5-6.5)$ but roughly uniform composition across the core region starting at 328 to $920 \mu \mathrm{m}$ in Fig. 5. For $100 \mu \mathrm{m}$ on either side of the core, in Rim 1 pyrope increases and grossular decreases while almandine stays the same. In the outermost rim, Rim 2, almandine drops sharply as pyrope increases (Alm ${ }_{44-52} \mathrm{Grs}_{15-23} \mathrm{Sps}_{0.5-1.7} \operatorname{Prp}_{20-32}$ ) (Fig. 5). The pyrope-rich outermost rim has a very sharp compositional boundary changing $\sim 15$ mol. \% over $20 \mu \mathrm{m}$ (Figs. 3a-c, 5).

\section{Omphacite}

In sample TM-15, omphacite accounts for $\sim 20.2 \%$ of the modal abundance. The matrix omphacite ranges in size from $100-500 \mu \mathrm{m}$ with subhedral crystallization and no marked zonation (Figs. 3b-d, 4c), and has a composition of Quad ${ }_{52} \mathrm{Jd}_{42} \mathrm{Ae}_{6}$ based on Morimoto (1988) nomenclature, and $x(\mathrm{Fe})=0.16-0.29(0.24$ avg. $)$, where $\mathrm{x}(\mathrm{Fe})=\mathrm{Fe}^{2+} /\left(\mathrm{Fe}^{2+}+\mathrm{Mg}\right)$. Minor aegirine-rich omphacite occurs in the garnet cores of TM-15 as mineral inclusions; these can be strongly zoned (Fig. 3a) and have composition of $\mathrm{Quad}_{61} \mathrm{Jd}_{51} \mathrm{Ae}_{21}$ and $\mathrm{x}(\mathrm{Fe})=0.38-0.53$ (0.52 avg.) (Fig. 4c; Table 4). The pyroxene formulas in Table 4 (including $\mathrm{Fe}^{3+}$ ) have been recalculated based on stoichiometry and charge balance (Droop, 1987).

\section{Amphibole}

Amphibole occurs in TM-15 as sodic-calcic amphibole (camp). The amphibole in TM-15 makes up $\sim 18.8 \%$ of the rock, and ranges in size from $200-1000 \mu$ m (Fig. $2 \mathrm{c} \&$ d). Amphibole in the matrix of TM-15 shows mostly idiomorphic texture, with only minor amphibole showing poikilitic texture (Fig. $2 \mathrm{c} \& \mathrm{~d}$ ). It belongs to the winchite sub-group based on the amphibole reclassification of IMA 2012 standard (Horák and Gibbons 1986; Locock 2014), with Si = 7.417.77 p.f.u. (7.49 avg.), $\mathrm{Mg} /\left(\mathrm{Mg}+\mathrm{Fe}^{2+}\right)=0.85-0.90$ and $\mathrm{Na}(\mathrm{M} 4)=0.66$ (Table 4). Amphibole in 
the garnet core of TM-15 shows no discernible texture and belongs to the winchite sub-group with $\mathrm{Si}=7.12-7.52$ p.f.u. (7.30 avg.), $\mathrm{Mg} /\left(\mathrm{Mg}+\mathrm{Fe}^{2+}\right)=0.56-0.62$ and $\mathrm{Na}(\mathrm{M} 4)=0.82$ (Table 4).

\section{White Mica}

White micas are the major potassium-bearing mineral phases in TM-15 (Table 4). White mica (phengite and paragonite), occurs mostly in the matrix TM-15, ranging in size from 100-1000 $\mu \mathrm{m}$ (Fig. 2c). When found in the core of garnet, white micas are $<50 \mu \mathrm{m}$ in size (Fig. 3d). White mica with $>3.12$ Si p.f.u. are referred to hereafter as phengite (Menold et al. 2009). Phengite in TM-15 have a large compositional range (Si p.f.u. $=3.24-3.54)($ Fig. 4d), suggesting growth over a range of $P-T$ conditions. The highest silica phengite has 3.51-3.54 Si p.f.u. Paragonite (muscovite) in the matrix of TM-15 has a Si p.f.u. $=2.91-2.98, \mathrm{Al}_{\mathrm{IV}}=1.02-1.09$ and $\mathrm{Na} /(\mathrm{Na}+\mathrm{K})=0.03-0.07$ (Table 4) and mostly occurs as a thin ring around phengite in the rock matrix (Fig. 2d). No paragonite has been found in garnet cores in this study.

\section{Carbonates}

Carbonate phases, primarily dolomite make up $<1 \%$ of sample TM-15 occurring as small porphyroblasts in the matrix (Fig. 2d). Dolomite and calcite also occur as inclusions in the cores of garnets (Fig. 3b \& c).

\section{Accessory Phases}

Epidote accounts for $\sim 9-11 \%$ of the minerals TM-15, occurs as apparently idiomorphic crystals in the rock matrix $(\sim 150 \times 750 \mu \mathrm{m})$ (Fig. $2 \mathrm{c} \& \mathrm{~d})$, and as tiny inclusions in garnet $(\sim 10 \mu \mathrm{m})$ with no proximity to paragonite. The average epidote in the matrix of TM-15 has an 
$\mathrm{Fe}^{3+} /\left(\mathrm{Al}^{3+}+\mathrm{Fe}^{3+}\right)$ ratio of $0.08-0.12(0.11$ avg.) (Table 4$)$. Accessory minerals in TM-15 include chlorite (Fig. 3d), albite (Fig. 3b), K-feldspar, rutile (Fig. 3b), ilmenite (Fig. 3b) and magnetite (Fig. 3b).

\section{Conventional Thermobarometry}

\subsection{Thermobarometry Methods}

Multiple conventional thermobarometers were utilized to constrain metamorphic $P-T$ conditions to compare with predictions from modeling trials, including garnet-clinopyroxene thermometry (Powell 1985; Ravna 2000), garnet-phengite thermometry (Green and Hellman 1982), garnet-omphacite-phengite geobarometry (Waters and Martin 1996), phengite geobarometry (Kamzolkin et al. 2016), and muscovite-paragonite thermobarometry (Guidotti et al. 1994; Roux and Hovis 1996) (presented in Section 5.2).

To provide some estimate of the uncertainty associated with the $P-T$ predictions from conventional thermobarometry, workers commonly use a function in THERMOCALC version 3.33 (TC3.33) called AVE_PT mode (e.g., Powell and Holland 1994; Worey and Powell 2000; Walker and Searle 2001; Proyer et al. 2004; Endo et al. 2012; St-Onge et al. 2013). This function calculates an average $P-T$ for a given mineral assemblage and bulk composition, as well as an associated model error estimate. The error ellipses in Fig. 6a were determined with AVE_PT mode as described here.

To minimize the effect of disequilibrium of selected mineral pairs on the accuracy of the thermobarometers, EPMA data from the highest-Si phengite, garnet rim domain, and matrix omphacite with $\mathrm{x}(\mathrm{Fe})<0.25$ in $\mathrm{TM}-15$ have been used to calculate peak pressure conditions. Due 
to limited EPMA data on inclusions from the garnet core (Table 4), we did not use data from those phases to conduct thermobarometry calculations.

Eclogite facies mineral assemblages facilitate the use of $\mathrm{Fe}^{2+}-\mathrm{Mg}$ partitioning between both garnet-clinopyroxene (GC) and garnet-phengite (GP) pairs for geothermometry, as the partitioning of these two elements is strongly temperature dependent in these mineral pairs (GC: Powell 1985; Ravna 2000; GP: Green and Hellman 1982; see thermobarometry methods Section 1.1-1.3 in supplementary materials). However, cation exchange between $\mathrm{Fe}^{2+}$ and $\mathrm{Mg}$ has two major issues regarding its accuracy in application to eclogites: (1) diffusional re-equilibration during retrograde metamorphism and (2) the high uncertainties associated with calculations of $\mathrm{Fe}^{3+} / \mathrm{Fe}^{2+}$. The first is highly temperature dependent and therefore will be a bigger problem for high temperature $\left(>800{ }^{\circ} \mathrm{C}\right)$ eclogite and granulite facies rocks (Florence and Spear 1995; Pattinson et al. 2003). Previous work on the Tso Morari suggests peak temperatures $<700{ }^{\circ} \mathrm{C}$ (e.g., St. Onge et al. 2013). Regarding the second issue, mineral $\mathrm{Fe}^{3+} / \mathrm{Fe}^{2+}$ can be determined indirectly by charge balance methods (e.g., Droop 1987) or directly measured by Mössbauer spectroscopy. Omphacite from UHP terranes have been analyzed previously by Mössbauer spectroscopy, revealing that $\mathrm{Fe}^{3+}$ can be up to $50 \%$ of $\mathrm{Fe}_{\text {Total }}$, and values measured often exceed those calculated by charge balance on the same samples (Ravna and Paquin 2003; Proyer et al. 2004). The charge-balance calculation (Droop 1987) has been used here to estimate $\mathrm{Fe}^{3+} / \mathrm{Fe}^{2+}$ in garnet and omphacite. Concentrations of $\mathrm{Fe}^{3+}$ in garnet are estimated to be $\sim 0.2 \%$ of $\mathrm{Fe}_{\text {Total }}$; in omphacite estimates range from $11 \%$ to $60 \%$. The result of underestimation of $\mathrm{Fe}^{3+} / \mathrm{Fe}^{2+}$ will be an overestimation of temperatures.

Geologic barometers utilize net-transfer reactions instead of exchange reactions (e.g., Spear 1995). Net-transfer reactions avoid the issues mentioned above by requiring longer diffusive length-scales (Hacker et al. 2006). A commonly used barometer for phengite-bearing eclogites is 
the garnet-omphacite-phengite geobarometer (GOP) of Waters and Martin (1996), which can be calculated through the KMASH mode reaction equilibrium (See Section 1.4 Garnet-OmphacitePhengite Geobarometer (GOP) in supplementary materials). Use of the GOP barometer (Waters and Martin 1996) is predicated on the fact that the silica concentration in phengite has been found to be strongly pressure dependent, linearly increasing from $>3.00$ to values $<4.00$ in a $12(\mathrm{O}, \mathrm{OH})$ formula unit in response to $\mathrm{Mg}^{\mathrm{VI}} \mathrm{Si}^{\mathrm{IV}} \mathrm{Al}^{\mathrm{VI}}{ }_{-1} \mathrm{Al}^{\mathrm{IV}}{ }_{-1}$ substitution, since $\mathrm{Al}^{\mathrm{IV}}$ is not favored at high pressures (Massonne and Schreyer 1987; Carswell and Harley 1990). Activity models for garnet and clinopyroxene are a major source of uncertainty in applying this barometer. Following Waters and Martin (1996), the simple Mg-Ca mixing model of Newton and Haselton (1981) for garnet, the non-ideal activity model of Holland (1990) for omphacite, and ideal mixing model of Holland and Powell (1990) for phengite were used for this study. An empirical correction of -0.000543 is added to the original $T^{*} \ln K$ coefficient $(0.002995)$ to account for the discrepancy with the experiments of Schmidt (1993) (see Section 1.4 Garnet-Omphacite-Phengite Geobarometer (GOP) in supplementary materials). Another empirical phengite geobarometer (Kamzolkin et al. 2016) for conditions of $\mathrm{Si}>3.25$ p.f.u. and $\mathrm{T}<750{ }^{\circ} \mathrm{C}$ was used in this study to compare with the GOP barometer (see Section 1.5 phengite geobarometer in supplementary materials).

Muscovite-paragonite thermobarometry was used to estimate retrograde $P$ - $T$ conditions based on K-Na exchange equilibria (Guidotti et al. 1994; Roux and Hovis 1996) (Fig. 6b).

\subsection{Thermobarometry Results}

To estimate the metamorphic conditions in sample TM-15 from conventional thermobarometry, the following eclogite facies assemblage was used: garnet (TM-15G\#3) rim average composition between $367 \mu \mathrm{m}$ and $490 \mu \mathrm{m}$ (low-calcium), omphacite from the matrix (EPMA data show that 
the matrix omphacite has low compositional variation; average value in Table 4), and high silica phengite (3.51-3.54 Si p.f.u.) from the matrix (Figs. 2c and 4d). The intersections of lines generated using GC and GP thermometers, and GOP and empirical phengite barometers, provide a poorly constrained $P-T$ estimate of $\sim 520-700{ }^{\circ} \mathrm{C}$ and $\sim 20-26 \mathrm{kbar}$ (Fig. 6a) at peak pressure.

As discussed in Section 5.1, we used the AVE_PT function in TC3.33 to provide an estimate of the uncertainty for the thermobarometry calculations. The average $P-T$ conditions calculated using TC3.33 AVE_PT for the assemblage (omp, grt, ms, tlc, lws, rt, coe, $\mathrm{H}_{2} \mathrm{O}$ ) from the garnet rim was $572 \pm 15{ }^{\circ} \mathrm{C}$ and $23.3 \pm 1.2$ kbar. The average $P-T$ condition calculated using TC3.33 AVE_PT for the assemblage (omp, grt, hbl, ep, ms, rt, qtz, $\mathrm{H}_{2} \mathrm{O}$ ) from the garnet core is $523 \pm$ $37^{\circ} \mathrm{C}$ and $21.0 \pm 1.6 \mathrm{kbar}$. Low silica phengite and paragonite in the matrix of sample TM-15 (pgms) were used to estimate late retrograde metamorphic conditions (Guidotti et al. 1994; Roux and Hovis 1996), yielding a $P-T$ range of $\sim 450-500{ }^{\circ} \mathrm{C}$ and $7-14$ kbar (Fig. 6b).

\section{Thermodynamic Modeling of the Tso Morari Eclogite}

\subsection{Modeling Methods}

TC and TD programs operate in different ways. TC calculates equilibria by solving a set of nonlinear equations for model systems in equilibrium (Powell et al. 1998). TD calculates and plots equilibrium phase diagrams by means of Gibbs free energy minimization (de Capitani 1994). Both programs can use the same thermodynamic databases (e.g., ds 55 and ds 62) and $a-X$ relations for modeling metamorphic rocks. A thermodynamic database describes the internally consistent thermodynamic properties for mineral endmembers, while a set of $a$ - $X$ relations dictates calculations of the thermodynamics of mixing of multiple endmember phases (e.g., Holland and 
Powell 2011; Green et al. 2016). To generate a pseudosection, which is a diagram showing the fields of stability of different equilibrium mineral assemblages at a fixed bulk composition or along a chosen vector of variation within bulk composition space, and model the $P$ - $T$ history for metamorphic phases of interest, a thermodynamic database has to be combined with a set of $a-X$ relations when executing a modeling program.

The thermodynamic database and $a-X$ relations used in the two modeling programs (TC and TD) differ in format but are identical in terms thermodynamic properties and mixing properties of end-member phases, if they are from the same versions. The conversion of the latest metabasite $a$ $X$ relations (Green et al. 2016), originally built for TC, to one being compatible with the TD working environment (http://dtinkham.net/peq.html) made the modeling of metabasites easier and more automatic. Pseudosection construction is the key function of thermodynamic modeling programs (TC and TD), as it predicts the stability fields of equilibrium phases (i.e., minerals, melts, and fluids) in $P-T$ space, as well as their compositions and proportions. A prograde metamorphic $P-T$ path can be modeled for HP-UHP rocks by projecting garnet compositional data onto the theoretically predicted mineral compositional isopleths in pseudosections (e.g., St-Onge et al. 2013; Hernández-Uribe et al. 2018; Laurent et al. 2018; Yu et al. 2019).

As introduced in Section 1, the four protocols that we test here are: (1) TC33, which uses THERMOCALC version 3.33 with database ds 55 and $a-X$ relations of White et al. (2007) for garnet; (2) TC47, using THERMOCALC version 3.47 with database ds 62 and $a-X$ relations of White et al. (2014a) for garnet; (3) TDG, using Theriak-Domino with database ds 62 and $a-X$ relations of White et al. (2014a) for garnet; and (4) TDW, using Theriak-Domino with database ds 62 and modified $a-X$ relations using White et al. (2007) for garnet. The $a-X$ relations of nongarnet minerals used the different protocols are shown in Table 1. 


\subsection{Model Input and Components}

Garnet, being a key mineral in HP and UHP metamorphic rocks, is capable of recording evidence of the metamorphic history of the rock in its structure by responding to the changes in composition, $P, T$, and $f_{2}$, over time as the crystals grow (Spear and Selverstone 1983; Spear et al. 1990; Spear 1995; Vance and Mahar 1998; Stowell and Tinkham 2003; Ague and Axler 2016). This is due to the robust chemical and mechanical properties of garnet and its resistance to postgrowth dissolution (Caddick et al. 2010; Baxter et al. 2017). Pseudosections and garnet compositional isopleths (alm, prp and grs) are commonly used in thermodynamic modeling to constrain prograde metamorphism and corresponding $P-T$ conditions (Spear 1995; Tinkham and Ghent 2005; Gaidies et al. 2008a, 2008b; Massonne 2012; St-Onge et al. 2013).

Eclogite TM-15, and garnet crystal TM-15G\#3 (Fig. 3a-c) were selected as the representative eclogite bulk composition and garnet composition, respectively, to perform the modeling presented here - to create pseudosections and model $P$ - $T$ paths using the various protocols we test. The large grain size, evident growth zonation, $\mathrm{x}(\mathrm{Ca})_{\text {grt }}$ minimum and $\mathrm{x}(\mathrm{Mg})_{\text {grt }}$ maximum occurring along the garnet profile (Fig. 5), and the $\sim 200 \mu \mathrm{m}$ rim seen in photomicrographs and BSE images (Fig. $2 \mathrm{~b}$ and $3 \mathrm{~b}$ ), indicate that prograde metamorphism conditions, including peak pressure, have been recorded in garnet crystal TM-15G\#3. Also, among three measured garnet profiles this grain had the lowest grossular and highest pyrope content.

Table 3 presents the bulk composition of TM-15, measured by XRF, which was used as starting input to construct pseudosections. $\mathrm{MnO}$ is omitted from the bulk composition when constructing pseudosections and calculating EBCs during the early stages of garnet growth. This is because while $\mathrm{MnO}$ is a significant component in the garnet core composition (Fig. 3c), it becomes less 
significant at later stages of prograde metamorphism/garnet growth (Symmes and Ferry 1992; Mahar et al. 1997; White et al. 2014b). Carbonate and phosphorus minerals were omitted from the bulk composition due to low concentrations in this sample (Table 3). A compositional profile (1200 $\mu \mathrm{m}$ traverse) across garnet TM-15G\#3 (Fig. 5; Table S1), measured by EPMA, is utilized to model prograde garnet growth attending metamorphism.

Thermodynamic modeling and calculations in this paper are performed in the 10-component system, $\mathrm{Na}_{2} \mathrm{O}-\mathrm{CaO}-\mathrm{K}_{2} \mathrm{O}-\mathrm{FeO}-\mathrm{MgO}-\mathrm{Al}_{2} \mathrm{O}_{3}-\mathrm{SiO}_{2}-\mathrm{H}_{2} \mathrm{O}-\mathrm{TiO}_{2}-\mathrm{Fe}_{2} \mathrm{O}_{3}$ (NCKFMASHTO). See Table 1 for lists of minerals included in each of the modeling protocols and which $a-X$ relations were used for those minerals with solid-solution. The presence of hydrous mineral inclusions (e.g., phengite, epidote, chlorite) in the core of garnet TM-15\#G3 suggests that eclogite TM-15 was water-saturated in the early stages of metamorphism. Here we assume water is to be saturated along the prograde path in all calculations.

The bulk $\mathrm{Fe}^{3+} / \sum \mathrm{Fe}(\sim 10.9 \%)$ of eclogite TM-15 was estimated using stoichiometric criteria in the mineral compositions and recalculating the mineral ferric contents using the AX program of Holland and Powell (2000). The effect of garnet intra-crystal diffusion was not considered due to the high heating rate $\left(\sim 10^{\circ} \mathrm{C} \mathrm{My}^{-1}\right)$ (Gaidies et al. 2008a) and short duration $(<10 \mathrm{Ma})$ of prograde metamorphism (St-Onge et al. 2013; Wilke et al. 2015). Effects from mineral inclusions on modeling results are very limited due to the low abundance of inclusions in TM-15. Mineral inclusions occur mostly in the garnet core as omphacite, rutile, phengite, omphacite, albite, and quartz, and account for less than $\sim 1 \%$ of the bulk composition of the whole rock. 


\subsection{Effective Bulk Composition Calculations and Mineral Fractionation Methods}

EBC estimates are among the most important factors affecting the accuracy of predictions of metamorphic $P$ - $T$ conditions attending prograde metamorphism, and this task is non-trivial as the EBC continuously changes with progressive metamorphism and porphyroblastic mineral (e.g., garnet) crystallization (Marmo et al. 2002; Evans 2004; Tinkham and Ghent 2005; Warren and Waters 2006; Zeh 2006; Gaidies et al. 2008b; Lanari and Engi 2017). Reaction kinetics (e.g., reaction rate, driving force, and crystallization mechanism) can also hinder obtaining the realistic reactive equilibrium volume (e.g., Carlson et al. 2015; Lanari and Engi 2017). In this paper, only garnet is considered as affecting the EBC evolution with changes of $P$ and $T$, and hence only garnet removal is included in the $\mathrm{EBC}$ calculations.

The growth of garnet will consume larger proportions of $\mathrm{Fe}$ and $\mathrm{Al}$ relative to other elements from the initial bulk composition, and this can cause changes in the EBC and hence affect the modeling results. Assuming that garnet growth is occurring at an equilibrium state, the main principal driving $\mathrm{EBC}$ calculations is the quantitative removal of the newly formed portion of the garnet core domain from the bulk composition at each $P$ and $T$ step in the calculation. There are myriad approaches available to calculate the EBC (only considering garnet removal) at a given $P$ $T$ condition (e.g., Gaidies et al. 2008a; White 2010; Marmo et al. 2012; Moynihan and Pattison 2013; St-Onge et al. 2013). For this study, we used techniques specific to the modeling programs, TD and TC. These are described in detail in Supplementary Materials Section 2.

Fourteen fractionation steps were performed for garnet (TM-15G\#3) prograde growth, which specifically includes 7 steps in the core domain $(0-367 \mu \mathrm{m})$ and 7 steps in the rim $(367-490 \mu \mathrm{m})$ (Fig. 7; Table S2). The stepping of garnet fractionation in the modeling is based on changes in composition (i.e., alm, prp, and grs) along the EMPA profile. 


\subsection{Uncertainties}

Identifying the source and magnitude of uncertainties in the $P$ - $T$ predictions from thermodynamic modeling are essential when considering how realistically a calculated metamorphic $P-T$ path represents an actual geological process. Past studies have focused on identifying the nature of uncertainties, quantifying the magnitude, and evaluating their effects on geological interpretations (e.g., Kohn and Spear 1991; Powell and Holland 2008; Palin et al. 2016; Lanari and Engi 2017). In this paper, we consider two sources of uncertainty and their potential effects when modeling metabasites: (1) uncertainty associated with compositional variability in mineral domains, and (2) uncertainty associated with internally-consistent databases and $a-X$ relations used in modeling programs.

The uncertainty associated with compositional variability in mineral domains refers to the degree to which in situ mineral compositions (measured by EPMA) vary within a user defined mineral domain (e.g., rim, core). This will depend on how homogenous each domain is in a given crystal, how the domains are defined by the user, and the quality of the measurements. Therefore, both the degree to which the measured compositional profile accurately represents garnet growth during prograde metamorphism, and the errors of EPMA analyses (relative and systematic) can have an effect on modeling results (Lanari et al. 2017, 2019). This type of uncertainty will vary from sample to sample and depend heavily on user choices in defining mineral domains.

The second type of uncertainty, those associated with internally-consistent databases and $a-X$ relations used in modeling programs, have been heavily debated (Engi 1992), and are commonly neglected in presentations of modeling results. Attempts to quantify these modeling uncertainties in past studies yielded a generally accepted overall uncertainty of $\pm 50{ }^{\circ} \mathrm{C}$ and \pm 1 kbar $(2 \sigma)$ for 
mineral isopleth thermobarometry in pseudosections (Powell and Holland 2008). These values of overall modeling uncertainty are especially useful for directly comparing results of models that use the same compositions as input, as we do in this study. Here we will present both types of uncertainty. Calculations of uncertainty associated with compositional variability in garnet domains for TM-15G\#3 will be given when reporting $P$ - $T$ predictions from our modeling protocols to highlight the degree to which sample zonation can affect model results. Because the input for all of the modeling protocols is the same, we will use the overall modeling uncertainty $\left( \pm 50^{\circ} \mathrm{C}\right.$ and \pm 1 kbar, $2 \sigma$ ) of Powell and Holland (2008) when comparing results of the different modeling protocols.

The sources of uncertainty discussed above are not exhaustive by any means. In addition, consideration of the scale and constituents of selected equilibration volume, techniques to calculate EBC, factors affecting the phase reactions in equilibrium, and petrological observations, could potentially affect the results and associated uncertainties of models. Other factors that may affect the modeling of metabasites include uncertainties in the estimation of ferrous/ferric iron and $\mathrm{H}_{2} \mathrm{O}$ contents, and chemical diffusion during garnet growth (Kelsey and Hand 2015; Lanari and Engi 2017; Lanari and Duesterhoeft 2019). Evaluation of all potential sources of uncertainty is beyond the scope of this paper. Past studies have already done this work, and we adopt the overall modeling uncertainty of Powell and Holland (2008) for comparing modeling protocols in this study.

\section{Thermodynamic Modeling Results}

The results of each modeling protocol are presented individually below and summarized in Table 5. As discussed in Section 6.4, calculations of uncertainty associated with compositional variability in garnet domains are presented below $(1 \sigma)$. 


\subsection{Modeling Trial 1 (TC33): TC3.33 with ds 55 and Garnet W07}

Results of protocol TC33 are shown in Figs. 8a \& b, 9 and S1a, and in Table 5. The TC33 generated pseudosection (Fig. 9a) shows that garnet started to grow at $540 \pm 15^{\circ} \mathrm{C}$ and $21.5 \pm 1.5$ kbar in a mineral assemblage of gln + act + grt + omp $+\mathrm{ms}+\mathrm{chl}+\mathrm{lws}+\mathrm{rt}+\mathrm{H}_{2} \mathrm{O}$. Prograde metamorphism reached a peak pressure of $26 \pm 1$ kbar at $565 \pm 8{ }^{\circ} \mathrm{C}$, and then achieved peak metamorphism (peak temperature) of $603 \pm 3{ }^{\circ} \mathrm{C}$ at $24 \pm 0.5 \mathrm{kbar}$, when considering the effect of garnet crystallization on the EBC. This $P$ - $T$ path provides a constant geothermal gradient $d T / d P$ of $\sim 5{ }^{\circ} \mathrm{C} / \mathrm{kbar}$ during its burial stage and $\sim 15^{\circ} \mathrm{C} / \mathrm{kbar}$ during the exhumation stage. If garnet fractionation is not considered (i.e., no EBC calculations), the predicted peak pressure estimated with this protocol would be $32.5 \pm 3 \mathrm{kbar}$ at $571 \pm 11^{\circ} \mathrm{C}$ (Fig. 13), and the peak metamorphism would be beyond the constructed $P-T$ range.

As garnet grows, mineral compositions and the EBC continuously change (Fig. $8 \mathrm{a} \&$ b). This modeling protocol (TC33) predicts that as metamorphism progresses from the beginning of garnet growth $\left(540 \pm 15{ }^{\circ} \mathrm{C}\right.$ and $\left.21.5 \pm 1.5 \mathrm{kbar}\right)$ to peak metamorphism $\left(603 \pm 3{ }^{\circ} \mathrm{C}\right.$ and $\left.24 \pm 0.5 \mathrm{kbar}\right)$, FeO drops from 11.8 to 3.0 mol. \%; $\mathrm{MgO}$ increases from 11.9 to 16.0 mol. \%; and $\mathrm{Al}_{2} \mathrm{O}_{3}$ and $\mathrm{CaO}$ slightly decrease from 9.7 and 11.6 to 6.9 and 10.9 mol. \%, respectively (Fig. 8a). In terms of the changes in mineral assemblage during prograde metamorphism, garnet, omphacite and talc generally increase from $22.6,23.2$ and 0.0 to $35.9,39.3$, and 12.2 mol. \%, respectively. Glaucophane and actinolite drop to almost zero at peak-pressure metamorphism, and lawsonite drops from 13.8 to 8.6 mol. \% during prograde metamorphism (Fig. 8b). 


\subsection{Modeling Trial 2 (TC47): TC3.45 with ds 62 and Garnet W14}

The results of protocol TC47 are shown in Figs. $8 \mathrm{c} \&$ d, 10, and S1b, and in Table 5. Garnet begins to nucleate at $25 \pm 2.5 \mathrm{kbar}$ and $515 \pm 21^{\circ} \mathrm{C}$ in the phase stability field of gln $+\mathrm{di}+\mathrm{omp}+$ grt $+\mathrm{bt}+\mathrm{chl}+\mathrm{lws}+\mathrm{rt}+\mathrm{H}_{2} \mathrm{O}$; reaches a peak pressure of $34 \pm 1.5 \mathrm{kbar}$ at $544 \pm 15{ }^{\circ} \mathrm{C}$; and achieves peak metamorphism at $29 \pm 0.5$ kbar and $595 \pm 3{ }^{\circ} \mathrm{C}$ (Figs. 10a \& S1b). This $P-T$ path provides a constant geothermal gradient $d T / d P$ of $\sim 6^{\circ} \mathrm{C} / \mathrm{kbar}$ during burial and $\sim 11^{\circ} \mathrm{C} / \mathrm{kbar}$ during exhumation. If mineral fractionation is not considered, the predicted peak pressure would be $39 \pm$ 4 kbar at $539 \pm 15{ }^{\circ} \mathrm{C}$, and the peak metamorphism would be beyond the constructed $P$ - $T$ range (Fig. 13).

The evolution of the EBC and mineral assemblage during garnet growth predicted by modeling protocol TC47 are shown in Figs. $8 \mathrm{c} \&$ d. Starting from garnet nucleation $(25 \pm 2.5$ kbar and 515 $\left.\pm 21^{\circ} \mathrm{C}\right)$ to end of the prograde metamorphism $\left(29 \pm 0.5 \mathrm{kbar}\right.$ and $\left.595 \pm 3{ }^{\circ} \mathrm{C}\right), \mathrm{FeO}$ and $\mathrm{Al}_{2} \mathrm{O}_{3}$ abundances drop from 11.8 and 9.7, to 2.8 and $7.1 \mathrm{~mol}$ \%, respectively. During this metamorphic stage, $\mathrm{MgO}$ keeps increasing from 11.9 to $16.1 \mathrm{~mol}$ \%, and $\mathrm{CaO}$ remains mostly unchanged (Fig. 8c). Along the prograde metamorphism path, garnet, omphacite, and talc increase from 22.2, 0.15, and 0 , to $35.5,34.7$, and 8.7 mol. \%. Glaucophane and lawsonite drop from 30.6 and 21.5, to 5.1 and $8.2 \mathrm{~mol} . \%$, respectively. Diopside drops to zero at $\sim 596{ }^{\circ} \mathrm{C}$ and peak pressure (Fig. 8d).

\subsection{Modeling Trial 3 (TDG): TD with ds 62 and Garnet W14}

Results of protocol TDG are shown in Figs. 8e \& f, 11, and S1c, and in Table 5. As Figs. 11 and $\mathrm{S} 1 \mathrm{c}$ show, garnet begins to nucleate at $530 \pm 25^{\circ} \mathrm{C}$ and $26 \pm 2 \mathrm{kbar}$ in the phase stability field of gln + omp $+\mathrm{di}+\mathrm{grt}+\mathrm{bt}+\mathrm{chl}+\mathrm{lws}+\mathrm{rt}+\mathrm{H}_{2} \mathrm{O}$. Peak pressure is $34 \pm 1.5 \mathrm{kbar}$ at $551 \pm 12^{\circ} \mathrm{C}$, which is followed by exhumation to $29 \pm 1 \mathrm{kbar}$ and $602 \pm 8^{\circ} \mathrm{C}$, where it reaches peak temperature 
(Fig. 11). The $P-T$ path shows a general thermal gradient $(d T / d P)$ of $\sim 5{ }^{\circ} \mathrm{C} / \mathrm{kbar}$ from garnet nucleation to peak pressure, and $\sim 11^{\circ} \mathrm{C} / \mathrm{kbar}$ during exhumation period recorded by garnet (Fig. 11). If mineral fractionation is not considered, the predicted peak pressure would be $39 \pm 3 \mathrm{kbar}$ at $553 \pm 35^{\circ} \mathrm{C}$ (Fig. 13), and peak metamorphism would be beyond the constructed $P$ - $T$ range.

Figures $8 \mathrm{e} \& \mathrm{f}$ show the evolution of the EBC and mineral assemblages predicted by TDG from garnet nucleation $\left(530 \pm 25^{\circ} \mathrm{C}\right.$ and $26 \pm 2 \mathrm{kbar}$ ) to the end of prograde metamorphism (602 $\pm 8{ }^{\circ} \mathrm{C}$ and $\left.29 \pm 1 \mathrm{kbar}\right)$. As garnet crystallizes over a temperature range of $508-604{ }^{\circ} \mathrm{C}, \mathrm{FeO}$ and $\mathrm{Al}_{2} \mathrm{O}_{3}$ decrease from 11.7 and 9.7, to 2.9 and 7.0 mol. \%, respectively, while $\mathrm{MgO}$ increases from 11.8 to 15.9 mol. \% (Fig. 8e). Garnet and omphacite increase from 23.8 and 2.4, to 30.7 and 44.6 mol. \%, respectively, and diopside drops from 25.9 mol. \% to zero during prograde metamorphism. Glaucophane and lawsonite drop from 13.4 and 19.1, to 1.2 and 5.5 mol. \%, respectively (Fig. 8f).

\subsection{Modeling Trial 4 (TDW): TD with ds 62 and Garnet W07}

Results of protocol TDW are shown in Figs. $8 \mathrm{~g} \& \mathrm{~h}, 12$, and S1d, and in Table 5. The TDW protocol calculations predict garnet nucleation at $537 \pm 25{ }^{\circ} \mathrm{C}$ and $22 \pm 2 \mathrm{kbar}$ at the stable phase field of gln + omp $+\mathrm{di}+\mathrm{grt}+\mathrm{chl}+\mathrm{ms}+\mathrm{lws}+\mathrm{rt}+\mathrm{H}_{2} \mathrm{O}$, peak pressure of $28.5 \pm 1.5 \mathrm{kbar}$ at 563 $\pm 13{ }^{\circ} \mathrm{C}$, and peak $T$ of metamorphism of $613 \pm 7{ }^{\circ} \mathrm{C}$ at $24.5 \pm 0.5 \mathrm{kbar}$ (Fig. 12). The same effect from compositional fractionation is seen here as was seen with the other three modeling protocols: if mineral fractionation is not considered, the predicted peak pressure would be $30 \pm 3 \mathrm{kbar}$ at 564 $\pm 25^{\circ} \mathrm{C}$ (Fig. 13), and the peak metamorphism would be beyond the constructed $P-T$ range.

Figures $8 \mathrm{~g} \& \mathrm{~h}$ show how the EBCs and mineral modal abundances change with prograde metamorphism according to TDW modeling. As garnet crystallizes during prograde metamorphism, $\mathrm{FeO}$ and $\mathrm{Al}_{2} \mathrm{O}_{3}$ decrease from 11.7 and 9.7, to 3.6 and 6.9 mol. \%, respectively, 
while $\mathrm{MgO}$ increases from 11.8 to 15.8 mol. \% (Fig. 8g). In Fig. 8h, garnet and omphacite abundances increase from 18.6 and 12.4, to 28.2 and 45.9 mol. \%, respectively, and diopside drops to zero at $\sim 541{ }^{\circ} \mathrm{C}$. Glaucophane and lawsonite drops from 10.1 and 14.6 , to 2.2 and $4.7 \mathrm{~mol} . \%$, respectively.

\section{Discussion}

\subsection{Comparing the results of modeling protocols}

When comparing the results of the four modeling protocols tested here (TC33, TC47, TDG, and TDW), we find many similarities and some significant differences. The shapes of the fractionated $P-T$ paths (calculated considering removal of garnet from the EBC) in Figs. 9-12 are generally similar - all showing steep pressure increases during garnet core formation, weakly concave curves approaching peak $P$, followed by the classic "fishhook" turn as pressure drops steeply at first, then levels out as peak $T$ is achieved. Figures 9-12 show that the pseudosections constructed by the four trials are similar with regard to the stability fields of equilibrium mineral assemblages (gln, act, omp, di, grt, lws, tlc, ms, bt, ep, chl, rt, spn, $\mathrm{H}_{2} \mathrm{O}$ ). The pseudosection constructed with TC33 is slightly different from the other three with respect to the stability fields of clinoamphibole (gln and act) and clinopyroxene (omp and di), and it has no predicted diopside (amphibole and clinopyroxene $a-X$ relations from Diener and Powell 2012) whereas the TC47, TDG, and TDW protocols (clinoamphibole and clinopyroxene $a-X$ relations from Green et al. 2016) do.

Predicted temperatures agree within error $\left( \pm 50{ }^{\circ} \mathrm{C}, 2 \sigma\right.$; Powell and Holland 2008) among all of the models for all stages of metamorphism investigated (Fig. 13). This means that choice of 
program, database, and set of $a-X$ relations used in a modeling protocol will not significantly affect the resulting temperature predictions for metabasites. Pressure estimates, however, differ significantly. Considering the results of our modeling protocols that accounted for garnet fractionation and its effect on the EBC (solid curves in Fig. 13), and the generally accepted modeling uncertainty ( $\pm 1 \mathrm{kbar}, 2 \sigma$; Powell and Holland 2008), pressure predictions at all stages of metamorphism are higher in TC47 and TDG results than in TC33 and TDW, with TDG giving the highest $P$ predictions and TC the lowest. The differences in pressure predictions stem not from the user's choice of program or database, but from the choice of garnet solution model ( $a-X$ relations of White et al. 2007 vs. White et al. 2014a). The garnet grossular isopleths in TC33 and TDW (Figs. 9b and 12b, respectively), the pseudosections constructed with the White et al. (2007) garnet $a-X$ relations, predict lower pressures, in the graphite stability field. While TC47 and TDW, which use White et al. (2014a), indicate pressures in the diamond stability field (Figs. 10b and 11b, respectively). The difference in pressure exceeds overall modeling error, indicating that user's choice of garnet solution model in the modeling protocol has a significant impact on the pressure results for metabasites (Fig. 13).

The main difference between the two sets of $a-X$ relations is that the modified ASF (asymmetric formalism) interaction energy between pyrope and grossular ( $\left.W_{\text {prp-grs }}\right)$ in White et al. (2014a) is $30.1 \mathrm{~kJ}$, whereas it is $45 \mathrm{~kJ}$ in White et al. (2007). Also, the asymmetry parameters used in garnet $a$ - $X$ relations of White et al. (2014a) are $\mathrm{a}_{\mathrm{prp}}=\mathrm{a}_{\mathrm{alm}}=\mathrm{a}_{\mathrm{kho}}=1$, agrs $=2.7$, whereas, the agrs adopted in the previous iteration of this parameter (from White et al. 2007) is 3.0 (Table 1). The modification of the ASF interaction energies and asymmetry parameters among garnet endmembers (from White et al. (2007) to White et al. (2014a)) apparently has a significant effect on the grossular proportion in equilibrium garnet calculations (especially at high pressures), and 
thus TC47 and TDG lead to much higher pressure estimates than that predicted using the $W_{\text {prp-grs }}$ and agrs in the garnet $a-X$ relations formulation of White et al. (2007).

Comparing the $P-T$ paths generated by assuming no garnet fractionation (i.e., no EBC calculations; dashed curves in Fig. 13) with the paths generated using garnet fractionation (i.e., incorporating EBC calculations; solid curves in Fig. 13), we see that not accounting for changes to the bulk composition as garnet grows causes significant overestimations of peak pressure for TM-15; yielding pressure predictions of $>38 \mathrm{kbar}$ for TC47 and TDG, $\sim 5 \mathrm{kbar}$ higher than the peak pressures calculated assuming garnet fractionation. These differences exceed the overall modelling error, telling us that EBC calculations have a significant effect on $P$ predictions. User's should be cautioned that neglecting to use EBC calculations when constructing $P-T$ paths for metabasites, will result in nontrivial overestimations of peak pressure.

Figures $8 \mathrm{a}, \mathrm{c}$, e \& g show that the four trials, TC33, TC47, TDG, and TDW, predict similar patterns of EBC evolution during mineral fractionation and prograde metamorphism. During this stage in all protocols, $\mathrm{SiO}_{2}$ and $\mathrm{MgO}$ increase slightly, while $\mathrm{FeO}$ and $\mathrm{Al}_{2} \mathrm{O}_{3}$ drop significantly, and $\mathrm{CaO}$ generally remains unchanged. Mineral evolution with prograde metamorphism is shown in Figs. $8 b, d, f \&$ h. Similar patterns are observed when using the same program (TC or TD). TC33 and TC47 trials (Figs. 8b \& d) result in similar trends of mineral evolution and mineral proportions with increasing $T$, with the exception of diopside in TC33 (as noted above). TDW and TDG (Figs. 8f \& h) also exhibit similar mineral evolution patterns during prograde metamorphism, but these patterns are different to those from TC protocols. When comparing the modal proportions predicted by the two programs (TC vs. TD), we observe that TC protocols predict a higher modal abundance of garnet (35.5 and 35.9 vs. 28.2 and $30.7 \%$, respectively) and lower modal abundance of omphacite (39.3 and 34.7 vs. 44.6 and $45.9 \%$, respectively) than TD protocols (Fig. 8). The 
TDG and TDW results of 30.7 and $28.2 \%$ garnet and 44.6 and $45.9 \%$ omphacite are much closer to the actual mineral modal abundance observed in sample TM-15 for garnet ( $28.6 \%)$. The modal abundance of omphacite ( $20.2 \%)$ in TM-15 is much lower than the model results ( $45 \%)$ likely due to retrograde metamorphism.

For all protocols, the calculated EBC prograde path produces almost identical compositional evolution with $T$ (Fig. 8a, c, e \& g). By comparing model predictions with actual petrographic and geochemical data from the well characterized eclogite sample used in the models, we conclude that the differences between fractionation methods of the modeling programs (TC and TD) cause minor differences in $\mathrm{EBC}$ and mineral evolution predictions.

\subsection{Modeling Predictions vs. Petrological Observations}

Thermodynamic modeling programs provide an important and useful method for numerically simulating metamorphic histories. The accuracy, functionality, and ease of use of these techniques have improved immensely over the past few decades making them applicable to a wide variety of $P-T$ ranges and bulk compositions. However, care should be taken when making interpretations based on model outputs considering the significant overall modeling uncertainties. Model results should be evaluated by ground-truthing with geochemical and textural data from the actual sample as much as possible.

The prograde $P-T$ paths predicted by TC47 and TDG modeling predict an assemblage of garnet, lawsonite, sodic amphibole (glaucophane), diopside, omphacite, and biotite (only major phases listed) in the Tso Morari eclogite (Figs. 9-12); TDW predicts muscovite instead of biotite (other minerals are the same as in TC47 and TDG); TC33 predicts garnet, lawsonite, glaucophane, calcic amphibole (actinolite), omphacite and muscovite (Table 5). None of the models predict 
phengite. The protocols also predict the modal abundance of each phase. The TC47, TDG, and TDW protocols predict that garnet starts to grow along the prograde path in the presence of significant amounts of lawsonite (15-20 mol. \%), clinopyroxene (15-25 mol. \%) and glaucophane (10-30 mol. \%) (Fig. 8d, f \& h). Clinopyroxene and glaucophane are consumed earlier but lawsonite is predicted to be modally significant for most of the prograde path as the abundance of especially omphacite increases (Fig. $8 \mathrm{~d}, \mathrm{f} \& \mathrm{~h}$ ), in all cases lawsonite is predicted to be present through peak UHP metamorphism. Actinolite is predicted instead of clinopyroxene for only one protocol: TC33 (Fig. 8b). Prograde garnet growth is interpreted as being recorded in the core domain in most Tso Morari eclogitic garnets (O'Brien et al. 2019).

The observed inclusion population of the garnet cores in this study and others (see O'Brien et al. 2019 for a review) are inconsistent with modeling predictions for early stages of metamorphism in all four modeling trials. The inclusion phases in garnet cores include aegirine-rich omphacite, sodic-calcic amphibole (winchite), epidote, muscovite, jadeite, chlorite, quartz, magnetite, and rutile (Fig. 3). We did not observe any lawsonite or its pseudomorphs (as epidote or paragonite), glaucophane, or biotite in garnet cores in this study. Only minor sodic amphibole and lawsonite have been reported in garnet cores from this outcrop by one study (St-Onge et al. 2013). Garnet rims have fewer mineral inclusions, including jadeite-rich omphacite, clinoamphibole, phengite, quartz, and carbonates; these closely correlate with the matrix assemblage of TM-15 (Figs. $2 \& 3$ ) and agree better with model predictions, with the exception of lawsonite which the models predict to remain at 10 mol. \% post-peak metamorphism (Fig. 8b, d, f \& h).

Figure 14 shows pseudosections constructed by the four protocols at the stage of peak pressure (using EBCs calculated from just before peak pressure), overlain by a grey bar showing the highest phengite Si p.f.u. (3.51-3.54) observed in eclogite TM-15. The TC33 and TDW protocols (using 
the White et al. 2007 garnet solution model) predict peak $P-T$ conditions close to observed phengite compositions, with TC33 overlapping the region and TDW approaching closely (Fig. 14a \& d). The highest phengite Si p.f.u. reported in this eclogite boudin is 3.56 by de Sigoyer et al. (1997). If peak pressure had reached $\sim 35 \mathrm{kbar}$ as predicted in the TC47 and TCG protocols, the silicon concentrations in phengite should greatly exceed values measured here and elsewhere (Fig. 14b \& c).

There are several possible reasons for the mismatch between the inclusion population of the garnet cores in TM-15 and the predicted prograde assemblages. The first possibility discussed in this section relates to garnet equilibration and preservation of phases grown during early metamorphism. Electron microprobe data from garnet TM-15G\#3 (and other garnet crystals in TM-15) confirms compositions and zoning observed in other studies (e.g., St. Onge et al. 2013) Garnets in Tso Morari eclogites have large, relatively flat, homogeneous core regions $\left(\mathrm{Alm}_{62} \mathrm{Grs}_{28} \mathrm{Sps}_{2-3} \operatorname{Prp}_{10}\right.$ for TM-15G\#3) (Fig. 5), which is not consistent with a progressively growing garnet along a specific $P$ - $T$ path. St-Onge et al. (2013) interprets the homogeneous garnet cores as garnet overgrowth on matrix minerals coupled with effective cation diffusion (e.g., Spear 1995) and homogenization of the already formed garnet domain at some point during prograde metamorphism. However, the $P-T$ conditions $\left(\sim 520^{\circ} \mathrm{C}\right.$ and $\sim 25 \mathrm{kbar}$, St-Onge et al. (2013)) calculated are too cool to cause cation diffusion during the relatively short prograde metamorphism stage (Donaldson et al. 2013).

The observations of a homogenous garnet core domain in TM-15G\#3 and lack of some of the predicted mineral phases (e.g., sodic amphibole, lawsonite) might be due to fluid release during prograde metamorphism. Our modeling indicates that dehydration reactions (breakdown of sodic amphibole and lawsonite) occur at $\sim 515-530{ }^{\circ} \mathrm{C}$ and $\sim 23.5 \mathrm{kbar}$, prior to peak pressure conditions 
(Figs. 9-12). Those released fluids may have reset the system and homogenized or semihomogenized the already formed garnet core domain (e.g., Wei and Clarke 2011; Hernández-Uribe et al. 2018). Partial water driven recrystallization and the resulting disequilibrium can also help explain the disparate results by the conventional thermobarometers using data from garnet core domains (Chatterjee and Jagoutz 2015).

\subsection{P-T Paths for the Tso Morari Eclogite}

All modeling protocols examined here predict cold, concave $P-T$ paths, similar to recent thermodynamic modelling studies on Tso Morari eclogite (e.g., St-Onge et al. 2013; Palin et al. 2017). The predicted peak pressures in all protocols (possibly excepting TC33) are consistent with the discovery of coesite in the garnet rim domain (Mukherjee and Sachan 2001; Sachan et al. 2004). TC33 and TDW are represented by the red solid curve on Fig. 15, with peak pressures of $\sim 27$ kbar at $\sim 540-590{ }^{\circ} \mathrm{C}$. The TC47 and TDG protocols, represented by the solid orange curve, predict a significantly higher peak pressure of $\sim 34 \mathrm{kbar}$ at $\sim 540-550{ }^{\circ} \mathrm{C}$. These differences, as discussed earlier, are likely due to the choice of garnet $a-X$ relations used in the protocols, not the choices of modelling program, version, or database.

Conventional thermobarometry calculations from this and previous studies were used to evaluate which protocol best fits available data (Fig. 15). For sample TM-15, the intersections of lines generated using GC and GP thermometers, and GOP and empirical phengite barometers using the peak assemblage, provide a poorly constrained $P$ - $T$ estimate of $\sim 520-700{ }^{\circ} \mathrm{C}$ and $\sim 20-26 \mathrm{kbar}$ (Fig. 6a). Additional estimates using AVE_PT function in TC3.33 for the assemblage from the garnet rim was $572 \pm 15{ }^{\circ} \mathrm{C}$ and $23.3 \pm 1.2 \mathrm{kbar}$, and $523 \pm 37{ }^{\circ} \mathrm{C}$ and $21.0 \pm 1.6 \mathrm{kbar}$ from the garnet core (Figs. 6a and 15). Low silica phengite and paragonite in the matrix of sample TM-15 
(ms-pg) were used to estimate late retrograde metamorphic conditions (Guidotti et al. 1994; Roux and Hovis 1996) of $\sim 450-500{ }^{\circ} \mathrm{C}$ and $7-14$ kbar (Fig. 6b).

The peak pressure conditions determined by the TDW $\left(28.5 \pm 1.5 \mathrm{kbar}\right.$ at $\left.563 \pm 13{ }^{\circ} \mathrm{C}\right)$ and TC33 (26 $\pm 1 \mathrm{kbar}$ at $\left.565 \pm 8{ }^{\circ} \mathrm{C}\right)$ protocols are within error of calculations by conventional thermobarometry on the same sample (TM-15); TC47 and TDG predict much higher pressures (>30 kbar) (Figs. 6a and 15). Thermobarometric studies of the Tso Morari eclogite using GC, GP, and GOP yield peak conditions of $27-29 \mathrm{kbar}$ and $690-750{ }^{\circ} \mathrm{C}$ (O'Brien et al. 2001), consistent with TDW and TC33 results. Conventional estimates that were pinned by carbonate assemblages have predicted much higher pressures in the diamond stability field ( $>39$ kbar) (Wilke et al. 2015; Mukherjee et al. 2003). These estimates are significantly higher than all other results for Tso Morari from modeling or conventional thermobarometry. None of the $P-T$ estimates from conventional thermobarometry (high or low), are within the uncertainty of our predictions from the TC47 and TDG protocols, suggesting that these protocols do not yield realistic results.

Figure 15 presents our preferred $P-T$ path for the Tso Morari eclogite (the bold red line), which is a result of considering all results from our modeling trials and thermobarometric calculations. Four $P$ - $T$ constraints (M0-M3) for the metamorphic evolution of Tso Morari eclogite are presented (Fig. 15). Position M0 represents the $P$ - $T$ conditions during formation of the garnet core (before onset of bulk composition fractionation). Position M1 represents the $P-T$ conditions at peak pressure predicted by models (TC33 and TDW), which is more consistent with the pressure obtained from calculations using highest silica phengite (3.54 Si p.f.u.) in TM-15 (Fig. 14a \& d). Position M2 represents the peak metamorphic conditions preserved by the garnet composition in the rim of $\mathrm{TM}-15 \mathrm{G} \# 3$ (low $\mathrm{x}(\mathrm{Ca})_{\text {grt }}$ ), which is interpreted to have formed during peak 
metamorphism. Position M3 represents a point along the retrograde path, calculated using the muscovite-paragonite barometer of Roux and Hovis (1996).

Figure 15 also shows paths from previous studies. St-Onge et al. (2013) used the same approach as protocol TC33 (TC version 3.33, ds 55, and garnet $a-X$ relation in White et al. 2007) yeilding similar $P$ - $T$ results (path 10 in Fig. 15). Palin et al. (2017) predicted peak $P-T$ conditions of $26-28 \mathrm{kbar}$ and $600-620^{\circ} \mathrm{C}$ (paths 12 and 13 in Fig. 15), and estimated garnet nucleation occurred at $350-370{ }^{\circ} \mathrm{C}$ and $18-20 \mathrm{kbar}$ using combined thermodynamic (TC version $3.40 \mathrm{i}$, ds 55 , and garnet $a-X$ relations in White et al. 2007) and geodynamic numerical modeling (MVEP2). However, Konrad-Schmolke et al. (2008), using TD and different garnet $a$ - $X$ relations (Berman 1990), predicted a warmer, convex prograde $P$ - $T$ path starting from $17.2 \mathrm{kbar}$ and $545{ }^{\circ} \mathrm{C}$, with amphibole- instead of lawsonite-rich assemblages. This study produced similar peak conditions of $628^{\circ} \mathrm{C}$ at 24.4 kbar (path 8 in Fig. 15).

Metamorphic $P-T$ paths obtained by thermodynamic modeling (regardless of modeling program, version of thermodynamic database, and mineral $a-X$ relations) for the Tso Morari eclogite predict a cold subduction path (this study; St-Onge et al. 2013; Chatterjee and Jagoutz 2015; Palin et al. 2014, 2017). Protocols TC47 and TDG predictions (orange curve in Fig. 15) are close to the forbidden geothermal gradient $\left(5^{\circ} \mathrm{C} / \mathrm{km}\right)$ in the lawsonite-eclogite field (Schreyer 1995; Liou 1998), landing in the very rare ultralow thermal gradient classification (Brown 2014) of subduction related $P-T$ paths. Petrologic evidence does not support this low gradient or the elevated peak pressures. In addition, the protolith of Tso Morari UHP terrane is continental crust with significant sedimentary rock cover; thermomechanical modeling accounting for this produces warmer prograde paths (Warren et al. 2008; Beaumont et al. 2009). Thermodynamic modeling 
may be underestimating temperature by not accounting for the effect of shear heating, hydration reactions and fluid and rock advection (Penniston-Dorland et al. 2015).

\section{Conclusions}

Our petrologic, compositional, and thermodynamic evidence from eclogite from the Tso Morari UHP, NW India yield the following conclusions:

1. After comparing the modeling results of all four protocols with supporting petrologic and thermobarometric data, we conclude that the selection of $a-X$ relations, specifically for garnet, is more important than the choice of modeling program, version, or database. In metabasites, the $a-X$ relations chosen for garnet have the largest impact on estimate of peak pressure. The thermodynamic models using the newer $a-X$ relations for garnet (White et al. 2014a) predict a higher metamorphic peak pressure than the modeling results by using the garnet $a-X$ relations of White et al. (2007). Using the White et al. (2014a) data for garnet also produces unreasonable cool prograde paths.

2. In metabasites, the changes in mineral assemblage and relative proportions predicted by thermodynamic modeling are very sensitive to whether garnet is assumed to be in equilibrium during its entire growth or whether it is fractionating. As demonstrated above, independent of the protocol selected, peak pressure will be significantly over-estimated in the non-fractionated case (Fig. 13).

3. The cool prograde paths and higher pressures predicted using the newer garnet $a-X$ relations (White et al. 2014a) are not supported by petrologic observations. The peak pressures predicted by TC33 and TDW modeling $\left(26 \pm 1 \mathrm{kbar}\right.$ at $565 \pm 8{ }^{\circ} \mathrm{C}$ and $28.5 \pm 1.5$ kbar at $563 \pm 13{ }^{\circ} \mathrm{C}$, respectively), are consistent with the conventional thermobarometry 
results in this study and previous work using thermodynamic models from the well-studied Tso Morari (e.g., St-Onge et al. 2013; Chatterjee and Jagoutz 2015; Palin et al. 2017). However, TC33 and TDW still produce prograde paths that predict significant lawsonite, which is not observed in the rocks. Thermodynamic modelling alone may underestimate temperature during prograde metamorphism.

4. Quantitative results from thermodynamic modeling should be integrated with petrographic observations to obtain a geologically meaningful interpretation. More careful consideration of the key mineral $a-X$ relations, comparison between multiple techniques, and sourcing and controlling of uncertainties can essentially help interpret geological problems.

\section{Acknowledgements}

We thank Emilee Darling for preparing the samples. C. Menold thanks Dennis Donaldson and Alex Webb for help in the field. The manuscript was greatly improved with the help of detailed reviews from two anonymous reviewers, to whom we are grateful. We also thank the CMP editorial team for their assistance in the review process. This research was funded by NSF EAR 1822524 to C. Macris and C. Menold. 


\section{References}

Ague JJ, Axler JA (2016) Interface coupled dissolution-reprecipitation in garnet from subducted granulites and ultrahigh-pressure rocks revealed by phosphorous, sodium, and titanium zonation. Am Mineral 101:1696-1699. https://doi.org/10.2138/am-2016-5707

Baxter E, Caddick M, Dragovic B (2017) Garnet: A rock-forming mineral petrochronometer. Rev Mineral Geochem 83(1):469-533. https://doi.org/10.2138/rmg.2017.83.15

Beaumont C, Jamieson RA, Butler JP, Warren CJ (2009) Crustal structure: A key constraint on the mechanism of ultra-high-pressure rock exhumation. Earth Planet Sci Lett 287(1-2):116-129. https://doi.org/10.1016/j.epsl.2009.08.001

Berman RG (1988) Internally-consistent thermodynamic data for minerals in the system. $\mathrm{Na}_{2} \mathrm{O}$ $\mathrm{K}_{2} \mathrm{O}-\mathrm{CaO}-\mathrm{MgO}-\mathrm{FeO}-\mathrm{Fe}_{2} \mathrm{O}_{3}-\mathrm{Al}_{2} \mathrm{O}_{3}-\mathrm{SiO}_{2}-\mathrm{TiO}_{2}-\mathrm{H}_{2} \mathrm{O}-\mathrm{CO}_{2}$. J Petrol 29(2):445-522. https://doi.org/10.1093/petrology/29.2.445

Berman RG (1990) Mixing properties of Ca-Mg-Fe-Mn garnets. Amer Miner 75:328-344.

Berthelsen A (1953) On the geology of the Rupshu District, NW Himalaya: a contribution to the problem of the Central Gneisses. Medd fra Dansk Geol, Forening Kobenkhavn 12:350-415.

Brown M (2014) The contribution of metamorphic petrology to understanding lithosphere evolution and geodynamics. Geosci Front 5(4):553-569.

https://doi.org/10.1016/j.gsf.2014.02.005

Bucher K, Grapes R (2011) Petrogenesis of Metamorphic Rocks, Springer Science and Business Media, pp 21-56

Caddick MJ, Konopásek J, Thompson AB (2010) Preservation of garnet growth zoning and the duration of prograde metamorphism. J Petrol 51(11):2327-2347.

https://doi.org/10.1093/petrology/egq059

Carlson WD, Pattison DRM, Caddick MJ (2015) Beyond the equilibrium paradigm: How consideration of kinetics enhances metamorphic interpretation. Amer Miner 100(8-9):16591667. https://doi.org/10.2138/am-2015-5097

Carswell DA, Harley SL (1990) Mineral baromety and thermometry. In Carswell, D.A. (ed.): Eclogite facies rocks. Glasgow, London: Blackie, pp 83-110.

Carswell DA, Wilson RN, Zhai MG (2000) Metamorphic evolution, mineral chemistry and thermobarometry of schists and orthogneisses hosting ultra-high pressure eclogites in the 
Dabieshan of central China. Lithos 52(1-4):121-155. https://doi.org/10.1016/S00244937(99)00088-2

Chatterjee N, Jagoutz O (2015) Exhumation of the UHP Tso Morari eclogite as a diapir rising through the mantle wedge. Contrib Mineral Petrol 169(3). https://doi.org/10.1007/s00410-0141099-y

Coggon R, and Holland TJB (2002) Mixing properties of phengitic micas and revised garnetphengite thermobarometers. J Metamorph Geol 20(7):683-696. https://doi.org/10.1046/j.15251314.2002.00395.x

Dale J, Holland T, Powell R (2000) Hornblende-garnet-plagioclase thermobarometry: a natural assemblage calibration of the thermodynamics of hornblende. Contrib Mineral Petrol 140(3):353-362. https://doi.org/10.1007/s004100000187

Dale J, Powell R, White L, Elmer FL, Holland TJB (2005) A thermodynamic model for Ca-Naamphiboles in $\mathrm{Na}_{2} \mathrm{O}-\mathrm{CaO}-\mathrm{FeO}-\mathrm{MgO}-\mathrm{Al}_{2} \mathrm{O}_{3}-\mathrm{SiO}_{2}-\mathrm{H}_{2} \mathrm{O}-\mathrm{O}$ for prtrological calculations. $\mathrm{J}$ Metamorph Geol 23:771-791. https://doi.org/10.1111/j.1525-1314.2005.00609.x

De Andrade V, Vidal O, Lewin E, O'brien P, Agard P (2006) Quantification of electron microprobe compositional maps of rock thin sections: an optimized method and examples. J Metamorph Geol 24(7):655-668. https://doi.org/10.1111/j.1525-1314.2006.00660.x

de Capitani C (1994) Gleichgewichts-Phasendiagramme: Theorie und Software. Beihefte zum Eur J Mineral 72:48.

de Sigoyer J, Chavagnac V, Baldwin J, Luais B, Blichert-Toft J, Villa I, Guillot S (1999) Timing of the Hp-Lt Tso Morari evolution: from continental subduction to collision in the NW Himalaya. Terra Nostra 99:141-142.

de Sigoyer J, Guillot S, Lardeaux JM, Mascle G (1997) Glaucophane-bearing eclogites in the Tso Morari dome (eastern Ladakh, NW Himalaya). Eur J Mineral 9(5):1073-1084. https://dx.doi.org/10.1127/ejm/9/5/1073

de Sigoyer J, Chavagnac V, Blichert-Toft J, Villa IM, Luais B, Guillot S, Cosca M, Mascle G (2000) Dating the Indian continental subduction and collisional thickening in the northwest Himalaya: Multichronology of the Tso Morari eclogites. Geology 28(6):487-490. https://doi.org/10.1130/0091-7613(2000)28\%3C487:DTICSA\%3E2.0.CO;2

de Sigoyer J, Guillot S, Dick P (2004) Exhumation of the ultrahigh-pressure Tso Morari unit in eastern Ladakh (NW Himalaya): a case study. Tectonics 23(3).

https://doi.org/10.1029/2002TC001492 
Diener JFA, Powell R, White RW, Holland TJB (2007) A new thermodynamic model for clinoand orthoamphiboles in the system $\mathrm{Na}_{2} \mathrm{O}-\mathrm{CaO}-\mathrm{FeO}-\mathrm{MgO}-\mathrm{Al}_{2} \mathrm{O}_{3}-\mathrm{SiO}_{2}-\mathrm{H}_{2} \mathrm{O}-\mathrm{O}$. J Metamorph Geol 25(6):631-656. https://doi.org/10.1111/j.1525-1314.2007.00720.x

Diener JFA, Powell R (2012) Revised activity-composition models for clinopyroxene and amphibole. J Metamorph Geol 30(2): 131-142. https://doi.org/10.1111/j.15251314.2011.00959.x

Donaldson DG, Webb AAG, Menold CA, Kylander-Clark AR, Hacker BR (2013) Petrochronology of Himalayan ultrahigh-pressure eclogite. Geology 41(8):835-838. https://doi.org/10.1130/G33699.1

Droop G (1987) A general equation for estimating $\mathrm{Fe}^{3+}$ concentrations in ferromagnesian silicates and oxides from microprobe analyses, using stoichiometric criteria. Mineral Mag 51(361):431-435. https://doi.org/10.1180/minmag.1987.051.361.10

Endo S, Wallis SR, Tsuboi M, Aoya M, Uehara SI (2012) Slow subduction and buoyant exhumation of the Sanbagawa eclogite. Lithos 146:183-201. https://doi.org/10.1016/j.lithos.2012.05.010

Engi M (1992) Thermodynamic data for minerals: A critical assessment. In The Stability of Minerals. Springer, Dordrecht, pp 267-328.

Evans T (2004) A method for calculating effective bulk composition modification due to crystal fractionation in garnet - bearing schist: implications for isopleth thermobarometry. J Metamorph Geol 22(6):547-557. https://doi.org/10.1111/j.1525-1314.2004.00532.x

Florence FP, Spear FS (1995) Intergranular diffusion kinetics of Fe and Mg during retrograde metamorphism of a pelitic gneiss from the Adirondack Mountains. Earth Planet Sci Lett 134(34):329-340. https://doi.org/10.1016/0012-821X(95)00129-Z

Gaidies F, de Capitani C, Abart R (2008a) THERIA_G: a software program to numerically model prograde garnet growth. Contrib Mineral Petrol 155(5):657-671.

https://doi.org/10.1007/s00410-007-0263-z

Gaidies F, de Capitani C, Abart R, Schuster R (2008b) Prograde garnet growth along complex PT-t paths: results from numerical experiments on polyphase garnet from the Wölz Complex (Austroalpine basement). Contrib Mineral Petrol 155(6):673-688.

https://doi.org/10.1007/s00410-007-0264-y

Green TH, Hellman PL (1982) Fe-Mg partitioning between coexisting garnet and phengite at high pressure, and comments on a garnet-phengite geothermometer. Lithos 15(4):253-266. https://doi.org/10.1016/0024-4937(82)90017-2 
Green E, Holland T, Powell R (2007) An order-disorder model for omphacitic pyroxenes in the system jadeite-diopside-hedenbergite-acmite, with applications to eclogitic rocks. Amer Miner 92(7):1181-1189. https://doi.org/10.2138/am.2007.2401

Green ECR, Holland TJB, Powell R (2012) A thermodynamic model for silicate melt in CaO$\mathrm{MgO}-\mathrm{Al}_{2} \mathrm{O}_{3}-\mathrm{SiO}_{2}$ to $50 \mathrm{kbar}$ and $1800{ }^{\circ} \mathrm{C}$. J Metamorph Geol 30(6):579-597. https://doi.org/10.1111/j.1525-1314.2012.00982.x

Green ECR, White RW, Diener JFA, Powell R, Holland TJB, Palin RM (2016) Activitycomposition relations for the calculation of partial melting equilibria in metabasic rocks. J Metamorph Geol 34(9):845-869. https://doi.org/10.1111/jmg.12211

Guidotti CV, Sassi FP, Blencoe JG, Selverstone J (1994) The paragonite-muscovite solvus: I. PTX limits derived from the Na-K compositions of natural, quasibinary paragonite-muscovite pairs. Geochim Cosmochim Acta 58(10):2269-2275. https://doi.org/10.1016/00167037(94)90009-4

Guillot S, de Sigoyer J, Lardeaux J, Mascle G (1997) Eclogitic metasediments from the Tso Morari area (Ladakh, Himalaya): Evidence for continental subduction during India-Asia convergence. Contrib Mineral Petrol 128(2-3):197-212. https://doi.org/10.1007/s004100050303

Guillot S, Hattori KH, de Sigoyer J (2000) Mantle wedge serpentinization and exhumation of eclogites: insights from eastern Ladakh, northwest Himalaya. Geology 28:199-202. https://doi.org/10.1130/0091-7613(2000)28\%3C199:MWSAEO\%3E2.0.CO;2

Guillot S, Mahéo G, de Sigoyer J, Hattori KH, Pecher A (2008) Tethyan and Indian subduction viewed from the Himalayan high-to ultrahigh-pressure metamorphic rocks. Tectonophysics, 451(1-4), 225-241. https://doi.org/10.1016/j.tecto.2007.11.059

Hacker BR (2006) Pressures and temperatures of ultrahigh-pressure metamorphism: implications for UHP tectonics and $\mathrm{H}_{2} \mathrm{O}$ in subducting slabs. Int Geol Rev 48(12), 1053-1066. https://doi.org/10.2747/0020-6814.48.12.1053

Helgeson HC, Delaney JM, Nesbitt HW, Bird DK (1978) Summary and critique of the thermodynamic properties of rock-forming minerals. Amer J Sci 278A:1-229.

Hernández-Uribe D, Gutiérrez-Aguilar F, Mattinson CG, Palin RM, Neill OK (2019) A new record of deeper and colder subduction in the Acatlán complex, Mexico: Evidence from phase equilibrium modelling and Zr-in-rutile thermometry. Lithos 324:551-568.

https://doi.org/10.1016/j.lithos.2018.10.003 
Hernández- Uribe D, Mattinson CG, Zhang J (2018) Phase equilibrium modelling and implications for P-T determinations of medium- temperature UHP eclogites, North Qaidam terrane, China. J Metamorph Geol 36(9):1237-1261. https://doi.org/10.1111/jmg.12444

Holland TJ (1990) Activities of components in omphacitic solid solutions. Contrib Mineral Petrol 105(4):446-453. https://doi.org/10.1007/BF00286831

Holland T, Powell R (1990) An enlarged and updated internally consistent thermodynamic dataset with uncertainties and correlations: the system $\mathrm{K}_{2} \mathrm{O}-\mathrm{Na}_{2} \mathrm{O}-\mathrm{CaO}-\mathrm{MgO}-\mathrm{MnO}-\mathrm{FeO}-\mathrm{Fe}_{2} \mathrm{O}_{3}-$ $\mathrm{Al}_{2} \mathrm{O}_{3}-\mathrm{TiO}_{2}-\mathrm{SiO}_{2}-\mathrm{C}-\mathrm{H}_{2}-\mathrm{O}_{2}$. J Metamorph Geol 8(1):89-124. https://doi.org/10.1111/j.15251314.1990.tb00458.x

Holland T, Powell R (1996) Thermodynamics of order-disorder in minerals; II, Symmetric formalism applied to solid solutions. Amer Miner 81(11-12):1425-1437.

https://doi.org/10.2138/am-1996-11-1215

Holland T, Powell R (1998) An internally consistent thermodynamic data set for phases of petrological interest. J Metamorph Geol 16(3):309-343. https://doi.org/10.1111/j.15251314.1998.00140.x

Holland T, Powell R (2000) AX: A program to calculate activities of mineral end members from chemical analyses (usually determined by electron microprobe). Available at: http: 11〉vww. esc. cam. ac. uklastafflhollandlax. html.

Holland T, Powell R (2003) Activity-composition relations for phases in petrological calculations: an asymmetric multicomponent formulation. Contrib Mineral Petrol 145(4):492501. https://doi.org/10.1007/s00410-003-0464-z

Holland TJB, Powell R (2011) An improved and extended internally consistent thermodynamic dataset for phases of petrological interest, involving a new equation of state for solids. J Metamorph Geol 29(3):333-383. https://doi.org/10.1111/j.1525-1314.2010.00923.x

Horák J, Gibbons W (1986) Reclassification of blueschist amphiboles from Anglesey, North Wales. Mineral Mag 50(357):533-535. https://doi.org/10.1180/minmag.1986.050.357.18

Imayama T (2014) P-T conditions of metabasites within regional metapelites in far-eastern Nepal Himalaya and its tectonic meaning. Swiss Journal of Geosciences, 107(1), 81-99.

https://doi.org/10.1007/s00015-014-0159-7

Jonnalagadda MK, Karmalkar NR, Duraiswami RA (2017a) Geochemistry of eclogites of the Tso Morari complex, Ladakh, NW Himalayas: Insights into trace element behavior during subduction and exhumation. Geosci Front 10(3):811-826.

https://doi.org/10.1016/j.gsf.2017.05.013 
Jonnalagadda MK, Karmalkar NR, Duraiswami RA, Harshe S, Gain S, Griffin WL (2017b) Formation of atoll garnets in the UHP eclogites of the Tso Morari Complex, Ladakh, Himalaya. J Earth Syst Sci 126(8):107. https://doi.org/10.1007/s12040-017-0887-y

Kamzolkin VA, Ivanov SD, Konilov AN (2016) Empirical phengite geobarometer: Background, calibration, and application. Geol Ore Deposits 58(8):613-622.

https://doi.org/10.1134/S1075701516080092

Kelsey DE, Hand M (2015) On ultrahigh temperature crustal metamorphism: Phase equilibria, trace element thermometry, bulk composition, heat sources, timescales and tectonic settings. Geosci Front 6(3):311-356. https://doi.org/10.1016/j.gsf.2014.09.006

Kohn MJ, Parkinson CD (2002) Petrologic case for Eocene slab breakoff during the Indo-Asian collision. Geology 30(7):591-594. https://doi.org/10.1130/0091-

7613(2002)030\%3C0591:PCFESB\%3E2.0.CO;2

Kohn MJ, Spear FS (1991) Error propagation for barometers; 2, Application to rocks. Amer Miner, 76(1-2):138-147.

Konrad-Schmolke M, Handy MR, Babist J, O'Brien PJ (2005) Thermodynamic modelling of diffusion-controlled garnet growth. Contrib Mineral Petrol 149(2):181-195.

https://doi.org/10.1007/s00410-004-0643-6

Konrad-Schmolke M, O'Brien PJ, de Capitani C, Carswell DA (2008) Garnet growth at high-and ultra-high pressure conditions and the effect of element fractionation on mineral modes and composition. Lithos 103(3-4):309-332. https://doi.org/10.1016/j.lithos.2007.10.007

Kretz R (1983) Symbols for rock-forming minerals. Amer Miner 68(1-2):277-279.

Kylander-Clark AR, Hacker BR, Mattinson CG (2012) Size and exhumation rate of ultrahighpressure terranes linked to orogenic stage. Earth Planet Sci Lett 321:115-120.

https://doi.org/10.1016/j.epsl.2011.12.036

Lanari P, Duesterhoeft E (2019) Modeling Metamorphic Rocks Using Equilibrium Thermodynamics and Internally Consistent Databases: Past Achievements, Problems and Perspectives. J Petrol 60(1):19-56. https://doi.org/10.1093/petrology/egy105

Lanari P, Engi M (2017) Local Bulk Composition Effects on Metamorphic Mineral Assemblages. Rev Mineral Geochem 83(1):55-102. https://doi.org/10.2138/rmg.2017.83.3

Lanari P, Giuntoli F, Loury C, Burn M, Engi M (2017) An inverse modeling approach to obtain $\mathrm{P}-\mathrm{T}$ conditions of metamorphic stages involving garnet growth and resorption. Eur J Mineral 29:181-199. https://doi.org/10.1127/ejm/2017/0029-2597 
Lanari P, Riel N, Guillot S, Vidal O, Schwartz S, Pêcher A, Hattori KH (2013) Deciphering high-pressure metamorphism in collisional context using microprobe mapping methods: Application to the Stak eclogitic massif (northwest Himalaya). Geology 41(2):111-114. https://doi.org/10.1130/G33523.1

Lanari P, Vho A, Bovay T, Airaghi L, Centrella S (2019) Quantitative compositional mapping of mineral phases by electron probe micro-analyser. Geological Society, London, Special Publications 478(1):39-63. https://doi.org/10.1144/SP478.4

Laurent V, Lanari P, Naïr I, Augier R, Lahfid A, Jolivet L (2018) Exhumation of eclogite and blueschist (Cyclades, Greece): Pressure-temperature evolution determined by thermobarometry and garnet equilibrium modelling. J Metamorph Geol 36(6):769-798.

https://doi.org/10.1111/jmg.12309

Leech ML, Singh S, Jain AK (2007) Continuous metamorphic zircon growth and interpretation of U-Pb SHRIMP dating: An example from the Western Himalaya. Int Geol Rev 49(4):313-328. https://doi.org/10.2747/0020-6814.49.4.313

Leech ML, Singh S, Jain AK, Klemperer SL, Manickavasagam RM (2005) The onset of IndiaAsia continental collision: early, steep subduction required by the timing of UHP metamorphism in the western Himalaya. Earth Planet Sci Lett 234:83-97.

https://doi.org/10.1016/j.epsl.2005.02.038

Liou J (1998) High-pressure minerals from deeply subducted metamorphic rocks. Ultrahighpressure mineralogy 33-96.

Locock AJ (2014) An Excel spreadsheet to classify chemical analyses of amphiboles following the IMA 2012 recommendations. Comput and Geosci 62:1-11.

https://doi.org/10.1016/j.cageo.2013.09.011

Lombardo B, Rolfo F (2000) Two contrasting eclogite types in the Himalayas: implications for the Himalayan orogeny. J Geodyn 30(1-2):37-60. https://doi.org/10.1016/S02643707(99)00026-5

Lombardo B, Rolfo F, Compagnoni R (2000) Glaucophane and barroisite eclogites from the Upper Kaghan nappe: implications for the metamorphic history of the NW Himalaya. Geological Society, London, Special Publications 170(1):411-430.

https://doi.org/10.1144/GSL.SP.2000.170.01.22

Mahar EM, Baker JM, Powell R, Holland TJB, Howell N (1997) The effect of Mn on mineral stability in metapelites. J Metamorph Geol 15(2):223-238. https://doi.org/10.1111/j.15251314.1997.00011.x 
Marmo B, Clarke G, Powell R (2002) Fractionation of bulk rock composition due to porphyroblast growth: effects on eclogite facies mineral equilibria, Pam Peninsula, New Caledonia. J Metamorph Geol 20(1):151-165. https://doi.org/10.1046/j.0263-4929.2001.00346.x

Massonne HJ (2012) Formation of amphibole and clinozoisite-epidote in eclogite owing to fluid infiltration during exhumation in a subduction channel. J Petrol 53(10):1969-1998. https://doi.org/10.1093/petrology/egs040

Massonne HJ, Schreyer W (1987) Phengite geobarometry based on the limiting assemblage with K-feldspar, phlogopite, and quartz. Contrib Mineral Petrol 96(2):212-224. https://doi.org/10.1007/BF00375235

Menold CA, Manning CE, Yin A, Tropper P, Chen XH, Wang XF (2009) Metamorphic evolution, mineral chemistry and thermobarometry of orthogneiss hosting ultrahigh-pressure eclogites in the North Qaidam metamorphic belt, Western China. J Asian Earth Sci 35(3-4):273284. https://doi.org/10.1016/j.jseaes.2008.12.008

Meyre C, de Capitani C, Partzsch JH (1997) A ternary solid solution model for omphacite and its application to geothermobarometry of eclogites from the middle Adula Nappe (Central Alps, Switzerland). J Metamorph Geol 15:687-700. https://doi.org/10.1111/j.1525-1314.1997.00042.x

Morimoto N (1988) Nomenclature of pyroxenes. Mineral Petrol 39(1):55-76. https://doi.org/10.1007/BF01226262

Moynihan DP, Pattison DRM (2013) An automated method for the calculation of P-Tpaths from garnet zoning, with application to metapelitic schist from the Kootenay Arc, British Columbia, Canada. J Metamorph Geol 31(5):525-548. https://doi.org/10.1111/jmg.12032

Mukherjee BK, Sachan HK (2001) Discovery of coesite from Indian Himalaya: a record of ultrahigh pressure metamorphism in Indian continental crust. Curr Sci 1358-1361.

Mukherjee BK, Sachan HK (2004) Garnet response diamond pressure metamorphism from Tso Morari region, Ladakh, India. Himalayan Journal of Sciences, 2(4):209. https://doi.org/10.3126/hjs.v2i4.902

Mukherjee BK, Sachan HK (2009) Fluids in coesite-bearing rocks of the Tso Morari Complex, NW Himalaya: evidence for entrapment during peak metamorphism and subsequent uplift. Geol Mag 146(06):876-889. https://doi.org/10.1017/S0016756809990069

Mukherjee BK, Sachan HK, Ogasawara Y, Muko A, Yoshioka N (2003) Carbonate-Bearing UHPM Rocks from the Tso-Morari Region, Ladakh, India: Petrological Implications. Int Geol Rev 45(1):49-69. https://doi.org/10.2747/0020-6814.45.1.49 
Newton RC, Haselton HT (1981) Thermodynamics of the Garnet-Plagioclase- $\mathrm{Al}_{2} \mathrm{SiO}_{5}-\mathrm{Quartz}$ Geobarometer. In: Newton RC, Navrotsky A, Wood BJ (eds) Thermodynamics of Minerals and Melts. Advances in Physical Geochemistry, vol 1. Springer, New York, NY pp 131-147. https://doi.org/10.1007/978-1-4612-5871-1_7

O'Brien PJ (2018) Eclogites and other high-pressure rocks in the Himalaya: a review. Geological Society, London, Special Publications 483(1):183-213. https://doi.org/10.1144/SP483.13

O'Brien PJ (2019) Tso Morari coesite eclogite: pseudosection predictions v. the preserved record and implications for tectonometamorphic models. Geological Society, London, Special Publications 474(1):5-24. https://doi.org/10.1144/SP474.16

O'Brien PJ, Sachan HK (2000) Diffusion modelling in garnet from Tso Morari eclogite and implications for exhumation models. Earth Sci Front 7(Suppl):25-27.

O’Brien PJ, Zotov N, Law R, Khan MA, Jan MQ (1999) Coesite in eclogite from the upper Kaghan Valley, Pakistan: a first record and implications. Terra Nostra 99(2):109-111.

O'Brien PJ, Zotov N, Law R, Khan MA, Jan MQ (2001) Coesite in Himalayan eclogite and implications for models of India-Asia collision. Geology 29(5):435-438.

https://doi.org/10.1130/0091-7613(2001)029\%3C0435:CIHEAI\%3E2.0.CO;2

Palin RM, St-Onge MR, Waters DJ, Searle MP, Dyck B (2014) Phase equilibria modelling of retrograde amphibole and clinozoisite in mafic eclogite from the Tso Morari massif, northwest India: constraining the P-T-M( $\left.\mathrm{H}_{2} \mathrm{O}\right)$ conditions of exhumation. J Metamorph Geol 32(7):675693. https://doi.org/10.1111/jmg. 12085

Palin RM, Reuber GS, White RW, Kaus BJP, Weller OM (2017) Subduction metamorphism in the Himalayan ultrahigh-pressure Tso Morari massif: An integrated geodynamic and petrological modelling approach. Earth Planet Sci Lett 467:108-119.

https://doi.org/10.1016/j.eps1.2017.03.029

Palin RM, Weller OM, Waters DJ, Dyck B (2016) Quantifying geological uncertainty in metamorphic phase equilibria modelling; a Monte Carlo assessment and implications for tectonic interpretations. Geosci Front 7(4):591-607. https://doi.org/10.1016/j.gsf.2015.08.005

Pattinson DRM (2003) Petrogenetic significance of orthopyroxene-free garnet plus clinopyroxene plus plagioclase+/- quartz-bearing metabasites with respect to the amphibolite and granulite facies. J Metamorph Geol 21(1):21-34. https://doi.org/10.1046/j.15251314.2003.00415.x 
Penniston-Dorland SC, Kohn MJ, Manning CE (2015) The global range of subduction zone thermal structures from exhumed blueschists and eclogites: Rocks are hotter than models. Earth Planet Sci Lett 428:243-254. https://doi.org/10.1016/j.eps1.2015.07.031

Pognante U, Castelli D, Benna P, Genovese G, Oberli F, Meier M, Tonarini S (1990) The crystalline units of the High Himalayas in the Lahul-Zanskar region (northwest India):

Metamorphic-tectonic history and geochronology of the collided and imbricated Indian plate. Geol Mag 127(2):101-116. https://doi.org/10.1017/S0016756800013807

Pognante U, Spencer DA (1991) First report of eclogites from the Himalayan belt, Kaghan valley (northern Pakistan). Eur J Mineral 3(3):613-618. https://dx.doi.org/10.1127/ejm/3/3/0613

Powell R (1985) Regression diagnostics and robust regression in geothermometer/geobarometer calibration: the garnet-clinopyroxene geothermometer revisited. J Metamorph Geol 3(3):231243. https://doi.org/10.1111/j.1525-1314.1985.tb00319.x

Powell R, Holland T. (1994) Optimal geothermometry and geobarometry. Amer Miner 79(1-2): $120-133$.

Powell R, Holland T, Worley B (1998) Calculating phase diagrams involving solid solutions via non-linear equations, with examples using THERMOCALC. J Metamorph Geol 16(4):577-588. https://doi.org/10.1111/j.1525-1314.1998.00157.x

Powell R, Holland TJB (2008) On thermobarometry. J Metamorph Geol 26(2):155-179. https://doi.org/10.1111/j.1525-1314.2007.00756.x

Proyer A, Dachs E, McCammon C (2004) Pitfalls in geothermobarometry of eclogites: $\mathrm{Fe}^{3+}$ and changes in the mineral chemistry of omphacite at ultrahigh pressures. Contrib Mineral Petrol 147(3):305-318. https://doi.org/10.1007/s00410-004-0554-6

Ravna K (2000) The garnet-clinopyroxene $\mathrm{Fe}^{2+}-\mathrm{Mg}$ geothermometer: an updated calibration. J Metamorph Geol 18(2):211-219. https://doi.org/10.1046/j.1525-1314.2000.00247.x

Ravna EK, Paquin J (2003) Thermobarometric methodologies applicable to eclogites and garnet ultrabasites. EMU notes in mineralogy 5(8):229-259. https://doi.org/10.1180/EMU-notes.5.8

Rehman HU, Yamamoto H, Kaneko Y, Kausar AB, Murata M, Ozowa H (2007) Thermobaric structure of the Himalayan metamorphic belt in Kaghan Valley, Pakistan. J Asian Earth Sci 29(2-3)390-406. https://doi.org/10.1016/j.jseaes.2006.06.002

Rehman HU, Yamamoto H, Khalil MAK, Nakamura E, Zafar M, Khan T (2008) Metamorphic hiostory and tectonic evolution of the Himalayan UHP eclogites in Kaghan valley, Pakistan. J Miner Petrol Sci 103(4):242-254. https://doi.org/10.2465/jmps.080222 
Roux J, Hovis GL (1996) Thermodynamic Mixing Models for Muscovite-Paragonite Solutions Based on Solution Calorimetric and Phase Equilibrium Data. J Petrol 37(5):1241-1254. https://doi.org/10.1093/petrology/37.5.1241

Sachan HK, Bodnar RJ, Islam R, Szabo CS, Law RD (1999) Exhumation history of eclogites from the Tso Morari crystalline complex in eastern Ladakh: mineralogical and fluid inclusion constraints. J Geol Soc India 53(2):181-190. http://www.geosocindia.org/index.php/jgsi/article/view/68998

Sachan HK, Mukherjee BK, Ogasawara Y, Maruyama S, Ishida H, Muko A, Yoshioka N (2004) Discovery of coesite from Indus Suture Zone (ISZ), Ladakh, India: Evidence for deep subduction. Eur J Mineral 16(2):235-240. https://doi.org/10.1127/0935-1221/2004/0016-0235

Schmidt M (1993) Phase relations and compositions in tonalite as a function of pressure: an experimental study at 650 C. Amer J Sci 293:1011-1060.

Schneider CA, Rasband WS, Eliceiri KW (2012) NIH Image to ImageJ: 25 years of image analysis. Nature methods 9(7):671-675. https://doi.org/10.1038/nmeth.2089

Schreyer W (1995) Ultradeep metamorphic rocks: The retrospective viewpoint. J Geophys Res: Solid Earth 100(B5):8353-8366. https://doi.org/10.1029/94JB02912

Singh P, Saikia A, Pant NC, Verma PK (2013a) Insights into the P-T evolution path of Tso Morari eclogites of the north-western Himalayas: Constraints on the geodynamic evolution of the region. J Earth Syst Sci 122(3):677-698. https://doi.org/10.1007/s12040-013-0307-x

Singh P, Pant NC, Saikia A, Kundu A (2013b) The role of amphiboles in the metamorphic evolution of the UHP rocks: a case study from the Tso Morari Complex, northwest Himalayas. Int J Earth Sci 102(8):2137-2152. https://doi.org/10.1007/s00531-013-0920-6

Spear FS (1988) Metamorphic fractional crystallization and internal metasomatism by diffusional homogenization of zoned garnets. Contrib Mineral Petrol 99(4):507-517. https://doi.org/10.1007/BF00371941

Spear FS (1995) Metamorphic phase equilibria and pressure-temperature-time paths. $\left(2^{\text {nd }}\right.$ print., corr). Mineralogical Society of America, Washington, D.C.

Spear FS, Kohn M, Florence F, Menard T (1990) A model for garnet and plagioclase growth in pelitic schists: implications for thermobarometry and P-T path determinations. J Metamorph Geo 18(6):683-696. https://doi.org/10.1111/j.1525-1314.1990.tb00495.x

Spear FS, Selverstone J (1983) Quantitative PT paths from zoned minerals: theory and tectonic applications. Contrib Mineral Petrol, 83(3-4): 348-357. https://doi.org/10.1007/BF00371203 
Spear FS, Wolfe OM (2018) Evaluation of the effective bulk composition (EBC) during growth of garnet. Chem Geol 491:39-47. https://doi.org/10.1016/j.chemgeo.2018.05.019

Spencer DA (1993) Tectonics of the Higher-and Tethyan Himalaya, Upper Kaghan Valley, NW Himalaya, Pakistan: Implications of an early collisional, high pressure (eclogite facies) metamorphism to the Himalayan belt (Doctoral dissertation, ETH Zurich).

https://doi.org/10.3929/ethz-a-000924618

Spencer DA, Tonarini S, Pognante U (1995) Geochemical and Sr-Nd isotopic characterisation of Higher Himalayan eclogites (and associated metabasites). Eur J Mineral 7(1):89-102. https://dx.doi.org/10.1127/ejm/7/1/0089

St-Onge MR, Rayner N, Palin RM, Searle MP, Waters DJ (2013) Integrated pressuretemperature-time constraints for the Tso Morari dome (Northwest India): implications for the burial and exhumation path of UHP units in the western Himalaya. J Metamorph Geol 31(5):469-504. https://doi.org/10.1111/jmg.12030

Steck A (2003) Geology of the NW Indian Himalaya. Eclogae Geol Helv 96:147-196.

Steck A, MatthieuGirard AM, Robyr M (1998) Geological transect across the Tso Morari and Spiti areas: The nappe structures of the Tethys Himalaya.

Stowell HH, Tinkham DK (2003) Integration of phase equilibria modelling and garnet Sm-Nd chronology for construction of PTt paths: examples from the Cordilleran Coast Plutonic Complex, USA. Geological Society, London, Special Publications, 220(1):119-145. https://doi.org/10.1144/GSL.SP.2003.220.01.07

Symmes GH, Ferry JM (1992) The effect of whole- rock MnO content on the stability of garnet in pelitic schists during metamorphism. J Metamorph Geol 10(2):221-237. https://doi.org/10.1111/j.1525-1314.1992.tb00080.x

Syracuse EM, van Keken PE, Abers GA (2010) The global range of subduction zone thermal models. Phys Earth Planet Inter 183(1-2):73-90. https://doi.org/10.1016/j.pepi.2010.02.004

Thakur V, Misra D (1984) Tectonic framework of the Indus and Shyok suture zones in eastern Ladakh, northwest Himalaya. Tectonophysics 101(3-4):207-220. https://doi.org/10.1016/00401951(84)90114-8

Thakur V, Virdi N (1979) Lithostratigraphy, structural framework, deformation and metamorphism of the southeastern region of Ladakh, Kashmir Himalaya, India. Himal Geol 9:63-78. 
Tinkham DK, Ghent ED (2005) Estimating PT conditions of garnet growth with isochemical phase-diagram sections and the problem of effective bulk-composition. Can Mineral 43(1):3550. https://doi.org/10.2113/gscanmin.43.1.35

Tracy RJ (1982) Compositional zoning and inclusions in metamorphic minerals.

Characterization of Metamorphism through Mineral Equilibria. Review in Mineralogy:355-397.

Vance D, Mahar E (1998) Pressure-temperature paths from PT pseudosections and zoned garnets: potential, limitations and examples from the Zanskar Himalaya, NW India. Contrib Mineral Petrol 132:225-245. https://doi.org/10.1007/s004100050419

Walker CB, Searle MP, Waters DJ (2001) An integrated tectonothermal model for the evolution of the High Himalaya in western Zanskar with constraints from thermobarometry and metamorphic modeling. Tectonics 20(6):810-833. https://doi.org/10.1029/2000TC001249

Warren CJ, Beaumont C, Jamieson RA (2008) Modelling tectonic styles and ultra-high pressure (UHP) rock exhumation during the transition from oceanic subduction to continental collision. Earth Planet Sci Lett 267(1-2):129-145. https://doi.org/10.1016/j.epsl.2007.11.025

Warren CJ, Waters DJ (2006) Oxidized eclogites and garnet-blueschists from Oman: P?T path modelling in the NCFMASHO system. J Metamorph Geol 24(9):783-802. https://doi.org/10.1111/j.1525-1314.2006.00668.x

Waters DJ, Martin HN (1996) The garnet-Cpx-phengite barometer. Recommended Calibration and Calculation Method. https://www.earth.ox.ac.uk/ davewa/research/eclogites/ecbarcal.html

Wei CJ, Clarke GL (2011) Calculated phase equilibria for MORB compositions: a reappraisal of the metamorphic evolution of lawsonite eclogite. J Metamorph Geol 29(9):939-952.

https://doi.org/10.1111/j.1525-1314.2011.00948.x

White R (2010) Tutorial for Using the readbulkinfo (rbi) Script. In, vol. THERMOCALC website.

White RW, Powell R, Holland TJB (2007) Progress relating to calculation of partial melting equilibria for metapelites. J Metamorph Geol 25(5):511-527. https://doi.org/10.1111/j.15251314.2007.00711.x

White RW, Powell R, Holland TJB, Johnson TE, Green ECR (2014a) New mineral activitycomposition relations for thermodynamic calculations in metapelitic systems. J Metamorph Geol 32(3):261-286. https://doi.org/10.1111/jmg.12071 
White RW, Powell R, Johnson TE (2014b) The effect of Mn on mineral stability in metapelites revisited: new a-X relations for manganese-bearing minerals. J Metamorph Geol 32(8):809-828. https://doi.org/10.1111/jmg.12095

Wilke FDH, O'Brien PJ, Altenberger U (2010a) Multistage reaction history in different eclogite types from the Pakistan Himalaya and implications for exhumation processes. Lithos 114: 70-85. https://doi.org/10.1016/j.lithos.2009.07.015

Wilke FDH, O’Brien PJ, Gerdes A, Timmerman MJ, Sudo M, Ahmed Khan M (2010b) The multistage exhumation history of the Kaghan Valley UHP series, NW Himalaya, Pakistan from $\mathrm{U}-\mathrm{Pb}$ and ${ }^{40} \mathrm{Ar} /{ }^{39} \mathrm{Ar}$ ages. Eur J Mineral 22:703-719. https://doi.org/10.1127/0935$1221 / 2010 / 0022-2051$

Wilke FDH, O'Brien PJ, Schmidt A, Ziemann MA (2015) Subduction, peak and multi-stage exhumation metamorphism: Traces from one coesite-bearing eclogite, Tso Morari, western Himalaya. Lithos 231:77-91. https://doi.org/10.1016/j.lithos.2015.06.007

Worley B, Powell R (2000) High-precision relative thermobarometry: theory and a worked example. J Metamorph Geol 18(1):91-101. https://doi.org/10.1046/j.1525-1314.2000.00239.x

Yu H, Zhang L, Lanari P, Rubatto D, Li X (2019) Garnet Lu-Hf geochronology and PT path of the Gridino-type eclogite in the Belomorian Province, Russia. Lithos 326:313-326. https://doi.org/10.1016/j.lithos.2018.12.032

Zeh A (2006) Calculation of Garnet Fractionation in Metamorphic Rocks, with Application to a Flat-Top, Y-rich Garnet Population from the Ruhla Crystalline Complex, Central Germany. J Petrol 47(12):2335-2356. https://doi.org/10.1093/petrology/egl046 


\section{Figure Captions}

Figure 1. Geological map of the Himalayan orogenic belt showing the rock units, tectonic boundaries, and location of the Tso Morari ultra high pressure (UHP) terrane. The inset shows the Himalayan-Tibetan orogeny. ST: Stak Valley; ISZ: Indus Suture Zone; KG: Kaghan Valley; MFT: Main Frontal Thrust. Modified after (Thakur and Virdi 1979; Thakur and Misra 1984; Steck 2003).

Figure 2. Images of sample TM-15. (a) Mafic eclogite boudin (dark color) enclosed within the felsic gneiss (light color) in the field. (b) Plane polarized light photomicrograph of a thin section of eclogite sample TM-15. (c) False color BSE image of TM-15, showing major minerals and textures an $8 \times 6 \mathrm{~mm}$ portion of the thin section. (d) XMapTools processed image based on an X-ray compositional map of TM-15, showing phases and textures in a $2 \times 1.5 \mathrm{~mm}$ portion of the thin section. The box in this image shows evidence of poikilitic texture of amphibole, although this is texture is rarely observed in the sample. Mineral abbreviations as in Table 2.

Figure 3. Photomicrographs of garnet crystals in eclogite TM-15. (a) Crossed polarized image of garnet TM-15G\#3. (b) BSE image of garnet TM-15G\#3, showing the traverse of EPMAmeasured garnet compositional profile (A-A'). (c) XMapTools processed image of garnet TM-15G\#3 based on an X-ray map, showing the garnet zonation and inclusion phases. (d) BSE images of the mineral inclusions in garnet (TM-15G\#2) core. Mineral abbreviations as in Table 2. 
Figure 4. Diagrams of mineral (garnet, clinopyroxene, muscovite/phengite) compositions in eclogite sample TM-15. (a) Quadrilateral diagram of garnet compositions in TM-15, showing the compositional change from the central core to outermost rim. Data are from three garnet crystals in TM-15. (b) Diagram of Fe/Mg ratio vs. $\mathrm{X}(\mathrm{Ca})$ grt from rim to central core of three garnet crystals in TM-15. Garnet rim can be subdivided to Rim 1 and Rim 2 based on garnet compositional variability from core to rim (separation rules of the three garnet zones follows that of garnet TM-15G\#3). (c) Nomenclature ternary diagram of sodium pyroxenes, showing the composition of omphacitic pyroxene in eclogite TM-15. (e) Diagram of white mica Al p.f.u. vs. Si p.f.u. in eclogite TM-15.

Figure 5. Compositional profile indicating garnet endmember fractions of almandine (alm), pyrope (prp), grossular (grs), and spessartine (sps) across a traverse of garnet TM-15G\#3 from rim to core to rim (A-A'). The garnet rim has be subdivided to Rim 1 and Rim 2 based on garnet compositional variability from core to rim. EPMA spots can be seen in Fig. 3b, and data are presented in Table S1. The diameter of the garnet crystal is $\sim 1200 \mu \mathrm{m}$. 
Figure 6. Thermobarometry calculations using selected minerals from eclogite sample TM-15. (a) Lines are labeled with the thermobarometer used and sample number. The lines are calculated using data from the rim of garnet TM-15G\#3 and high-Si phengite in TM-15. The red error ellipse and point within are the output from AVE_PT mode on THERMOCALC (version 3.33) with the assemblage (omp, grt, ms, tlc, lws, rt, coe, and $\mathrm{H}_{2} \mathrm{O}$ ). Temperature maxima from GC thermometry (blue and orange dashed lines) are calculated using garnet $(\mathrm{FeO} / \mathrm{MgO})_{\text {minimum }}$ and omphacite $(\mathrm{FeO} / \mathrm{MgO})_{\text {maximum, }}$ and temperature maximum from GP thermometry (red dashed lines) is calculated using garnet $(\mathrm{FeO} / \mathrm{MgO})_{\text {minimum }}$ and phengite $(\mathrm{FeO} / \mathrm{MgO})_{\text {maximum }}$ (Carswell et al. 2000). Vice versa for temperature minima in thermometers. Garnet, omphacite, and phengite $\mathrm{FeO} / \mathrm{MgO}$ minima and maxima are calculated based on compositional variability at $1 \sigma$ level. Pressure maximum and minimum for Phg Si barometer (purple dashed lines) is based on the Si p.f.u. variability at $1 \sigma$ level from phengite with high Si p.f.u. (3.51-3.54). An overall uncertainty of $\pm 2.5 \mathrm{kbar}$ for the non-ideal garnet and clinopyroxene of typical eclogites is suggested for the GOP barometer (Waters and Martin 1996). The ellipse in AVE_PT depicts $(1 \sigma)$ uncertainties calculated by the program. The gray shaded region depicts the $P-T$ range suggested when comparing all thermobarometers. (b) Comparison between paragonite and low-Si phengite from eclogite TM-15 and the solvi calculated at 5, 10, and $15 \mathrm{kbar}$ (Roux and Hovis 1996). pg: paragonite; ms: muscovite.

Figure 7. Observed and calculated core-rim garnet zonation profile expressed in $a-X$ parameters $\mathrm{x}(\mathrm{g})=\mathrm{alm} /(\mathrm{alm}+\mathrm{prp})$ and $\mathrm{z}(\mathrm{g})=\mathrm{grs} /(\mathrm{alm}+\mathrm{prp}+\mathrm{grs})$ from TC modeling, and in alm, prp, and grs from TD modeling. See text and Fig. 5 for explanation of the three garnet zones (domains), Core, Rim 1, and Rim 2. 
Figure 8. Evolution of the effective bulk composition (EBC) and mineral phases calculated by TC33 for (a) and (b), TC47 for (c) and (d), TDG for (e) and (f), and TDW for (g) and (h).

Figure 9. (a) Pseudosection generated with modeling protocol TC33 (see text for details) for eclogite TM-15. The red dashed curve, $P-T$ Path, is calculated considering garnet fractionation using the garnet TM-15G\#3 compositional profile in Fig. 7. The three boxes labeled "Grt Core", "Peak $P$ ", and "Grt Rim" represent $P-T$ conditions of garnet nucleation, peak pressure, and peak metamorphism (i.e., peak temperature), respectively. These three $P-T$ conditions are calculated (Table 5 and Table S1) based on the EBCs obtained by modeling garnet TM-15G\#3 prograde growth assuming domains are as assigned in Fig. 7. Boxes span $1 \sigma$ uncertainties based on variation of garnet EPMA data within the domains defining each metamorphic stage (Fig. 7). (b) Diagram of garnet compositional isopleths expressed by TC parameters, $x(g)$ and $\mathrm{z}(\mathrm{g})$. The forbidden zone $\left(<5^{\circ} \mathrm{C} / \mathrm{km}\right)$ is determined based on Liou (1998) and Schreyer (1995). Mineral abbreviations as in Table 2.

Figure 10. (a) Pseudosection generated with modeling protocol TC47 (see text for details) for eclogite TM-15. (b) Diagram of garnet compositional isopleths expressed by TC parameters, $\mathrm{x}(\mathrm{g})$ and $\mathrm{z}(\mathrm{g})$. Other details are the same as those provided in the caption of Fig. 9.

Figure 11. (a) Pseudosection generated with modeling protocol TDG (see text for details) for eclogite TM-15. (b) Diagram of garnet compositional isopleths expressed by garnet individual endmembers, alm, prp, and grs. Other details are the same as those provided in the caption of Fig. 9. 
Figure 12. (a) Pseudosection generated with modeling protocol TDW (see text for details) for eclogite TM-15. (b) Diagram of garnet compositional isopleths expressed by garnet individual endmembers, alm, prp, and grs. Other details are the same as those provided in the caption of Fig. 9.

Figure 13. Comparison of $P-T$ paths with and without consideration of compositional (garnet) fractionation calculated by the four modeling protocols (TC33, TC47, TDG, and TDW). Error bars in lower right corner represent overall modeling uncertainty $(2 \sigma$; Powell and Holland 2008). Fract.: fractionated; Unfract.: unfractionated.

Figure 14. Pseudosections constructed by modeling protocol (a) TC33, (b) TC47, (c) TDG, and (d) TDW, using the EBC calculated at peak pressure. White mica Si p.f.u. isopleths are included and the grey shaded area represents the highest Si p.f.u. (3.51-3.54) phengite. Boxes in the pseudosections represent peak pressure with $1 \sigma$ errors calculated using compositional variation with assigned domains (see Section 6.4 for complete discussion of uncertainties). 
Figure 15. Comparison of $P-T$ paths predicted for the Tso Morari eclogite, including previous studies and the results of this study. Thermobarometers and $P$ - $T$ constraints in this study include: (1): TM-15 Phengite Si Peak <3.54 (Fig. 14); (2) TM-15 pg-ms (Fig. 6b); (3) TM-15 Garnet Core AVE_PT; (4) TM-15 Matrix AVE_PT (Fig. 6a); Previous Studies: (5) Guillot et al. (1997); (6) de Sigoyer et al. (2000); (7) Mukherjee et al. (2003); (8) Konrad-Schmolke et al. (2008); (9) Warren et al. (2008); (10) St Onge et al. (2013); (11) Singh et al. (2013a); (12) Full transformation, Palin et al. (2017); (13) Non-transformation, Palin et al. (2017). Metamorphic facies background after (Bucher and Grapes 2011) and abbreviations: $A M=$ amphibolite; Amp-EC = amphibolite-eclogite; $\mathrm{BS}=$ blueschist $; \mathrm{EA}=$ epidote amphibolite; $\mathrm{EC}=$ eclogite; Ep-EC = epidote-eclogite; GR = granulite; GS = greenschist; HGR = high-pressure granulite; Law-EC = lawsonite-eclogite. The forbidden zone $\left(<5^{\circ} \mathrm{C} / \mathrm{km}\right)$ is determined based on Liou (1998) and Schreyer (1995). The $P-T$ conditions of descending slab surfaces in modern-day subduction zones is shown in the shaded area (Syracuse et al. 2010).

Figure S1. Pseudosections and garnet phase boundaries constructed by (a) TC33, (b) TC47, (c) TDG, and (d) TDW, using incrementally fractionated bulk composition. 14 steps of garnet removal and $\mathrm{EBC}$ calculations have been performed. 


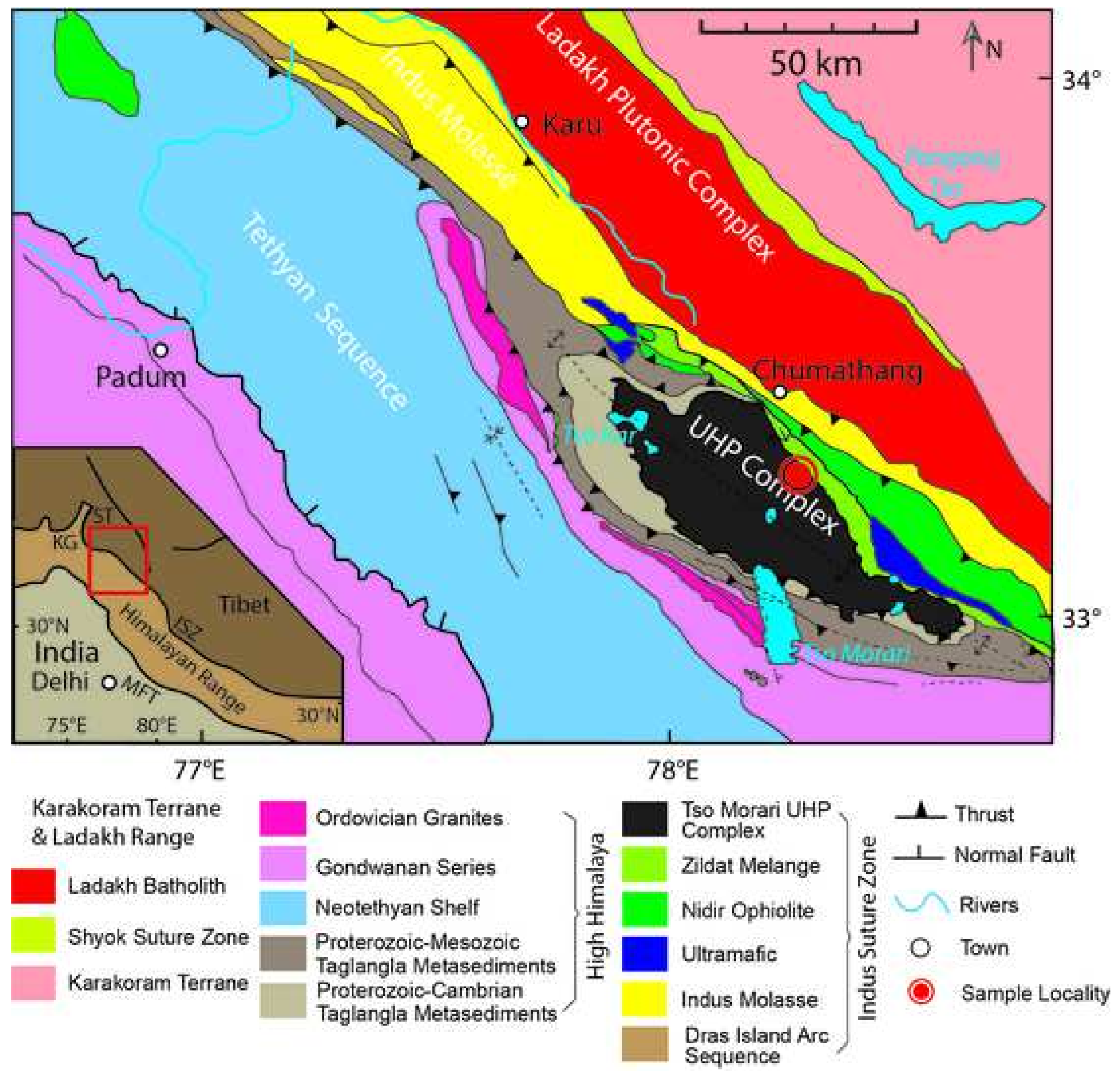



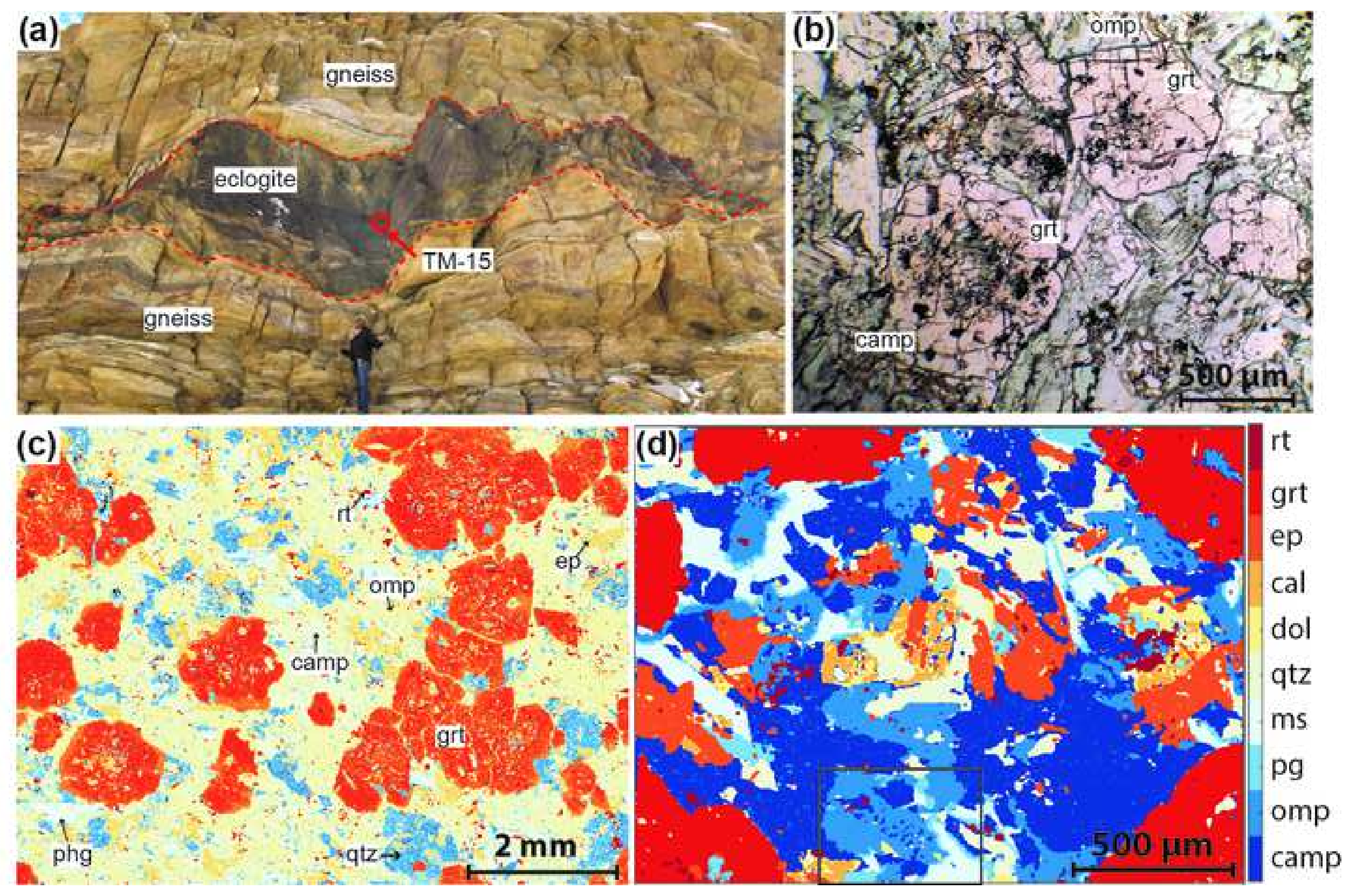

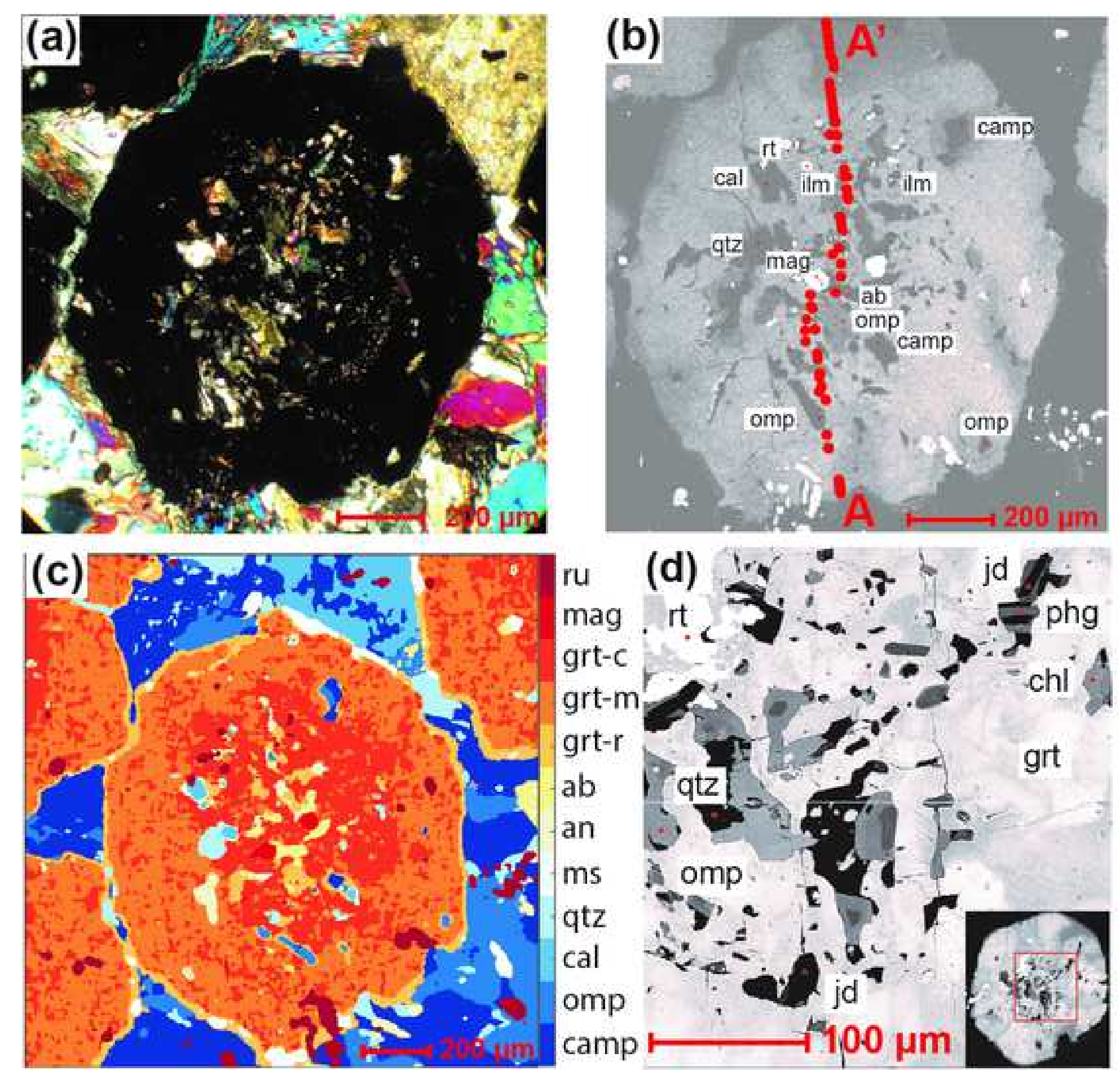
(a)
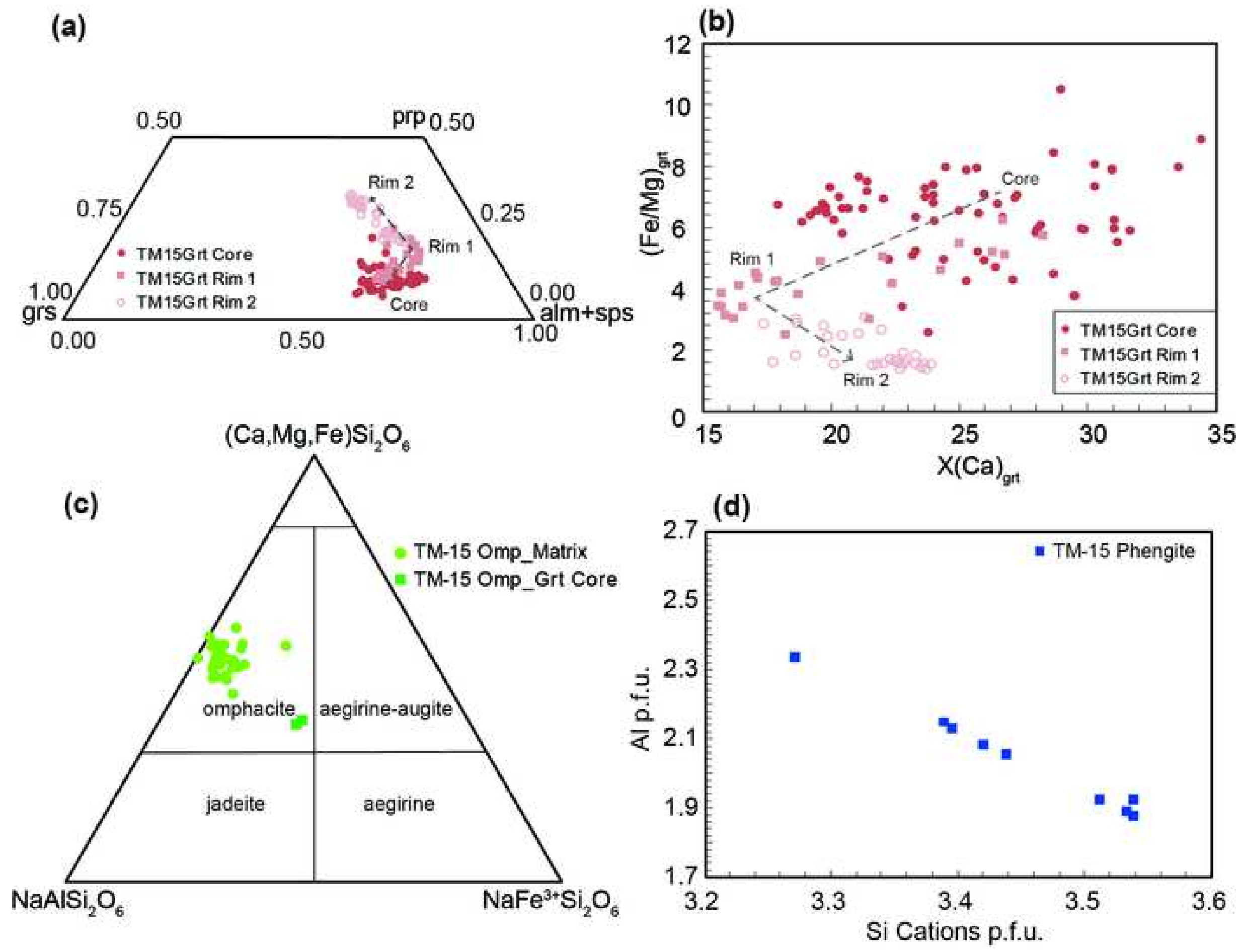


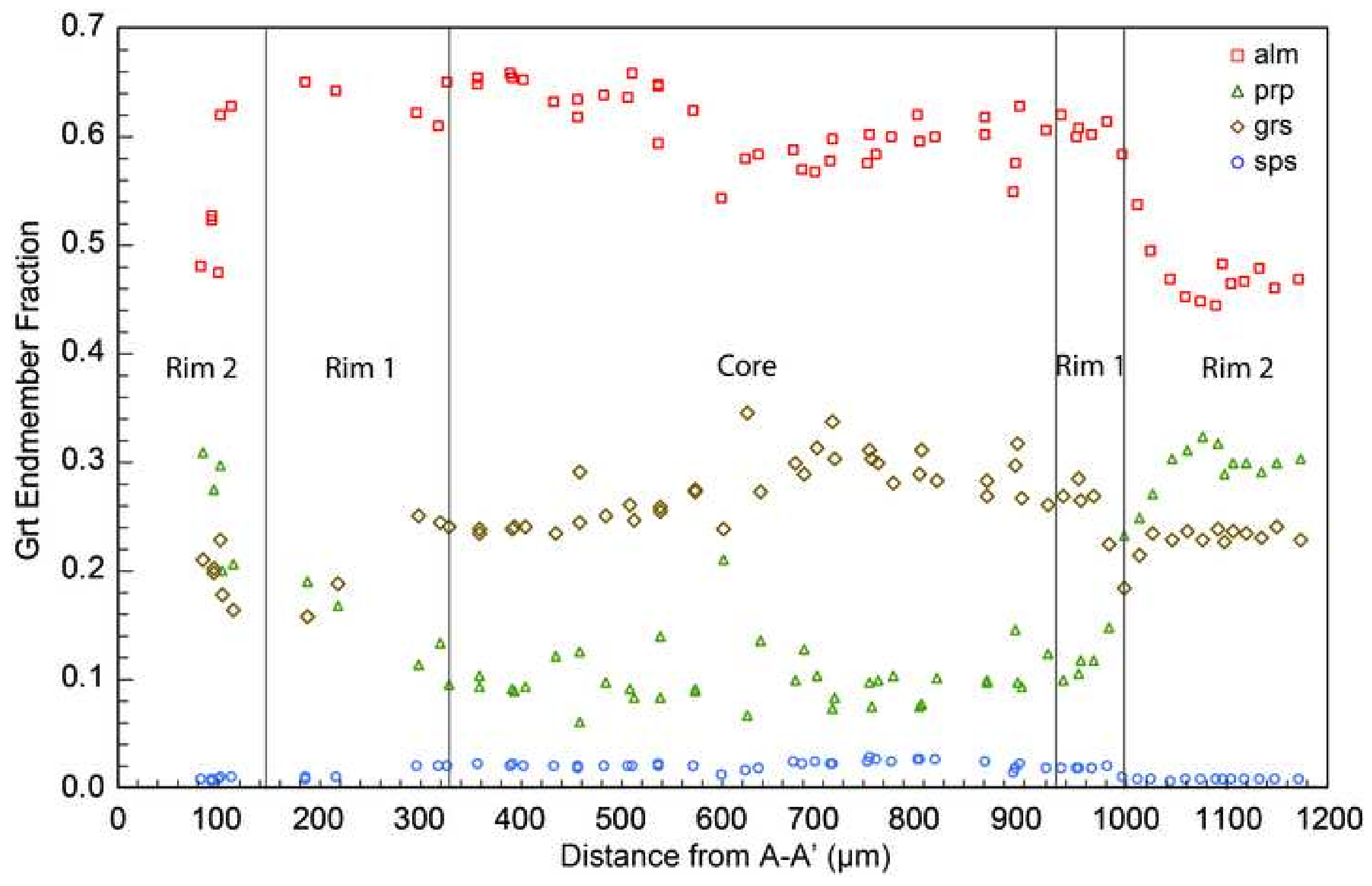



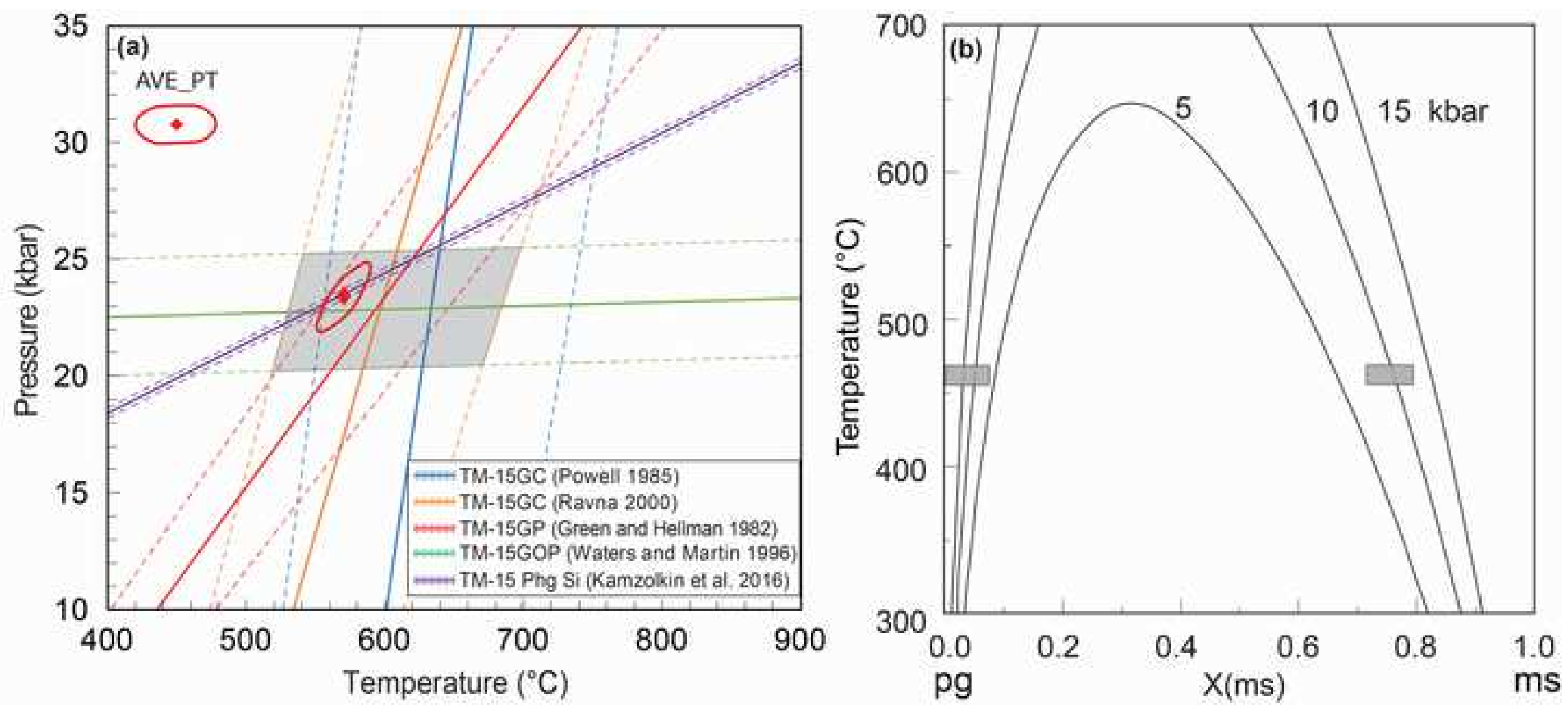


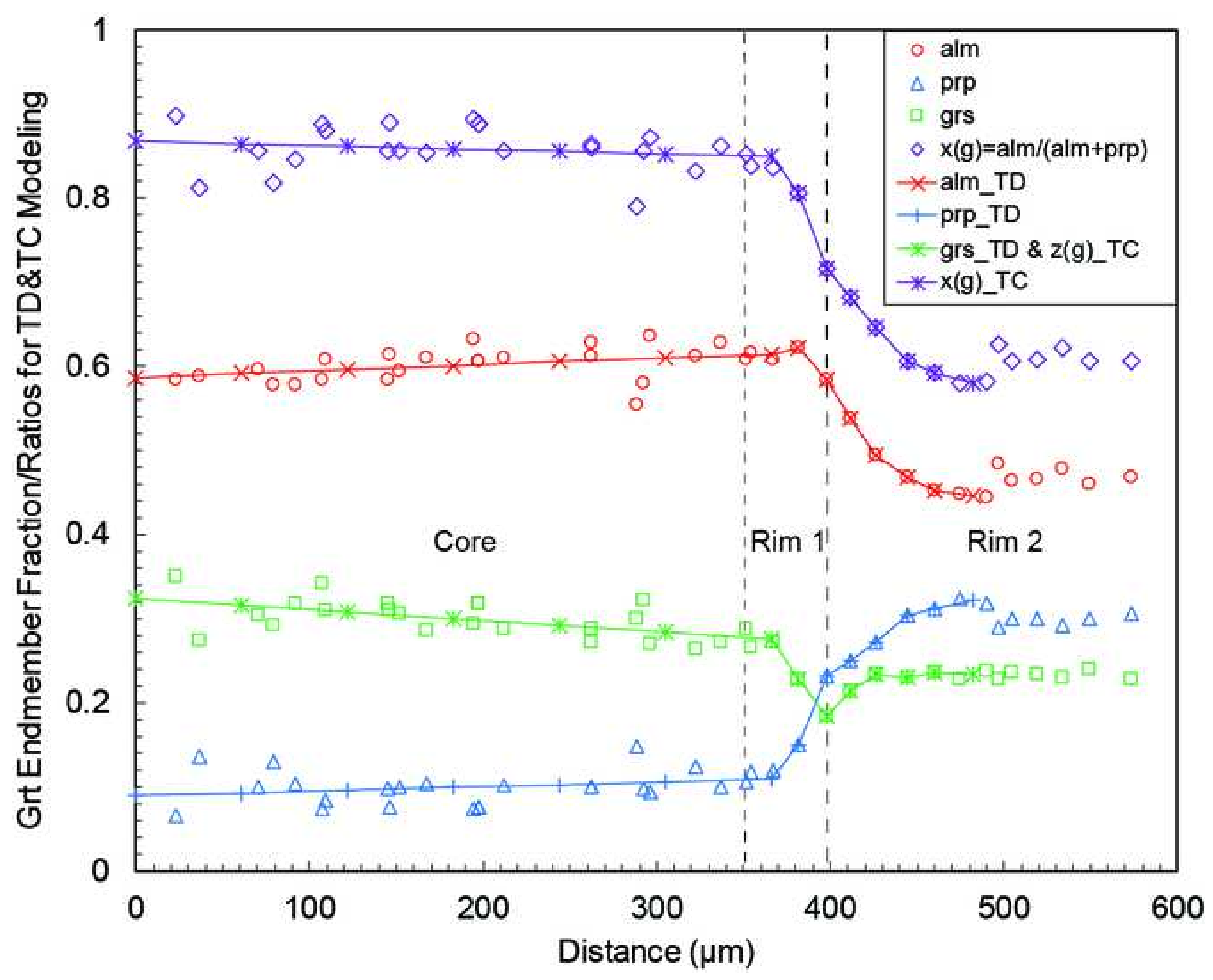



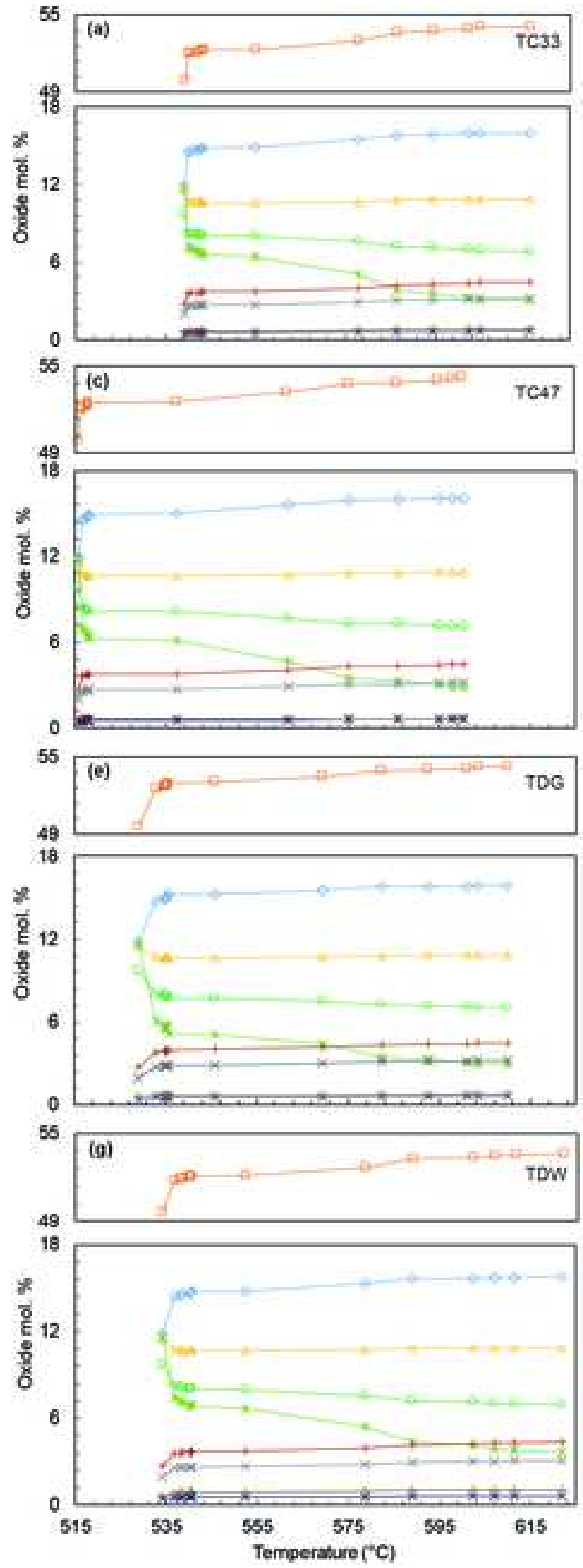
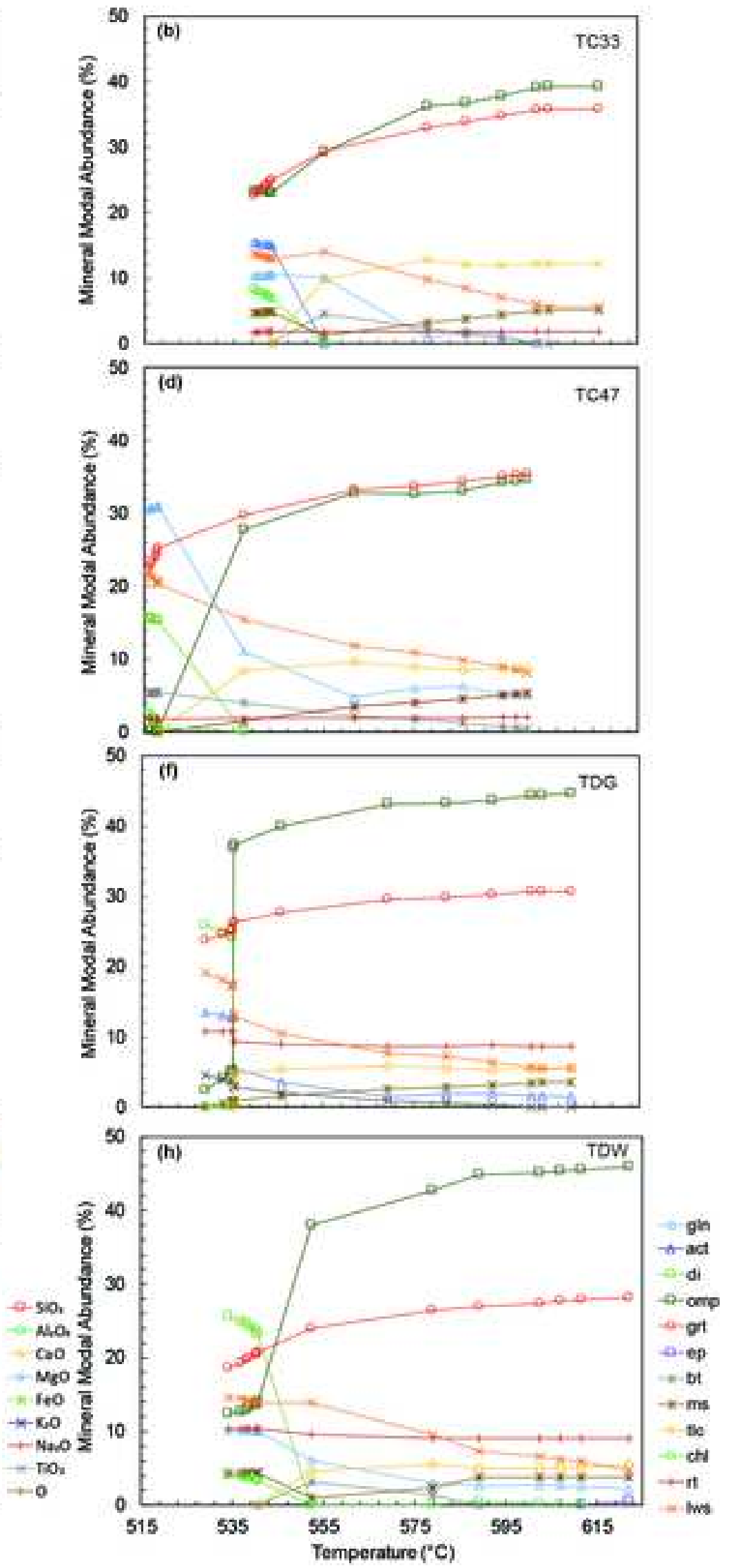
TM-15 NCKFMASHTO $\left(\mathrm{ru}+\mathrm{H}_{2} \mathrm{O}\right)$

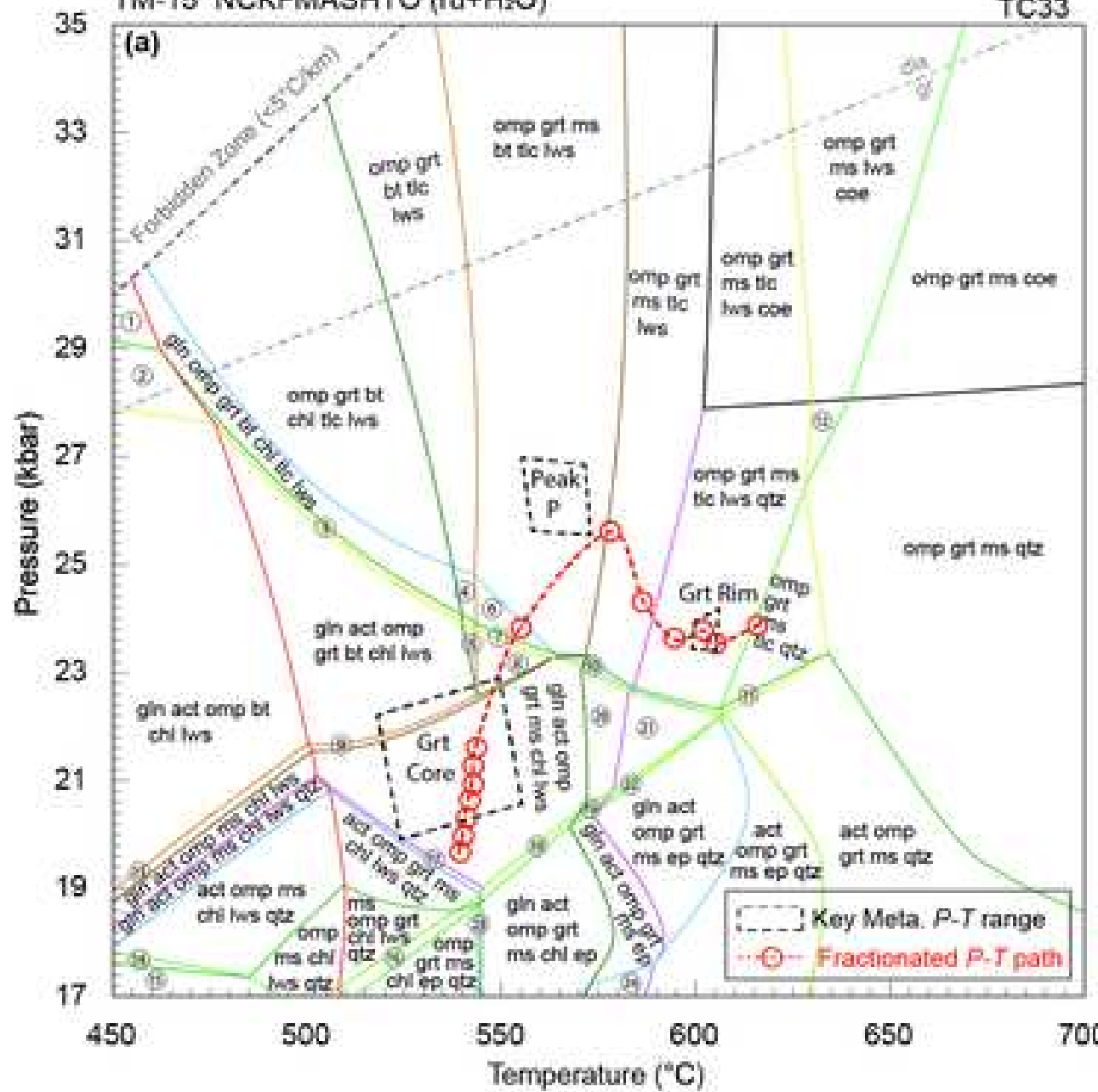

(1) gin omp be tic chl fws

(2) gin act omp of tic chil lws

(2) gin act omp bt tic chil wis . gn omp git bt ms tic hiws

(4) gin omp grt bt te hws
(3) gh act omp grt bt iws.

(2) gin act omp grt bt chil ms iws . 2xt omp grt mis tic lws (11) act cmp grt ms tlc qtz 6) omp grt ms hus qtz
TC33

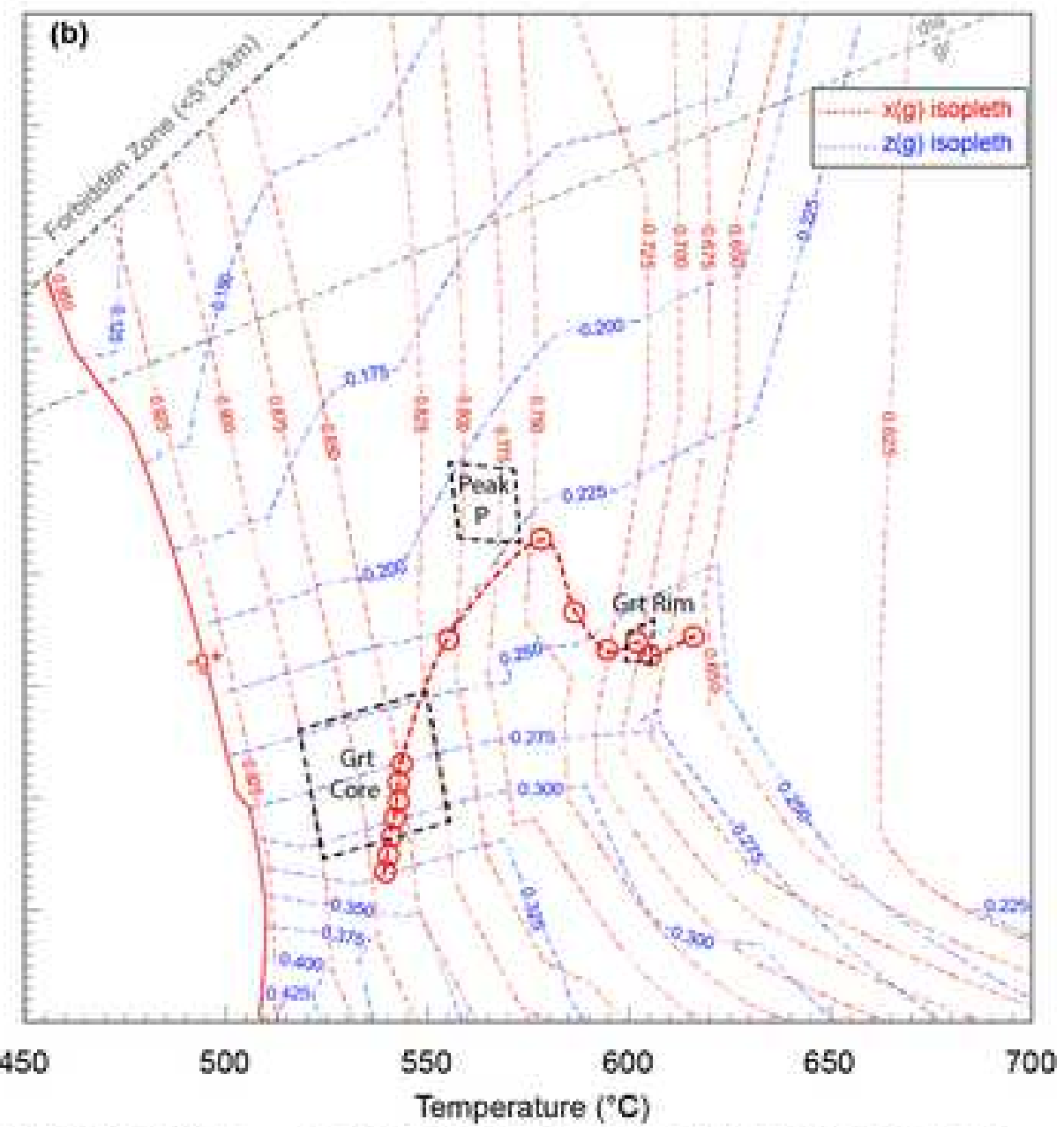

(10) gin act conp grt ms chil lws qtz (1) gin act omp grt ms iws ctz gin act omp grt mis chil tws ep ar gin act omp grt ms tws ep que gin act omp grt ms tws $\in p$ a gin omp git ms chl ep qtz yg gin act cmp git ms whs 15ing act omp be ms che iws He act omp ms chl tus qtz spo (6) cmp ms chl iws qtz spon (15) omp git ms chl ep lins qtz 010 gin omp grt ms chl ep qtz
6) act omp grt ms ep 


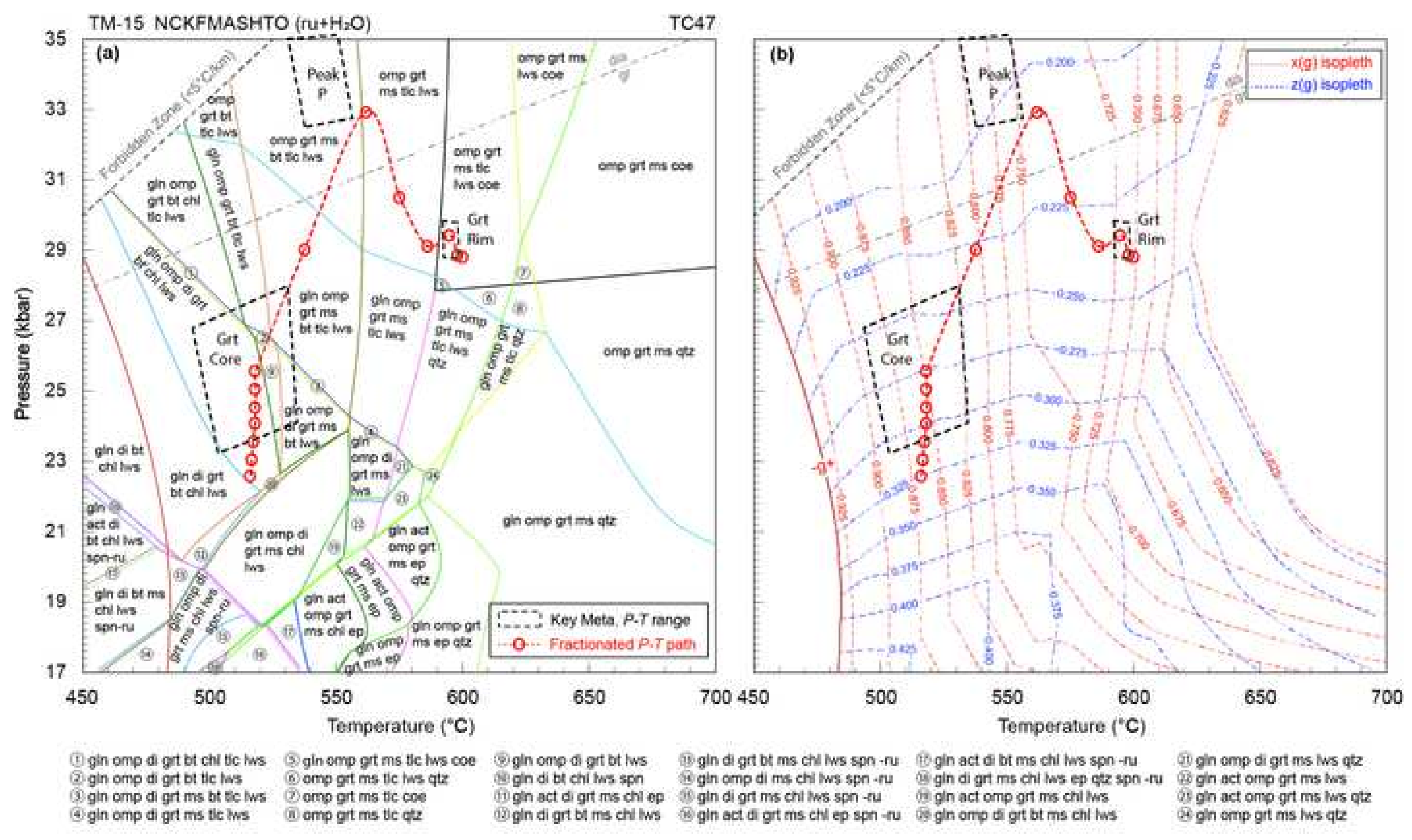

12) gin di grt bi ins chilws

gin di grt ms chit tws spn -ru, gin act omp grt ms chil ws

24 ght omp git ms hws qte 
TM-15 NCKFMASHTO (ru+ $\left.\mathrm{H}_{2} \mathrm{O}\right)$

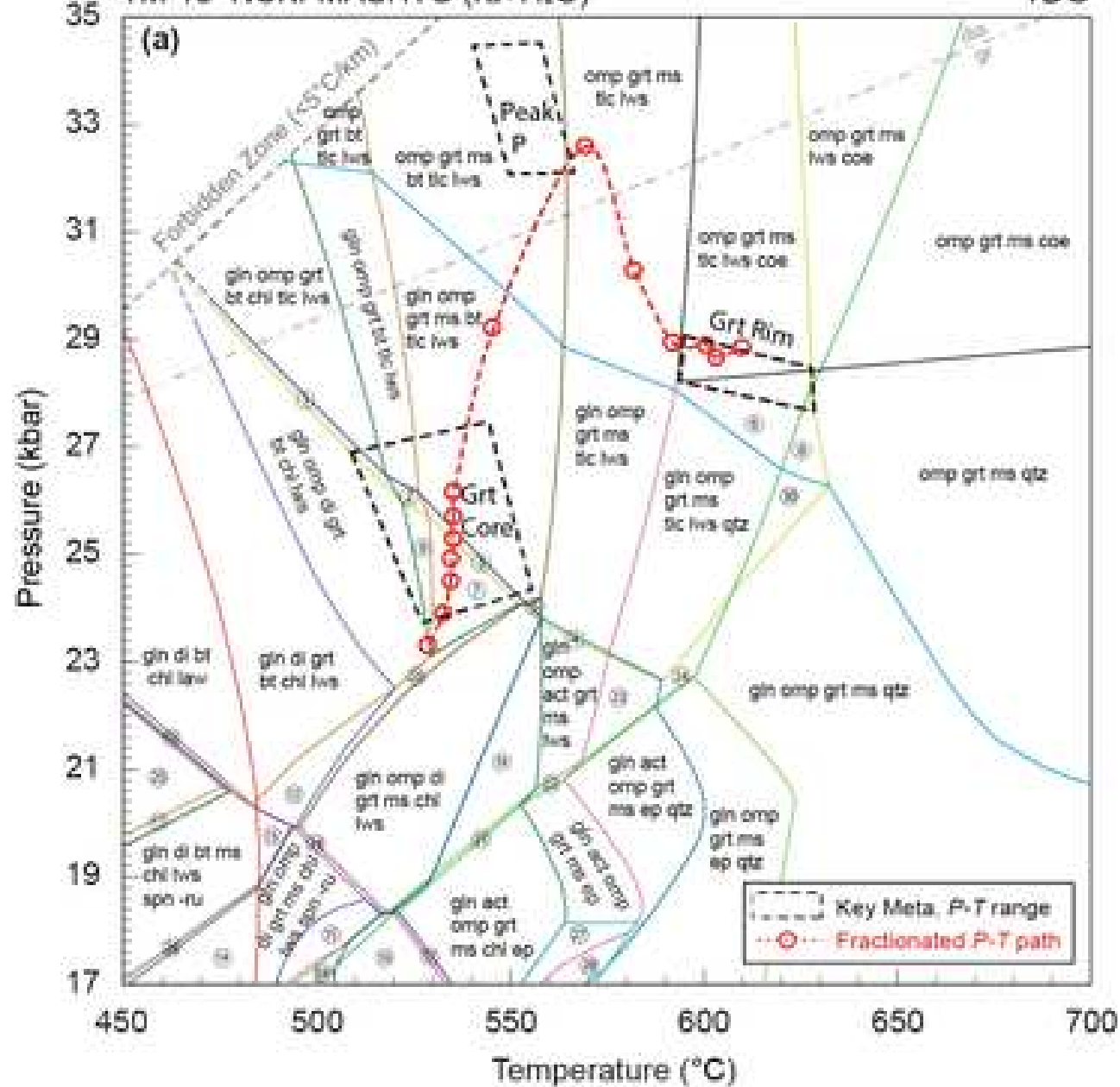

Temperature $\left({ }^{\circ} \mathrm{C}\right)$

(1) gin omp di grt bt chl tic lws (6) omp grt ms tic lws qtz (ii) gin act di grt ms chi ep (2) gin omp di grt bt tie lws (2) gin omp di grt ms bt lus (1) gin di grt bt ms chl tws

(4) gin omp di grt ms bt tic hws (ii) omp grt ms tle qtz

(9) gin omp di git ms tic .ws. (9 gin omp di grt bt iws

10. gin act di grt ms chl ep spon

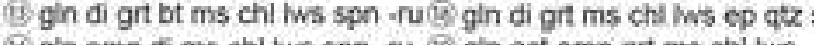

(44) gin omp di ms chil lws sph -ru 18 gin act omp grt ms chil lws

(19) gin di grt ms chil tws sph -ru 8 gh o di grt bt ms chil lws

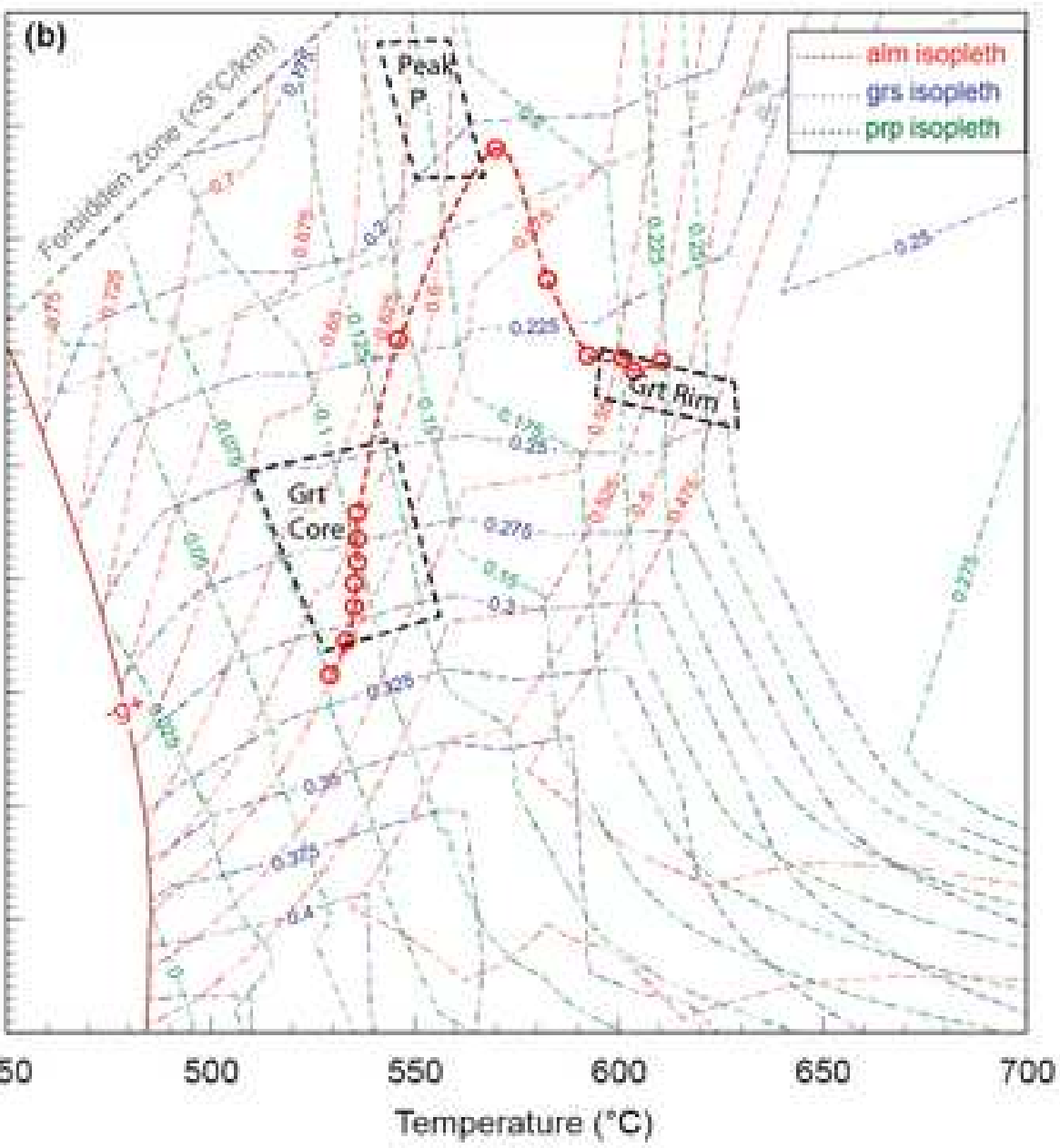

Q20 gin act omp grt ms chl hws ep omp gin di bt ms chl lws spn -ru (2) glin omp act gnt ms iws ep (D) gin act gru omp grt ms ep gut gin act omp grt ms tws qtz gin act gru omp grt ms ep qtz ¿e gin omp grt ms lws qu gin ome di git ms chil tws spon. (9) gin omp grt ms tle qtz 

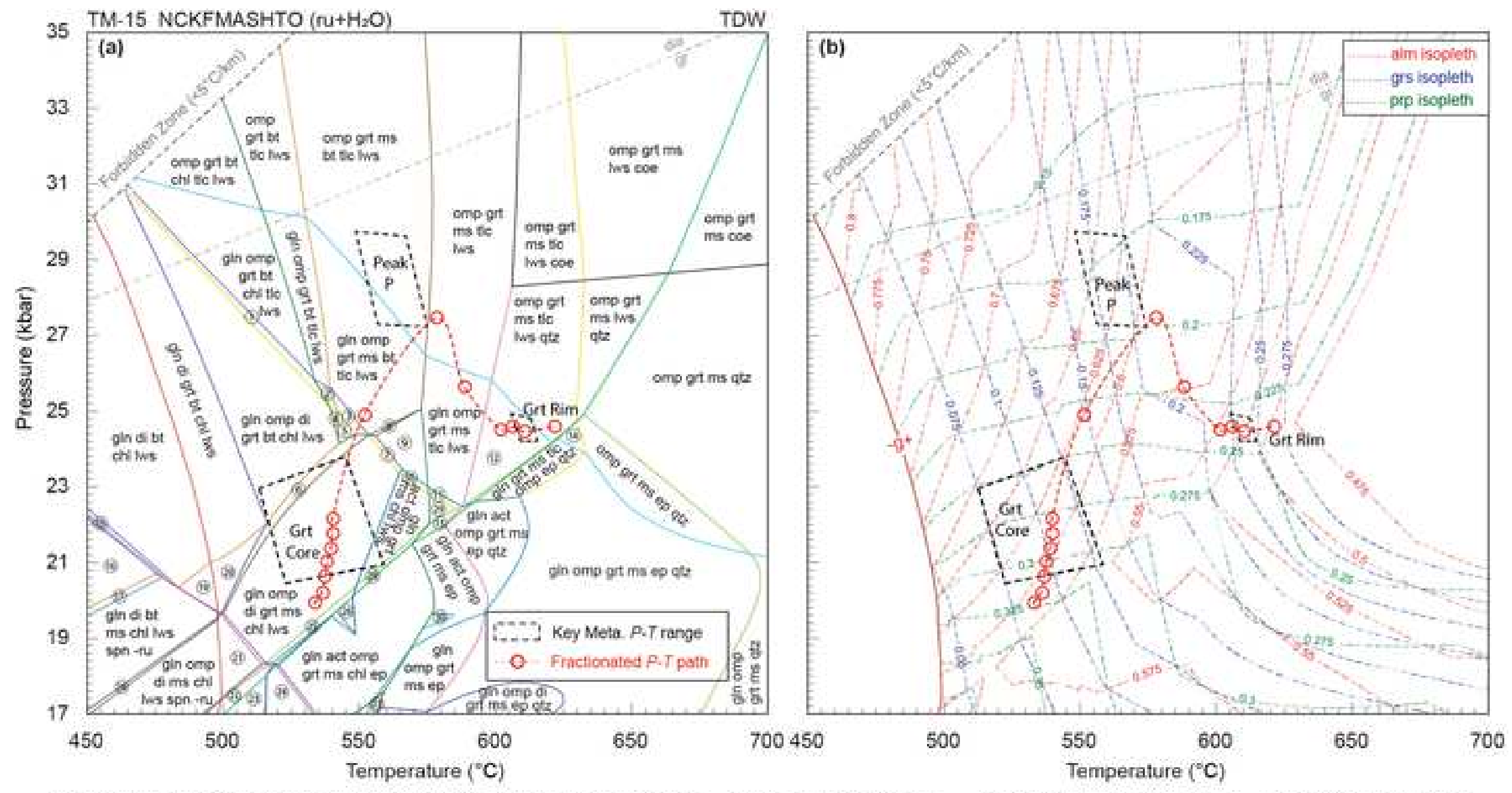

(1) gin omp a git bt tic chil us (6) gin cenp di grt ms bt chil hws (1) gin act omp grt ms tic lws (2) gin amp of grt bt tic lws. (7) gin oenp di grt ms tic chl tws (i) gin oenp lws mis tic grt qte (3) gin omp di grt ms bt tic lws be gin cenp grt ms bt tic chl lws of gin act omp git ms hirs ep (4) gin omp di git bt lws (9 gin omp git ms tic chl lws. (4) omp git ms tic ep qtz

9. gin act 6 i bt cht hws spe -ru

Qif gin comp di git mis chl ins spn tu Q9 gin omp di grt ins chl ep

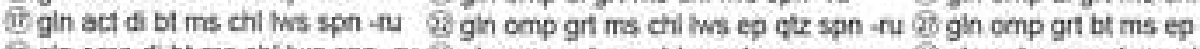

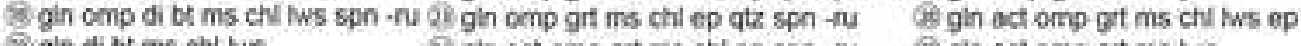
(5) gin omp e grt ms bt hws (8) gin act ornp grt ms tic chl lws el gin di bt chil lws spn

Vivglin dibt ms cht hws

gin di grt be ms chll lis

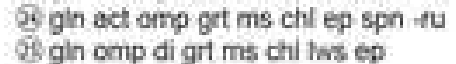

Q gin act onp gat ms ivs

(5) gle act gru omp grt ms ep 


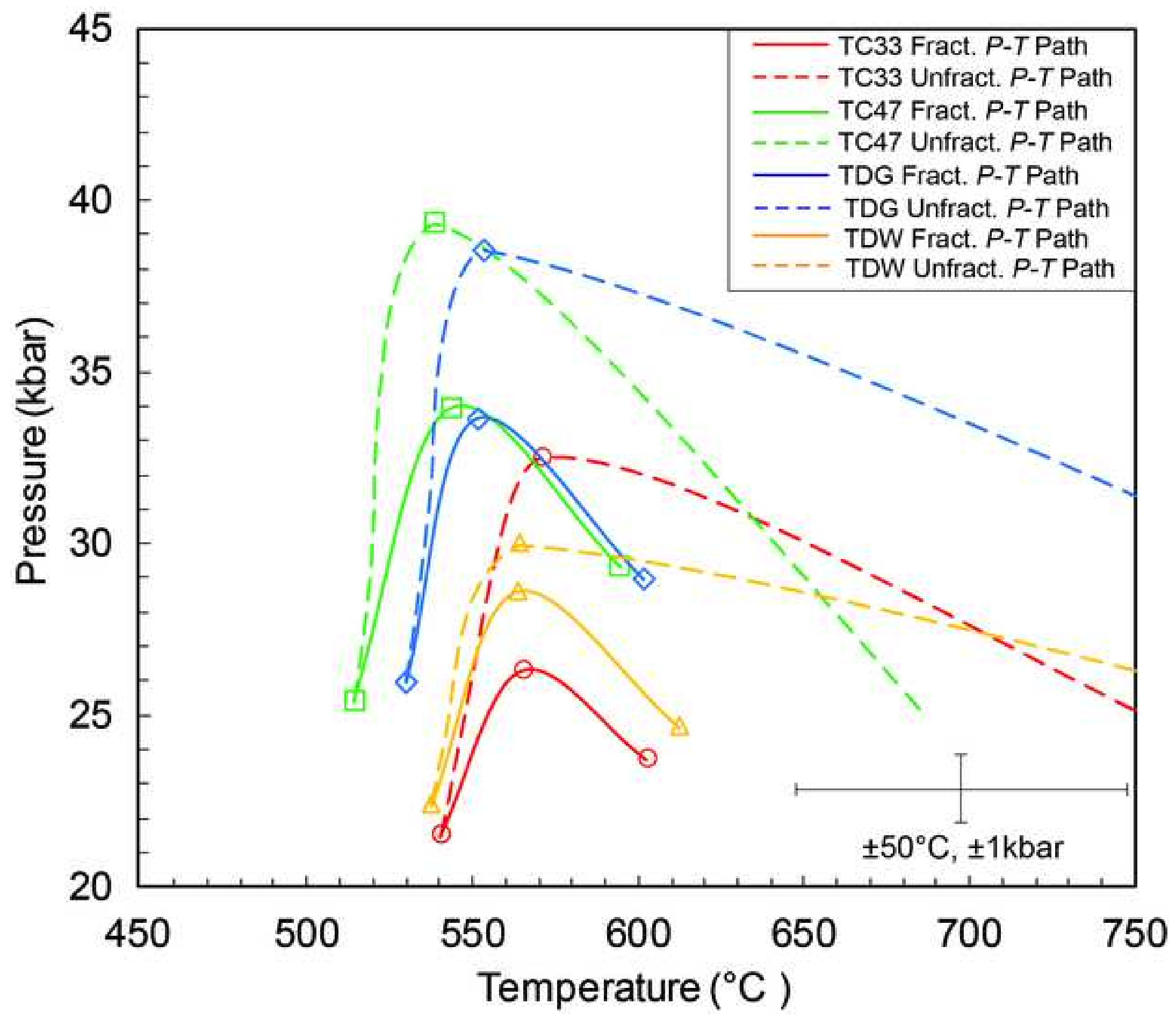



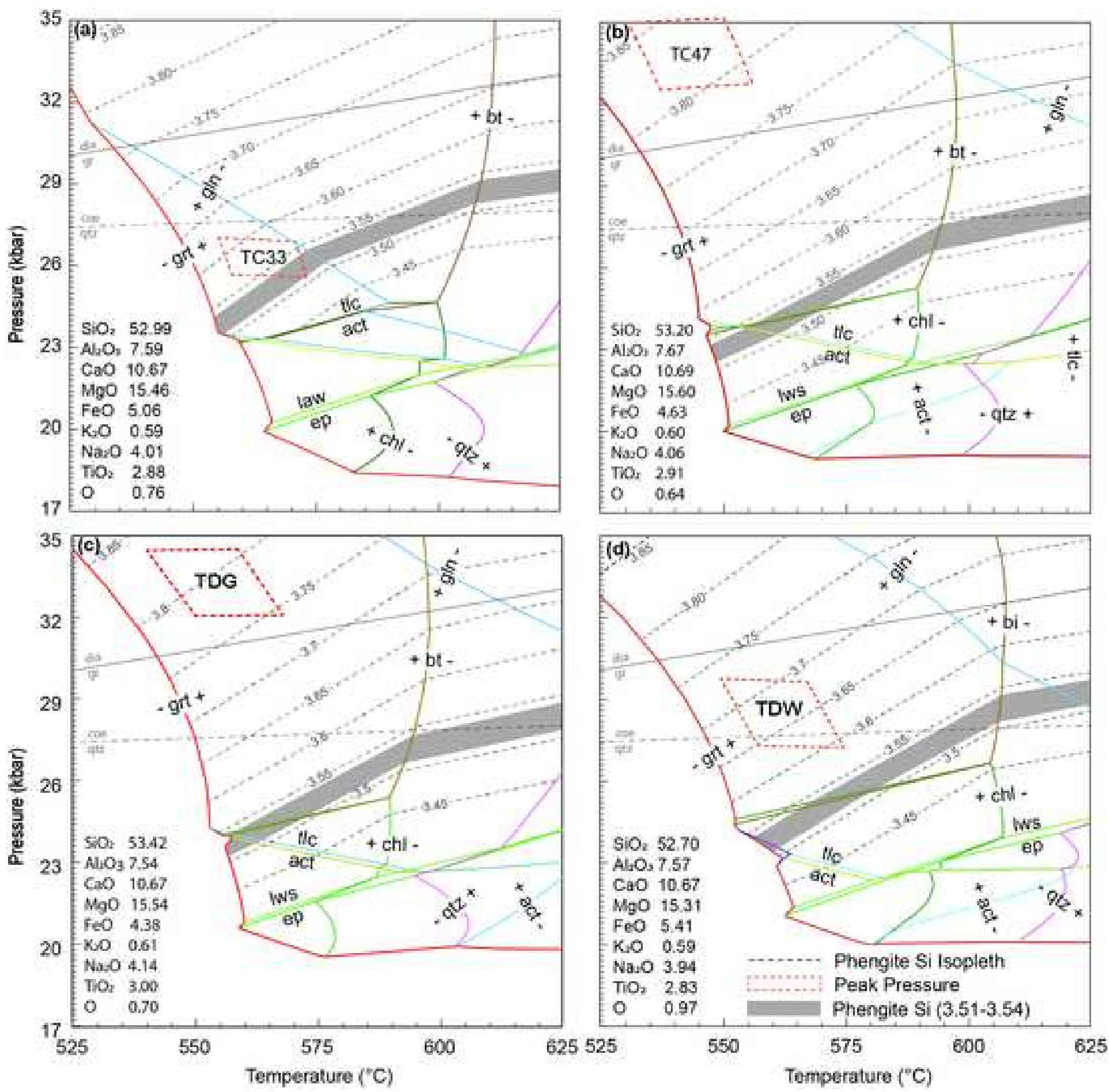


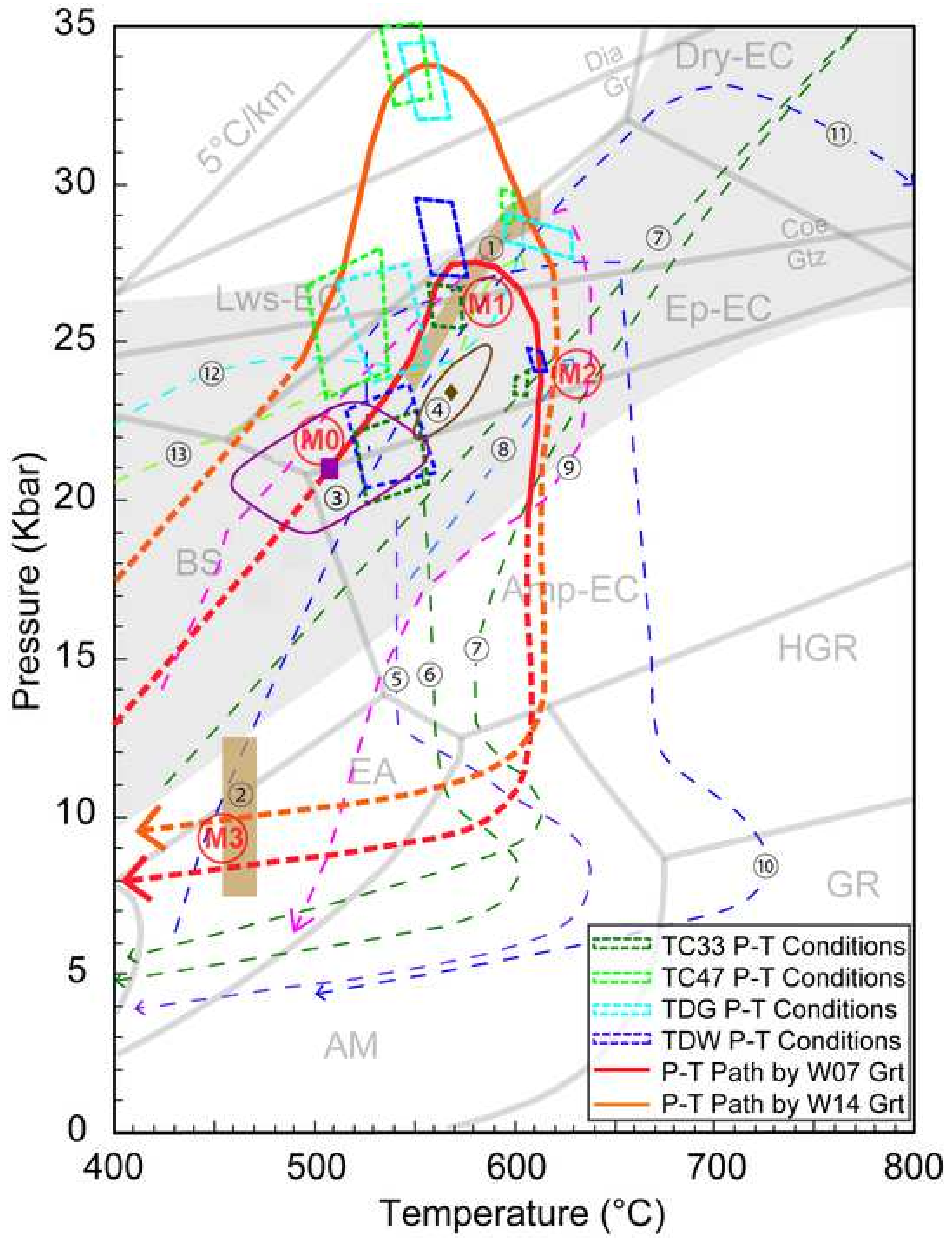



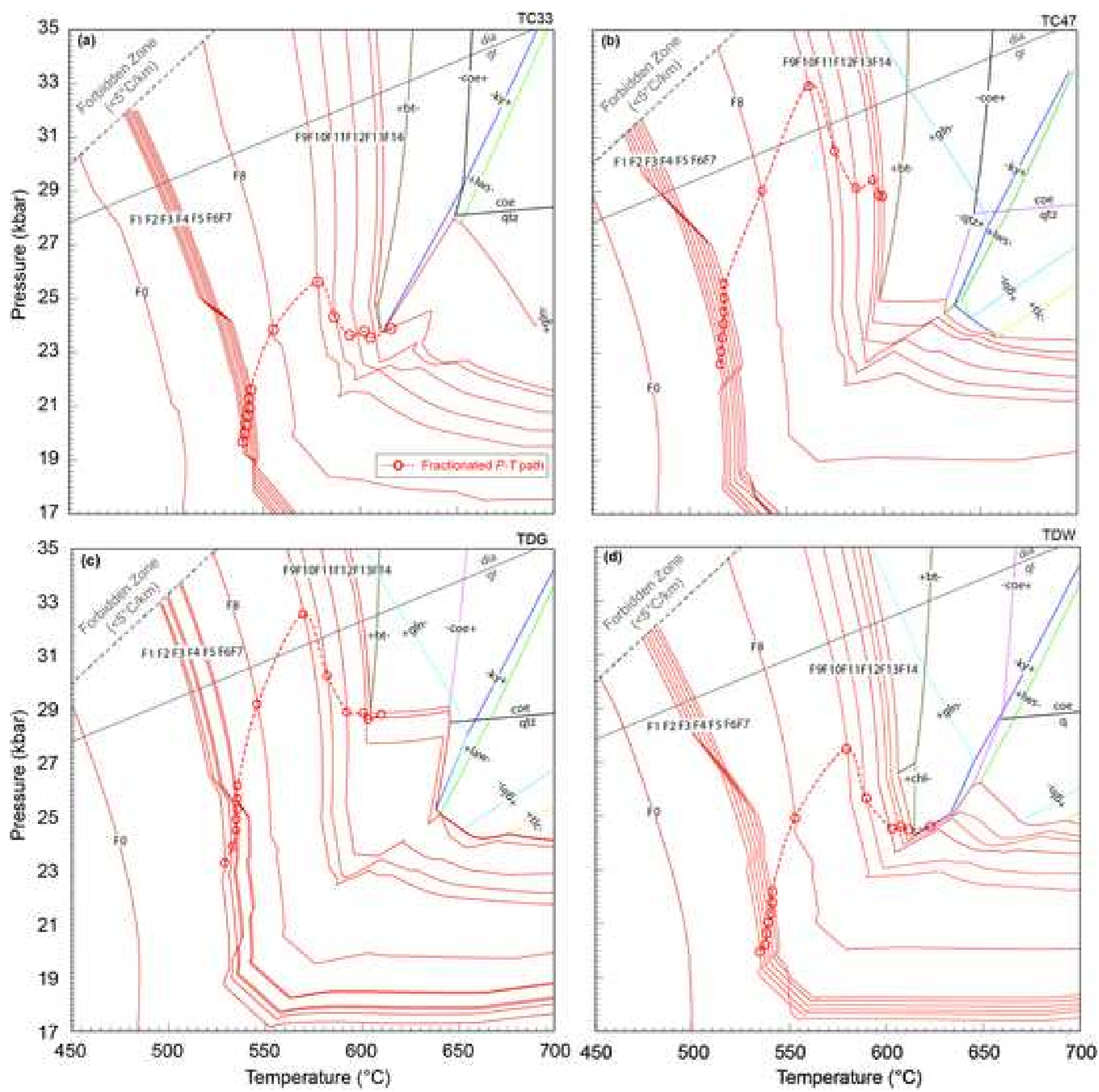
Table 1. Comparison of thermodynamic modeling parameters for TC33, TC47, TDG, and TDW in this study

\begin{tabular}{|c|c|c|c|c|c|c|c|c|c|c|c|}
\hline \multirow{2}{*}{ Program } & \multirow{2}{*}{$\begin{array}{l}\text { Thermo- } \\
\text { dataset }\end{array}$} & \multirow{2}{*}{$\begin{array}{l}\text { Grt } a-X \\
\text { relations }{ }^{\mathrm{a}}\end{array}$} & \multicolumn{6}{|c|}{ Major Grt $a-X$ relation parameters $(W / \mathrm{kJ})$} & \multirow{2}{*}{$\begin{array}{c}\text { Other } \\
\text { mineral } \\
a-X \\
\text { relations } \\
\end{array}$} & \multirow{2}{*}{$\begin{array}{l}\text { Mineral phases/endmembers } \\
\text { included }^{c}\end{array}$} & \multirow{2}{*}{$\begin{array}{c}\text { Grt } \\
\text { fractionation } \\
\text { procedure }^{\mathrm{d}}\end{array}$} \\
\hline & & & $W_{\text {(alm-prp) }}$ & $W_{\text {(alm-grs) }}$ & $W_{\text {(prp-grs) }}$ & $a_{\text {prp }}$ & $a_{\text {alm }}$ & $a_{\text {grs }}$ & & & \\
\hline TC33 & ds55 & W07 & 2.5 & 10 & 45 & 1 & 1 & 3 & $\mathrm{~A}$ & $\begin{array}{l}\text { grt, gln, act, omp, ms, bt, chl, } \\
\text { lws, ep qtz/coe, rt, } \mathrm{H}_{2} \mathrm{O}\end{array}$ & TC (rbi) \\
\hline $\mathrm{TC} 47$ & ds 62 & W14 & 2.5 & 5 & 30.1 & 1 & 1 & 2.7 & $\mathrm{~B}$ & $\begin{array}{l}\text { grt, gln, act, omp, di, ms, bt, chl, } \\
\text { lws, ep qtz/coe, rt, spn, } \mathrm{H}_{2} \mathrm{O}\end{array}$ & $\mathrm{TC}$ (rbi) \\
\hline TDG & ds 62 & W14 & 2.5 & 5 & 30.1 & 1 & 1 & 2.7 & $\mathrm{~B}$ & $\begin{array}{l}\text { grt, gln, act, gru, omp, di, ms, bt, } \\
\text { chl, lws, ep qtz/coe, rt, spn, } \mathrm{H}_{2} \mathrm{O}\end{array}$ & TD (Theriak) \\
\hline TDW & ds62 & W07 & 2.5 & 10 & 45 & 1 & 1 & 3 & $\mathrm{~B}$ & $\begin{array}{l}\text { grt, gln, act, gru, omp, di, ms, bt, } \\
\text { chl, lws, ep, qtz/coe, rt, spn, } \mathrm{H}_{2} \mathrm{O}\end{array}$ & TD (Theriak) \\
\hline
\end{tabular}

${ }^{\mathrm{a} W 07:}$ White et al. (2007); W14: White et al. (2014a)

${ }^{\mathrm{b}} \mathrm{A}$ : clinoamphibole (glaucophane and actinolite) (Diener and Powell. 2012), clinopyroxene (omphacite and diopside) (Diener and Powell. 2012), chlorite (Holland and Powell 1998), K-feldspar and plagioclase (Holland and Powell 2003), muscovite (Coggon and Holland 2002), and biotite (White et al. 2007). B: clinoamphibole (glaucophane (gl_dqf = -3 kJ/mol), actinolite, and grunerite) (Green et al. 2016), muscovite (White et al. 2014a), clinopyroxene (omphacite and diopside) (Green et al. 2016), talc (Holland and Powell 1998), epidote (Holland and Powell 2011), chlorite (White et al. 2014a), K-feldspar and plagioclase (Holland and Powell 2003), ilmenite (White et al. 2014a), and biotite (White et al. 2014a).

'See Table 2 for explanation of mineral abbreviations.

${ }^{\mathrm{d}}$ TD (Theriak): Theriak long output; TC (rbi): White (2010); See supplement section 2 for discussion of the different garnet fractionation procedures. 
Table 2. Mineral abbreviations used in this paper

\begin{tabular}{|c|c|c|c|}
\hline Abbreviation $^{\mathrm{a}}$ & Mineral & Abbreviation & Mineral \\
\hline $\mathrm{ab}$ & albite & $\mathrm{hbl}$ & hornblende \\
\hline act & actinolite & ilm & ilmenite \\
\hline $\mathrm{adr}$ & andradite & $\mathrm{jd}$ & jadeite \\
\hline alm & almandine & kho & khohorite \\
\hline an & anorthite & ky & kyanite \\
\hline ann & annite & lws & lawsonite \\
\hline $\mathrm{bt}$ & biotite & mag & magnetite \\
\hline cal & calcite & $\mathrm{ms}$ & muscovite \\
\hline camp & clinoamphibole & omp & omphacite \\
\hline chl & chlorite & pg & paragonite \\
\hline coe & coesite & phg & phengite \\
\hline $\mathrm{di}$ & diopside & prp & pyrope \\
\hline dol & dolomite & qtz & quartz \\
\hline ep & epidote & $\mathrm{rt}$ & rutile \\
\hline grt & garnet & spn & sphene \\
\hline gln & glaucophane & sps & spessartite \\
\hline gru & grunerite & tlc & talc \\
\hline grs & grossular & & \\
\hline
\end{tabular}

${ }^{a}$ Mineral abbreviations are after (Kretz 1983), except phengite and khohorite. 
Table 3. Eclogite major element whole-rock geochemistry from Tso Morari sample TM-15, reported in wt. \%

\begin{tabular}{ccccccccccccc}
\hline Sample & $\mathrm{SiO}_{2}$ & $\mathrm{TiO}_{2}$ & $\mathrm{Al}_{2} \mathrm{O}_{3}$ & $\mathrm{FeO}^{\mathrm{a}}$ & $\mathrm{MnO}$ & $\mathrm{MgO}$ & $\mathrm{CaO}$ & $\mathrm{Na}_{2} \mathrm{O}$ & $\mathrm{K}_{2} \mathrm{O}$ & $\mathrm{P}_{2} \mathrm{O}_{5}$ & $\mathrm{LOI} \%$ & $\mathrm{Sum}$ \\
\hline TM-15 & 45.53 & 2.37 & 15.06 & 11.92 & 0.19 & 7.27 & 10.3 & 2.79 & 0.57 & 0.24 & 2.74 & 96.22 \\
\hline
\end{tabular}

${ }^{\mathrm{a}}$ Total iron expressed as $\mathrm{FeO}$ 
Table 4. Average compositions of garnet, inclusions, and matrix phases in Tso Morari eclogite TM-15

\begin{tabular}{|c|c|c|c|c|c|c|c|c|c|c|c|}
\hline \multirow{2}{*}{$\frac{\text { Oxide }}{\text { Mineral }}$} & \multicolumn{11}{|c|}{ TM-15 Eclogite } \\
\hline & grt & grt & $\mathrm{pg}$ & phg & $a b$ & dol & ep & omp & camp & omp & camp \\
\hline Position $^{\mathrm{a}}$ & core & rim & matrix & matrix & grt in & matrix & matrix & matrix & matrix & grt in & grt in \\
\hline $\mathrm{Na}_{2} \mathrm{O}$ & 0.01 & 0.02 & 6.73 & 0.42 & 11.02 & 0.01 & 0.01 & 6.91 & 3.37 & 3.76 & 3.70 \\
\hline $\mathrm{Al}_{2} \mathrm{O}_{3}$ & 21.57 & 22.12 & 40.83 & 26.08 & 20.33 & 0.01 & 30.48 & 9.92 & 8.11 & 10.81 & 9.06 \\
\hline $\mathrm{SiO}_{2}$ & 37.16 & 37.75 & 47.02 & 51.87 & 67.4 & 0.01 & 38.52 & 55.81 & 53.84 & 42.26 & 50.45 \\
\hline $\mathrm{MgO}$ & 3.17 & 5.66 & 0.37 & 4.72 & 0.00 & 20.8 & 0.11 & 7.98 & 16.93 & 6.12 & 11.33 \\
\hline $\mathrm{FeO}$ & 28.25 & 27.03 & 0.42 & 1.56 & 0.65 & 4.40 & 0.00 & 4.52 & 0.00 & 11.82 & 13.91 \\
\hline $\mathrm{K}_{2} \mathrm{O}$ & 0.00 & 0.00 & 1.06 & 10.22 & 0.02 & 0.00 & 0.01 & 0.01 & 0.15 & 0.03 & 0.08 \\
\hline $\mathrm{MnO}$ & 0.73 & 0.32 & 0.00 & 0.01 & 0.00 & 0.04 & 0.01 & 0.01 & 0.03 & 0.40 & 0.20 \\
\hline $\mathrm{TiO}_{2}$ & 0.10 & 0.05 & 0.06 & 0.24 & 0.00 & 0.01 & 0.15 & 0.04 & 0.11 & 0.60 & 0.12 \\
\hline $\mathrm{CaO}$ & 8.58 & 6.96 & 0.30 & 0.02 & 0.83 & 32.36 & 23.19 & 12.44 & 8.4 & 8.14 & 6.83 \\
\hline $\mathrm{Fe}_{2} \mathrm{O}_{3}$ & 0.07 & 0.01 & 0.00 & 0.00 & 0.00 & 0.00 & 5.11 & 2.26 & 6.72 & 13.84 & 1.08 \\
\hline Total & 99.63 & 99.91 & 96.79 & 95.14 & 100.24 & 57.65 & 97.58 & 99.9 & 97.65 & 97.77 & 96.75 \\
\hline $\mathrm{Na}$ & 0.00 & 0.00 & 0.82 & 0.05 & 0.93 & 0.01 & 0.00 & 0.48 & 0.91 & 0.29 & 1.04 \\
\hline $\mathrm{Al}$ & 2.02 & 2.04 & 3.03 & 2.04 & 1.05 & 0.01 & 5.60 & 0.42 & 1.33 & 0.50 & 1.54 \\
\hline $\mathrm{Si}$ & 2.96 & 2.95 & 2.96 & 3.45 & 2.95 & 0.00 & 6.00 & 2.00 & 7.49 & 1.67 & 7.30 \\
\hline $\mathrm{Mg}$ & 0.38 & 0.66 & 0.03 & 0.47 & 0.00 & 10.18 & 0.02 & 0.43 & 3.51 & 0.36 & 2.44 \\
\hline $\mathrm{Fe}^{2+}$ & 1.88 & 1.77 & 0.02 & 0.09 & 0.02 & 1.15 & 0.00 & 0.14 & 0.00 & 0.39 & 1.38 \\
\hline $\mathrm{K}$ & 0.00 & 0.00 & 0.09 & 0.87 & 0.00 & 0.00 & 0.00 & 0.00 & 0.03 & 0.00 & 0.02 \\
\hline $\mathrm{Mn}$ & 0.05 & 0.02 & 0.00 & 0.00 & 0.00 & 0.01 & 0.00 & 0.00 & 0.00 & 0.01 & 0.03 \\
\hline $\mathrm{Ti}$ & 0.01 & 0.00 & 0.00 & 0.01 & 0.00 & 0.00 & 0.02 & 0.00 & 0.01 & 0.02 & 0.01 \\
\hline $\mathrm{Ca}$ & 0.73 & 0.58 & 0.02 & 0.00 & 0.04 & 11.35 & 3.87 & 0.48 & 1.25 & 0.34 & 1.06 \\
\hline $\mathrm{Fe}^{3+}$ & 0.00 & 0.00 & 0.00 & 0.00 & 0.00 & 0.00 & 0.67 & 0.06 & 0.78 & 0.41 & 0.42 \\
\hline Sum & 8.03 & 8.03 & 6.98 & 6.98 & 5.00 & 22.70 & 16.18 & 4.00 & 15.31 & 4.00 & 15.23 \\
\hline Oxygen & 12 & 12 & 11 & 11 & 8 & 60 & 25 & 6 & 23 & 6 & 23 \\
\hline adr & 0.39 & 0.10 & - & - & - & - & - & - & - & - & - \\
\hline grs & 23.6 & 19.07 & - & - & - & - & - & - & - & - & - \\
\hline prp & 12.37 & 21.67 & - & - & - & - & - & - & - & - & - \\
\hline sps & 1.61 & 0.70 & - & - & - & - & - & - & - & - & - \\
\hline $\mathrm{alm}$ & 62.02 & 58.46 & - & - & - & - & - & - & - & - & - \\
\hline
\end{tabular}

agarnet inclusion: grt in 
Table 5. Tso Morari $P-T$ conditions at different prograde metamorphic stages and the corresponding garnet composition in TM-15G\#3. Errors are $1 \sigma^{\mathrm{a}}$.

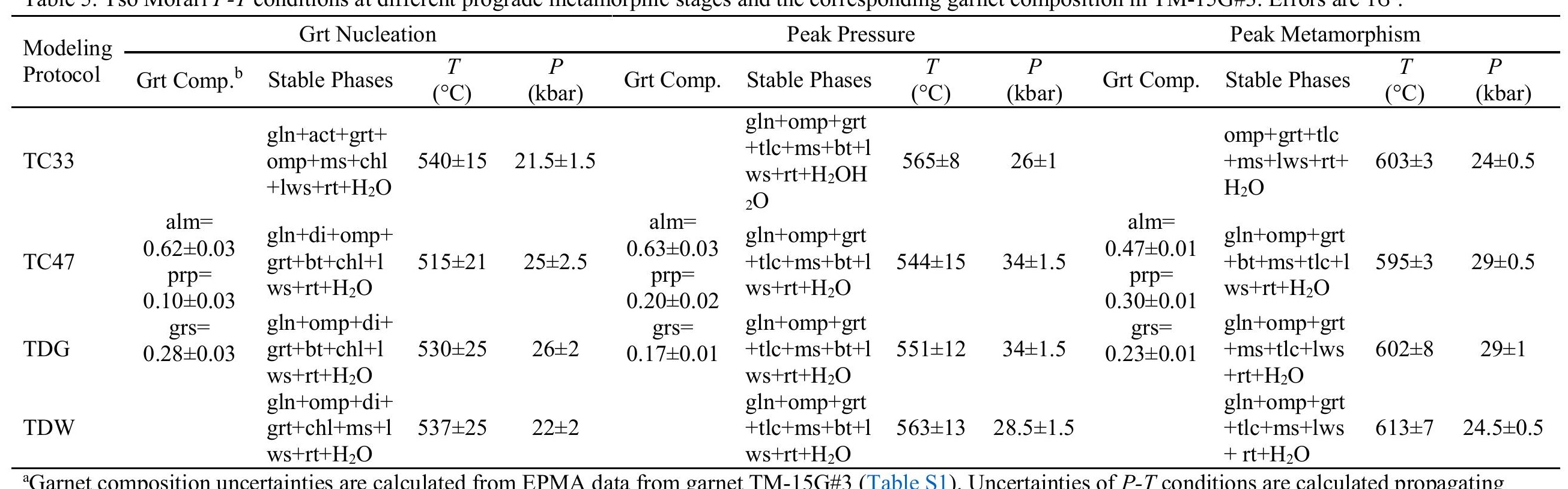

${ }^{\mathrm{a}}$ Garnet composition uncertainties are calculated from EPMA data from garnet TM-15G\#3 (Table S1). Uncertainties of $P$ - $T$ conditions are calculated propagating errors from the garnet composition in Grt Comp. columns.

${ }^{\mathrm{b}}$ Garnet Composition (Grt Comp.) is the same for all protocols, and is presented here as almandine (alm), pyrope (prp), and grossular (grs) endmember ratios from TD output. To convert to $\mathrm{x}(\mathrm{g})$ and $\mathrm{z}(\mathrm{g})$, the garnet composition parameters used in TC modeling, use $(\mathrm{x}(\mathrm{g})=\mathrm{alm} /(\mathrm{alm}+\mathrm{prp})$ and $\mathrm{z}(\mathrm{g})=\mathrm{gr} /(\mathrm{alm}+\mathrm{prp}+\mathrm{grs}))$. 
Table S1. TM-15 Eclogite TM-15G\#3 garnet crystal EPMA compositional profile

\begin{tabular}{|c|c|c|c|c|c|c|}
\hline Sample No. & Distance $(\mu \mathrm{m})$ & Position & $\mathrm{X}(\mathrm{Fe})$ & $\mathrm{X}(\mathrm{Mg})$ & $\mathrm{X}(\mathrm{Ca})$ & $\mathrm{X}(\mathrm{Mn})$ \\
\hline TM15G3L1P1 & 1173 & Rim & 0.465 & 0.303 & 0.227 & 0.005 \\
\hline TM15G3L1P2 & 1149 & Rim & 0.458 & 0.298 & 0.239 & 0.005 \\
\hline TM15G3L1P3 & 1134 & Rim & 0.476 & 0.29 & 0.229 & 0.006 \\
\hline TM15G3L1P4 & 1119 & Rim & 0.464 & 0.299 & 0.233 & 0.005 \\
\hline TM15G3L1P5 & 1105 & Rim & 0.461 & 0.299 & 0.236 & 0.005 \\
\hline TM15G3L1P6 & 1097 & Rim & 0.48 & 0.288 & 0.226 & 0.006 \\
\hline TM15G3L1P7 & 1090 & Rim & 0.442 & 0.317 & 0.237 & 0.005 \\
\hline TM15G3L1P8 & 1075 & Rim & 0.445 & 0.323 & 0.227 & 0.005 \\
\hline TM15G3L1P9 & 1060 & Rim & 0.45 & 0.31 & 0.235 & 0.005 \\
\hline TM15G3L1P10 & 1045 & Rim & 0.465 & 0.303 & 0.228 & 0.004 \\
\hline TM15G3L1P11 & 1026 & Intermediate & 0.492 & 0.27 & 0.233 & 0.005 \\
\hline TM15G3L1P12 & 1012 & Intermediate & 0.534 & 0.248 & 0.213 & 0.005 \\
\hline TM15G3L1P13 & 998 & Rim_Low grs & 0.58 & 0.231 & 0.182 & 0.007 \\
\hline TM15G3L1P14 & 982 & Core & 0.611 & 0.147 & 0.224 & 0.017 \\
\hline TM15G3L1P15 & 967 & Core & 0.599 & 0.117 & 0.268 & 0.015 \\
\hline TM15G3L1P16 & 954 & Core & 0.605 & 0.116 & 0.263 & 0.016 \\
\hline TM15G3L1P17 & 952 & Core & 0.597 & 0.104 & 0.283 & 0.016 \\
\hline TM15G3L1P18 & 937 & Core & 0.618 & 0.099 & 0.267 & 0.016 \\
\hline TM15G3L1P19 & 922 & Core & 0.602 & 0.122 & 0.26 & 0.016 \\
\hline TM15G3L1P20 & 896 & Core & 0.625 & 0.092 & 0.265 & 0.019 \\
\hline TM15G3L1P21 & 892 & Core & 0.572 & 0.097 & 0.317 & 0.015 \\
\hline TM15G3L1P22 & 889 & Core & 0.547 & 0.145 & 0.295 & 0.012 \\
\hline TM15G3L1P24 & 862 & Core & 0.598 & 0.098 & 0.282 & 0.021 \\
\hline TM15G3L1P23 & 862 & Core & 0.615 & 0.097 & 0.267 & 0.021 \\
\hline TM15G3L1P25 & 812 & Core & 0.596 & 0.1 & 0.281 & 0.023 \\
\hline TM15G3L1P27 & 797 & Core & 0.593 & 0.075 & 0.31 & 0.023 \\
\hline TM15G3L1P26 & 797 & Core & 0.592 & 0.075 & 0.31 & 0.023 \\
\hline TM15G3L1P28 & 795 & Core & 0.617 & 0.073 & 0.287 & 0.024 \\
\hline TM15G3L1P29 & 767 & Core & 0.597 & 0.102 & 0.28 & 0.022 \\
\hline TM15G3L1P30 & 752 & Core & 0.581 & 0.098 & 0.299 & 0.023 \\
\hline TM15G3L1P31 & 746 & Core & 0.598 & 0.074 & 0.303 & 0.026 \\
\hline TM15G3L1P32 & 745 & Core & 0.572 & 0.096 & 0.311 & 0.021 \\
\hline TM15G3L1P33 & 709 & Core & 0.595 & 0.081 & 0.303 & 0.02 \\
\hline TM15G3L1P34 & 707 & Core & 0.574 & 0.072 & 0.336 & 0.019 \\
\hline TM15G3L1P35 & 692 & Core & 0.565 & 0.102 & 0.312 & 0.021 \\
\hline TM15G3L1P36 & 679 & Core & 0.567 & 0.126 & 0.287 & 0.02 \\
\hline TM15G3L1P37 & 671 & Core & 0.584 & 0.098 & 0.298 & 0.021 \\
\hline TM15G3L1P38 & 637 & Core & 0.58 & 0.135 & 0.271 & 0.015 \\
\hline
\end{tabular}




\begin{tabular}{|c|c|c|c|c|c|c|}
\hline TM15G3L1P39 & 623 & Core & 0.577 & 0.065 & 0.345 & 0.014 \\
\hline TM15G3L1P40 & 600 & Core & 0.541 & 0.21 & 0.238 & 0.01 \\
\hline TM15G3L1P41 & 572 & Core & 0.621 & 0.088 & 0.273 & 0.018 \\
\hline TM15G3L1P42 & 572 & Core & 0.621 & 0.089 & 0.272 & 0.018 \\
\hline TM15G3L1P43 & 537 & Core & 0.59 & 0.138 & 0.253 & 0.019 \\
\hline TM15G3L1P44 & 537 & Core & 0.644 & 0.081 & 0.257 & 0.018 \\
\hline TM15G3L1P45 & 537 & Core & 0.646 & 0.082 & 0.253 & 0.019 \\
\hline TM15G3L1P46 & 511 & Core & 0.655 & 0.082 & 0.245 & 0.018 \\
\hline TM15G3L1P47 & 507 & Core & 0.633 & 0.089 & 0.26 & 0.018 \\
\hline TM15G3L1P48 & 482 & Core & 0.636 & 0.097 & 0.25 & 0.017 \\
\hline TM15G3L1P49 & 457 & Core & 0.632 & 0.06 & 0.29 & 0.017 \\
\hline TM15G3L1P50 & 457 & Core & 0.616 & 0.124 & 0.244 & 0.016 \\
\hline TM15G3L1P51 & 432 & Core & 0.629 & 0.12 & 0.233 & 0.018 \\
\hline TM15G3L1P52 & 402 & Core & 0.65 & 0.092 & 0.24 & 0.018 \\
\hline TM15G3L1P53 & 392 & Core & 0.652 & 0.088 & 0.24 & 0.019 \\
\hline TM15G3L1P54 & 390 & Core & 0.655 & 0.09 & 0.237 & 0.018 \\
\hline TM15G3L1P55 & 357 & Core & 0.652 & 0.093 & 0.237 & 0.019 \\
\hline TM15G3L1P56 & 357 & Core & 0.646 & 0.102 & 0.233 & 0.019 \\
\hline TM15G3L1P57 & 327 & Core & 0.647 & 0.095 & 0.24 & 0.018 \\
\hline TM15G3L1P58 & 319 & Core & 0.608 & 0.132 & 0.243 & 0.018 \\
\hline TM15G3L1P59 & 297 & Core & 0.619 & 0.113 & 0.25 & 0.018 \\
\hline TM15G3L1P60 & 217 & Rim_Low grs & 0.64 & 0.167 & 0.187 & 0.007 \\
\hline TM15G3L1P61 & 187 & Rim_Low grs & 0.648 & 0.188 & 0.156 & 0.007 \\
\hline TM15G3L1P62 & 187 & Rim_Low grs & 0.648 & 0.189 & 0.157 & 0.006 \\
\hline TM15G3L1P63 & 112 & Rim_Low grs & 0.626 & 0.205 & 0.162 & 0.007 \\
\hline TM15G3L1P64 & 102 & Rim_Low grs & 0.617 & 0.2 & 0.177 & 0.007 \\
\hline TM15G3L1P65 & 100 & Rim & 0.472 & 0.295 & 0.228 & 0.005 \\
\hline TM15G3L1P66 & 92 & Rim & 0.524 & 0.274 & 0.197 & 0.006 \\
\hline TM15G3L1P67 & 92 & Rim & 0.521 & 0.273 & 0.201 & 0.004 \\
\hline TM15G3L1P68 & 82 & Rim & 0.478 & 0.308 & 0.209 & 0.006 \\
\hline
\end{tabular}


Table S2. TM-15 fitted and selected garnet compositional data along the TM-15G\#3 profile

\begin{tabular}{ccccccc}
\hline Steps & Distance $(\mu \mathrm{m})$ & $\mathrm{X}(\mathrm{alm})_{\_} \mathrm{TD}$ & $\mathrm{X}(\mathrm{prp})_{\_} \mathrm{TD}$ & $\mathrm{X}(\mathrm{grs})_{\_} \mathrm{TD}$ & $\mathrm{x}(\mathrm{g})_{\_} \mathrm{TC}$ & $\mathrm{z}(\mathrm{g})_{-} \mathrm{TC}$ \\
\hline F0 & 0 & 0.586 & 0.089 & 0.325 & 0.868 & 0.325 \\
F1 & 61 & 0.591 & 0.092 & 0.317 & 0.865 & 0.317 \\
F2 & 122 & 0.596 & 0.096 & 0.308 & 0.862 & 0.308 \\
F3 & 183 & 0.601 & 0.099 & 0.300 & 0.858 & 0.300 \\
F4 & 244 & 0.605 & 0.102 & 0.292 & 0.855 & 0.292 \\
F5 & 305 & 0.610 & 0.106 & 0.284 & 0.852 & 0.284 \\
F6 & 366 & 0.615 & 0.109 & 0.276 & 0.849 & 0.276 \\
F7 & 382 & 0.622 & 0.150 & 0.228 & 0.806 & 0.228 \\
F8 & 398 & 0.584 & 0.233 & 0.183 & 0.715 & 0.183 \\
F9 & 412 & 0.537 & 0.249 & 0.214 & 0.683 & 0.214 \\
F10 & 426 & 0.495 & 0.271 & 0.234 & 0.646 & 0.234 \\
F11 & 445 & 0.467 & 0.304 & 0.229 & 0.606 & 0.229 \\
F12 & 460 & 0.452 & 0.311 & 0.237 & 0.593 & 0.237 \\
F13 & 483 & 0.445 & 0.321 & 0.233 & 0.581 & 0.233 \\
\hline
\end{tabular}


Electronic supplementary material

\section{Click here to access/download \\ Electronic supplementary material Supplement_final.docx}

